University of Nebraska - Lincoln

DigitalCommons@University of Nebraska - Lincoln

USDA Forest Service / UNL Faculty Publications U.S. Department of Agriculture: Forest Service -National Agroforestry Center

$9-2011$

\title{
A Comparative Risk Assessment Framework for Wildland Fire Management: The 2010 Cohesive Strategy Science Report
}

\author{
David E. Calkin \\ USDA Forest Service \\ Alan Ager \\ USDA Forest Service, aager@fs.fed.us \\ Matthew P. Thompson \\ Rocky Mountain Research Station \\ Mark A. Finney \\ USDA Forest Service, mfinney@fs.fed.us \\ Danny C. Lee \\ USDA Forest Service
}

See next page for additional authors

Follow this and additional works at: https://digitalcommons.unl.edu/usdafsfacpub

Part of the Forest Biology Commons, Forest Management Commons, Other Forestry and Forest Sciences Commons, and the Plant Sciences Commons

Calkin, David E.; Ager, Alan; Thompson, Matthew P.; Finney, Mark A.; Lee, Danny C.; Quigley, Thomas M.; McHugh, Charles W.; Riley, Karin L.; and Gilbertson-Day, Julie M., "A Comparative Risk Assessment Framework for Wildland Fire Management: The 2010 Cohesive Strategy Science Report" (2011). USDA Forest Service / UNL Faculty Publications. 360.

https://digitalcommons.unl.edu/usdafsfacpub/360

This Article is brought to you for free and open access by the U.S. Department of Agriculture: Forest Service -National Agroforestry Center at DigitalCommons@University of Nebraska - Lincoln. It has been accepted for inclusion in USDA Forest Service / UNL Faculty Publications by an authorized administrator of DigitalCommons@University of Nebraska - Lincoln. 


\section{Authors}

David E. Calkin, Alan Ager, Matthew P. Thompson, Mark A. Finney, Danny C. Lee, Thomas M. Quigley, Charles W. McHugh, Karin L. Riley, and Julie M. Gilbertson-Day 


\section{A Comparative Risk Assessment Framework for Wildland Fire Management:}

\section{The 2010 Cohesive Strategy Science Report}

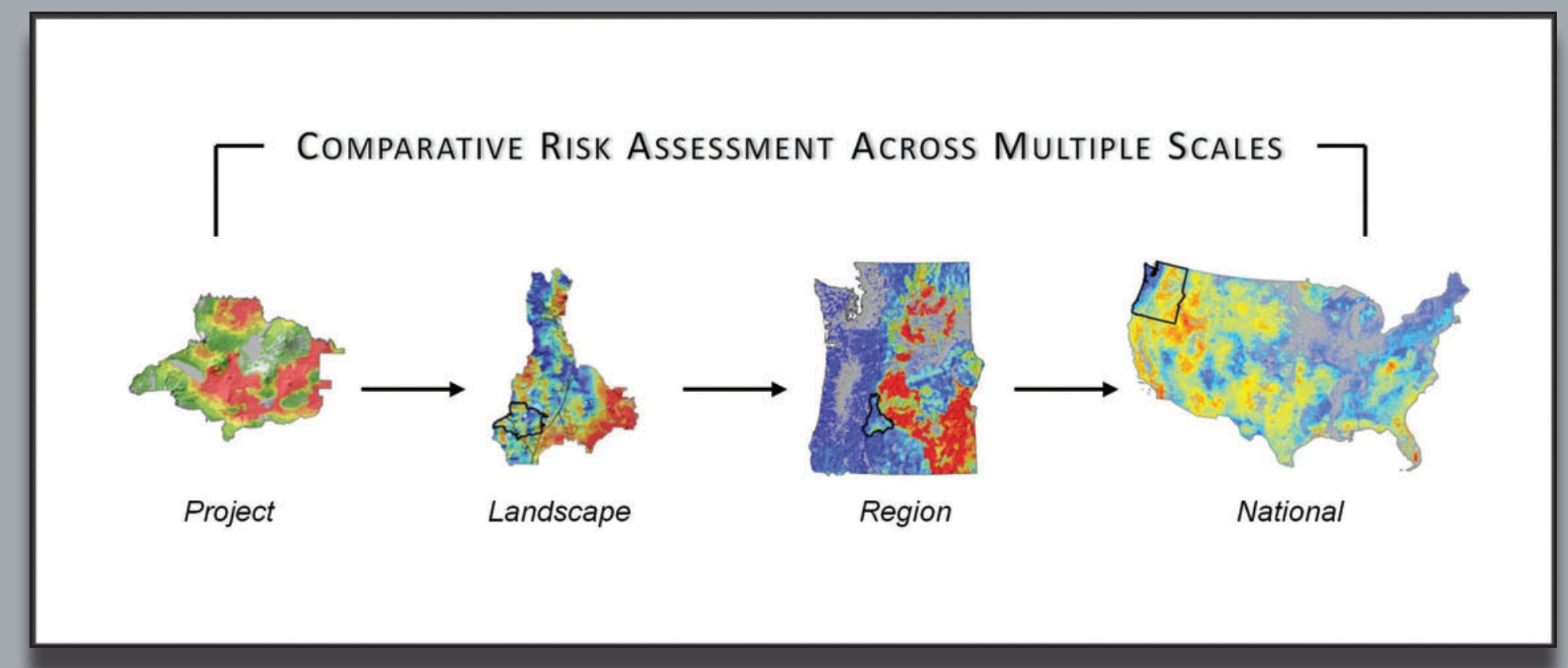


Calkin, David E.; Ager, Alan A.; Thompson, Matthew P., eds. 2011. A comparative risk assessment framework for wildland fire management: the 2010 cohesive strategy science report. Gen. Tech. Rep. RMRS-GTR-262. Fort Collins, CO: U.S. Department of Agriculture, Forest Service, Rocky Mountain Research Station. 63 p.

\section{Abstract}

The FLAME Act of 2009 requires the U.S. Department of Agriculture Forest Service and the U.S. Department of Interior to submit to Congress a Cohesive Wildfire Management Strategy. In this report, we explore the general science available for a risk-based approach to fire and fuels management and suggest analyses that may be applied at multiple scales to inform decisionmaking and tradeoff analysis. We discuss scientific strengths and limitations of wildfire risk assessment frameworks, including the benefit of broad scalability as demonstrated by four recent case studies. We further highlight the role of comparative risk assessment, which extends the analysis to include the decision space available to managers and stakeholders to allow them to explore the tradeoffs between alternative courses of action. We identify scientific limitations of the analytical protocol and discuss questions of how to better address climate change, smoke modeling issues, and socioeconomic vulnerability, and how to better quantify treatment effectiveness. Key challenges are: achieving a balance between retaining analytical flexibility at regional and sub-regional planning scales while simultaneously retaining data and methodological consistency at the national scale, and identifying and aligning regional and national priorities to inform multiobjective strategy development. As implementation proceeds, the analytical protocol will no doubt be modified, but the contents of this report comprise a rigorous and transparent framework for comparative risk assessment built from the best available science.

Keywords: wildfire risk assessment, comparative risk assessment, fire and fuels management, multi-criteria decision analysis, tradeoff analysis, fire behavior and effects, multi-scale decisionmaking framework

\section{ACKNOWLEDGMENTS}

We gratefully acknowledge the editorial assistance of Kate Marcille. Jason Kreitler provided content on socio-economic vulnerability and Jessica Haas, Nicole Vaillant, Charlie Schrader-Patton, and Allison Reger provided content assistance on case studies of wildfire risk assessment as well as with figures. Michelle Buonopane, Mike Rausher, Cindy Swanson, John Cissel, and Rebecca Efroymson provided technical review.

You may order additional copies of this publication by sending your mailing information in label form through one of the following media.

Please specify the publication title and series number.

\section{Publishing Services}

$\begin{aligned} \text { Telephone } & (970) \text { 498-1392 } \\ \text { FAX } & (970) 498-1122 \\ \text { E-mail } & \text { rschneider@fs.fed.us } \\ \text { Website } & \text { http://www.fs.fed.us/rm/publications } \\ \text { Mailing address } & \text { Publications Distribution } \\ & \text { Rocky Mountain Research Station } \\ & \text { 240 West Prospect Road } \\ & \text { Fort Collins, CO } 80526\end{aligned}$




\section{Authors}

David E. Calkin is a Research Forester in the Human Dimensions Program and is the Wildfire Economics Team Lead for the National Fire Decision Support Center. He is located at the USDA Forest Service Rocky Mountain Research Station in Missoula, Montana. He develops processes and tools for assessing the economic effects of wildland fire management and wildfire risk assessment decision support.

Alan A. Ager is an Operations Research Analyst at the Western Wildlands Environmental Threat Assessment Center, located at the USDA Forest Service Pacific Northwest Research Station in Prineville, Oregon. He is researching landscape modeling of fuel management policies and developing tools for wildfire risk assessment.

Matthew P. Thompson is a Research Forester in the Human Dimensions Program and is associated with the National Fire Decision Support Center. He is located at the Rocky Mountain Research Station in Missoula, Montana. He is researching the nexus of wildfire risk analysis, wildfire economics, and decisionmaking under uncertainty.

Mark A. Finney is a Research Forester at the Rocky Mountain Research Station, Fire Sciences Laboratory in Missoula, Montana. He is researching fire behavior, fire growth modeling, and landscape fuel management.

Danny C. Lee is the Director of the Eastern Forest Environmental Threat Assessment Center located at the USDA Forest Service Southern Research Station in Asheville, North Carolina. He is researching the application of systems analysis, risk assessment, and modeling of large-scale ecosystem management issues.

Thomas M. Quigley is a Senior Advisor for Natural Resource Management and Science, Management and Engineering Technologies International, Inc., in Saratoga Springs, Utah. He primarily works at the policy interface between science and management with emphasis on fire related issues.

Charles W. McHugh is a Forester at the Rocky Mountain Research Station, Fire Sciences Laboratory in Missoula, Montana. He is researching fire behavior, fire growth modeling, and landscape fuel management.

Karin L. Riley is a Research Geoscientist with Systems for Environmental Management, located at the Rocky Mountain Research Station, Fire Sciences Laboratory in Missoula, Montana. She is researching fire risk to terrestrial carbon stores and spatiotemporal patterning of wildfire effects.

Julie M. Gilbertson-Day is a Biological Scientist in the Human Dimensions Program and is associated with the National Fire Decision Support Center. She is located at the Rocky Mountain Research Station in Missoula, Montana. She is researching data and spatial-scale issues related to wildfire modeling and risk assessments. 


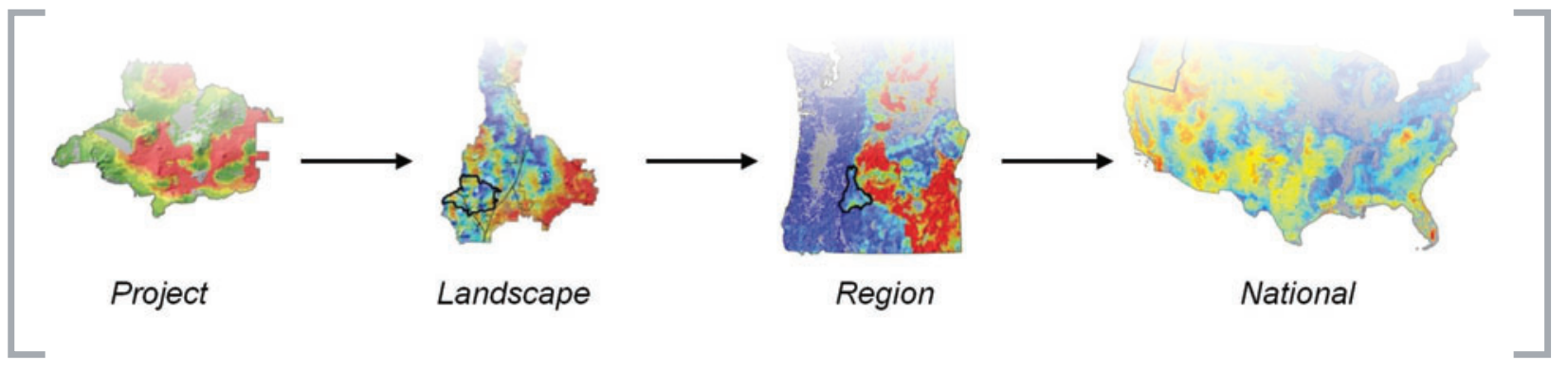

\section{Contents}

\section{Introduction 1}

\section{The Cohesive Strategy 3}

\section{Risk Framework 8}

4. Wildfire Risk Case Studies 11

Fire Modeling 11

Local-Scale Demonstration (Deschutes National Forest) 12

Local-Scale Demonstration (Beaverhead-Deerlodge National Forest) 13

Regional-Scale Demonstration 15

National-Scale Demonstration Overview 16

5. Comparative Risk Mitigation (Exploring Options for Reducing Risk) 23

Option 1. Invest to Prevent Human-Caused Ignitions 25

Option 2. Invest in Fuel Treatments 29

Option 3. Invest to Build Capacity in Fire Response 37

Option 4. Invest to Protect Values Exposed to Risk 39

General Observations on Analyzing Options 39

\section{Other Related Efforts 40}

Relation to the Previous Cohesive Strategy and Policy—Moving

Beyond FRCC 40

Wildfire Ignition and its Relation to Risk 43

Carbon and Emissions 45

Relationship to Existing State and Regional Wildfire Risk Assessments 47

Similarities and Differences with HFPAS Planning Efforts 48

Comparison of Wildfire Risk Measures with National Insect and

Disease Risk Map 49

\section{Science Limitations 51}

Defining and Measuring Risk 51

The Tipping Point Problem: Temporal Dynamics 53

Accounting for a Changing Climate 53

Quantifying Treatment Effectiveness 54

Resource Value Measures 54

Socioeconomic Vulnerability 54

Smoke Management 55

8. Policy Issues for Tradeoff Analysis 56

9. Discussion and Concluding Remarks 57

\section{References 58}




\section{Introduction}

Forests, rangelands, and other open spaces provide a broad array of ecological benefits, including critical habitat for protected species, drinking water, wood products, carbon storage, and scenic and recreational opportunities. Large, destructive wildfires threaten these values and communities adjacent to these lands. Large investments in wildland fire suppression and fuel reduction activities are being made throughout the United States in ongoing efforts to reduce human and ecological losses from wildfire (USDA and USDI 2001; Public Law 108-148 2003; Sexton 2006). Managing these investments is a challenge to multiple Federal, State, and local agencies as decision makers attempt to reduce wildfire risk over extensive areas while balancing public expectations with finite budgets (Agee 2002; Dicus and Scott 2006; Johnson and others 2006; Sexton 2006; Winter and Bigler-Cole 2006). Landscape-scale changes in vegetation structure and fuel loadings must be accomplished in order to significantly alter wildfire behavior, reduce wildfire losses, and achieve longer-term fire resiliency (for example, Agee and others 2000; Finney 2001; Peterson and others 2003; Graham and others 2004). However, the most efficient way to achieve these long-term landscape goals remains unclear, and there are different perceptions on the relative role and effectiveness of management activities versus natural and managed wildfire to reduce fuels (cf. Agee 2002; Finney and Cohen 2003; Reinhardt and others 2008).

The FLAME Act of 2009 requires the USDA Forest Service and the U.S. Department of Interior to submit to Congress a report that contains a Cohesive Wildfire Management Strategy (Cohesive Strategy). The Cohesive Strategy must address the three principles of Landscape Restoration, Fire Adapted Communities, and Response to Wildfires as outlined by the Wildland Fire Leadership Council $\left(W_{F L C}^{1}\right)$, along with:

- the identification of the most cost-effective means for allocating fire management budget resources;

- the reinvestment in non-fire programs by the Secretaries of the Interior and Agriculture;

- employing the appropriate management response to wildfire;

- assessing the level of risk to communities;

- the allocation of hazardous fuels reduction funds based on the priority of hazardous fuels reduction projects;

- assessing the impacts of climate change on the frequency and impact of wildfire; and

- studying the effects of invasive species on wildfire risk.

In addition, the Congressional requirements hold that the strategy meet U.S. Government Accountability Office standards for addressing cost effectiveness of suppression and mitigation, efficiency of treatments for fuels and fire-adapted communities, and establishment of meaningful performance measures.

The Cohesive Strategy Draft Report to Congress (November 2010) proposes a risk-based approach to fire and fuels management, as identified and assembled by the science panel. The panel was tasked with developing information, analytical processes, and datasets that could be used to analyze policy options or scenarios brought forward through the development and implementation of the Cohesive Strategy.

In this report, we explore the general science available for a risk-based approach to fire and fuels management, and we suggest analytical frameworks that can be consistently used at multiple scales to inform wildfire and fuels decisionmaking. We

\footnotetext{
${ }^{1}$ WFLC is comprised of members from Federal wildland agencies, National Association of State Foresters, National Association of Counties, Federal Emergency Management Agency, Intertribal Timber Council, and the National Governors Association.
} 
recognize that alternative approaches could be employed at various steps along the way, and further recognize that consistent analyses require simplifying assumptions and judgments about values. Successful implementation will require recognition of the limitations of the models employed, the limitations of data available to characterize the values and relationships, and the human judgments required to quantify the values themselves and how those values are likely to change under varying levels of fire intensity.

Specifically, we discuss the following approach to address the FLAME Act requirements:

- Describe concepts of risk management and assessment as they relate to the wildfire management context, including the utility of comparative risk assessment as a platform to analyze alternative policy options.

- Describe how transitioning to risk-based frameworks expands and improves upon concepts related to Fire Regime Condition Class (FRCC).

- Illustrate the application of wildfire risk management at multiple spatial scales ranging from project-level operational planning to national-level strategic assessment.

- Illustrate opportunities to use wildfire risk-based decision support tools to evaluate tradeoffs associated with alternative risk mitigation strategies.

- Identify limitations of our modeling approaches and recommend areas for further research.

In Chapter 2, we outline the intended implementation plan for the Cohesive Strategy, focusing on the role of the interaction and communication flow across planning scales. We describe how regional assessments are intended to be "rolled up" into a nationally consistent picture, and how various investment alternatives that are modeled within regional assessments can feed a national model, illustrating tradeoffs across goals and objectives. We highlight the challenges associated with retention of consistent methods, datasets, and performance measures, and offer suggestions to guide establishment of protocols.

Chapter 3 contains a primer on the concepts of risk and uncertainty as they relate to wildfire management. In Chapter 4, we build upon these concepts to demonstrate a consistent, scalable risk assessment framework in the sense that identical methodologies can be used to assess risk at project, unit, regional, and national scales. We demonstrate the primary components of risk assessments, in particular the suite of advanced fire modeling tools, and illustrate applications of these risk assessments across scales, stressing that our analyses should be viewed as demonstrative rather than definitive. We conclude Chapter 4 by describing the relationship of our risk assessment framework to other existing frameworks. Understanding how the current state of risk can be assessed is a prerequisite for understanding how mitigation efforts might affect risk, which is addressed in Chapter 5.

In Chapter 5, we present the comparative risk assessment framework. We describe options for assessing alternative investments to mitigate risk, including fuel treatments, prevention programs, and increasing response capacity. The material presented in Chapter 5 comprises the science panel's best efforts to respond to fulfill their task to "develop analytical processes and datasets that will be used to analyze policy options or scenarios brought forward through the development and implementation of the Cohesive Wildfire Management Strategy."

Although we believe this new framework is an improvement and can put to good use a suite of modern tools and datasets, limitations remain. In Chapter 6, we highlight several important scientific uncertainties. However, not all questions relevant to design and implementation of the Cohesive Strategy can be answered with scientific analysis alone. Chapter 7 highlights policy issues that must be addressed outside the scope of this report. Lastly, in Chapter 8, we summarize the material contained in this report and offer guidance for future work. 


\section{The Cohesive Strategy}

The current vision for the Cohesive Strategy is a multi-scale analysis process in which regional analyses and assessments provide input for development of a national strategy. The synthesis of regional assessments will inform a national tradeoff analysis that considers alternative investment levels and regional strategies to best meet national goals. A clear articulation of goals, objectives, and human and ecological values to be assessed will be required. While data are likely to vary across regional and local levels, consistency in the analytical methodology is required for national tradeoff analyses. Also, ensuring available data are of sufficient quality remains necessary to meaningfully address management goals. Most importantly, a consistent analytical structure needs to be defined that can be implemented regionally and evaluated in aggregate.

A cornerstone of the scientific underpinnings to the Cohesive Strategy is a wildfire risk assessment framework, described in more detail in Chapter 3. Successful application of such a framework is contingent upon definition of measurable and interpretable assessment endpoints and related performance measures. Assessment endpoints are defined by the EPA as "An explicit expression of the environmental value that is to be protected, operationally defined by an ecological entity and its attributes" (EPA 1998, p. A-6). Here, the definition is extended to encompass the full range of human and ecological values potentially impacted by wildland fire. Performance measures are then used to describe how a particular management activity or combination of activities can influence assessment endpoints (for example, reduced risk to critical habitat due to fuel treatments). Use of performance measures enables not only evaluation of strategic alternatives and associated budgetary options but it also facilitates monitoring and learning over time and can increase accountability.

The following are questions that need to be addressed when developing the regional strategies:

- What are the key fire and fuel management objectives in terms of protecting and enhancing highly valued resources (HVR)?

- What are the investment opportunities and policies to promote fire-adapted communities?

- What are the investment opportunities and policies that will enhance landscape restoration?

- What are the investment opportunities and policies that will improve the efficiency of fire response?

Alternative strategies represent investment portfolios that vary by composition of investment level and emphasis area. Allowing each region to define strategies according to emphasis areas and investment level provides analytical flexibility regarding the nature of fire management activities and the values to be protected. The results of the regional analyses are then compiled for tradeoff analysis, whereby a strategy for each region is selected according to national goals, pre-determined performance measures, and the constrained budget levels. WFLC (along with other national leaders) then considers these results in determining the National Cohesive Strategy. Once completed, the Strategy is presented to the Presidential Administration and Congress for adoption and funding appropriations through the budgeting process. Pending Congressional approval and subsequent implementation, funding is made available for the regional strategies. Regional, Forest and sub-regional, and project-level risk assessments play a substantial role in prioritization and justification of the resulting projects and activities.

One of the main problems with the proposed nested analyses is that disparate regional analyses are difficult to integrate into a consistent analysis. National-scale performance measures are needed that accurately represent accomplishments in risk reduction and that recognize the diversity of regionally specific resources and 
management priorities. Each region may identify alternative methods for considering risk to individual resources and may consider different sets of values, necessitating careful design with respect to methods and data.

Consistency among analyses can be defined in terms of both methods and data (figure 1). For instance, project-level fuel treatment National Environmental Policy Act (NEPA) analyses may use locally defined data and methodologies specific to the purposes and needs in question. The Southern Wildfire Risk Assessment (SWRA) uses regionally consistent data and methodologies to highlight priority areas for wildfire mitigation efforts. Finally, the FY11 Hazardous Fuels Prioritization and Allocation System (HFPAS) budgetary allocation model uses nationally uniform data and methodologies to derive funding priority scores. Possible options and challenges for designing the integration of multi-scale analysis are:

- Locally defined methods; locally defined data: Extremely difficult to aggregate regional strategies and compare results in a meaningful way, resulting in inconsistent performance measures.

- Locally defined methods; nationally uniform data: Available national-scale data may be too coarse to capture regional/local HVRs and assets, methodological inconsistency makes consistent application of performance measures challenging.

- Nationally uniform methods; locally defined data: Methodological consistency allows for measurement consistency; data refinement providing a better representation of local priorities is made possible, albeit challenging, to integrate strategies upward.

- Nationally uniform methods; nationally uniform data: Performance measures easiest to define and calculate, but coarse (national-scale) data are unable to represent regional values and priorities.

Many other options exist. Regions could use locally and regionally refined fuels and values data layers and could additionally define functions that quantify resource response to wildfire while retaining the overall composition of the risk framework illustrated in Chapter 4. Regional-scale values and data layers could be combined with nationally consistent wildfire hazard (as modeled by the large-fire simulation system). Ultimately, consistent performance measures across scales are needed that can be aggregated from regional to national levels via a multi-criteria hierarchy model. Thus, some consistency across data and methods is necessary. To realize the potential of the approach, each scale of the analysis needs to consider the required

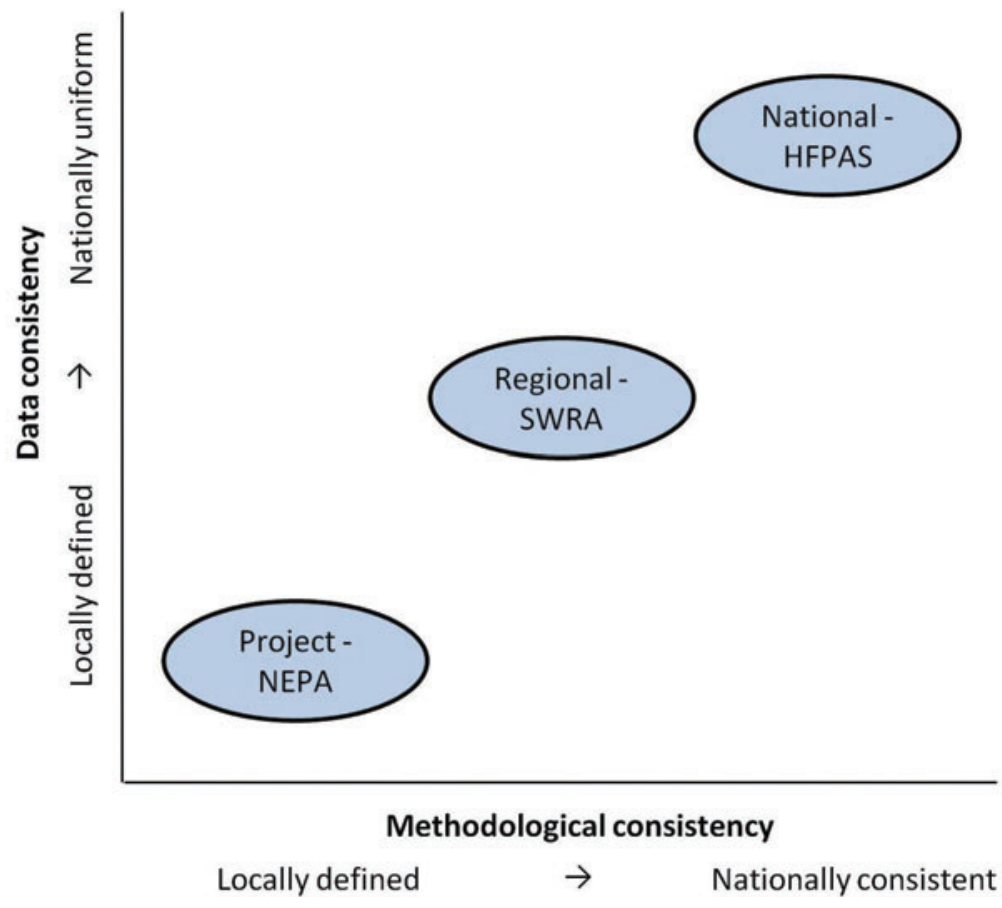

Figure 1-Two-dimensional continuum of methodological and data consistency. 
outputs and associated outcomes and how they interact with the finer- and broaderscale assessments. Table 1 describes the value of the assessment at various scales and identifies limitations, guiding documentation, and outputs that will be informed from the process.

The national tradeoff analysis is a problem suitable for multi-criteria decision analysis (MCDA). Applications of MCDA in the forestry literature range from "hard" quantitative techniques such as multi-objective optimization and goal programming to more "soft" approaches that can incorporate qualitative information and that search for acceptable rather than optimal solutions (Mendoza and Martins 2006; Diaz-Balteiro and Romero 2008). MCDA techniques have been used in the wildfire context to explore tradeoffs associated with alternate fuel management strategies (Ohlson and others 2006) and to better understand decision maker preferences across non-commensurate resources at risk to fire (Rideout and others 2008). Figures 2 and 3 illustrate conceptually how the multi-criteria analytical framework could be designed and how the hierarchies within this framework address the role of multiple planning scales. Critical to the success of an MCDA approach is clear articulation of quantitative (and qualitative) measures to compare against performance of alternative investment strategies. This requires balancing analytical flexibility with analytical consistency and repeatability, as previously alluded to. 
Table 1-Evaluation of risk assessments at various scales. Regional assessments and national assessments evolve in an iterative fashion (priorities, data layers, fire modeling, etc.) and can be refined periodically. It is important to separate the risk assessments from budgetary allocation processes and mechanisms.

\begin{tabular}{|c|c|c|c|c|}
\hline Assessment Scale & Value & Limitations & Guidance & Outcomes \\
\hline National & $\begin{array}{l}\text { Compare risk to broadly } \\
\text { defined set of resources using } \\
\text { consistent methods, data, and } \\
\text { performance measures. } \\
\text { Allows comparison among re- } \\
\text { gions using consistent process } \\
\text { and data. }\end{array}$ & $\begin{array}{l}\text { Not sensitive to regionally } \\
\text { based management priori- } \\
\text { ties or differences in how } \\
\text { resources respond to fire in } \\
\text { different geographic settings. }\end{array}$ & $\begin{array}{l}\text { FLAME Act, Guiding } \\
\text { Principles/Framework } \\
\text { National Performance } \\
\text { Measures } \\
\text { Regional Wildfire Risk } \\
\text { Assessments }\end{array}$ & $\begin{array}{l}\text { Assessment of risk at } \\
\text { national scale under } \\
\text { various scenarios } \\
\text { Aggregation and } \\
\text { analysis of regional } \\
\text { assessments in some } \\
\text { "cohesive" way to } \\
\text { inform policymakers } \\
\text { Identify opportunities } \\
\text { for risk reduction }\end{array}$ \\
\hline $\begin{array}{l}\text { Regional/ } \\
\text { Geographic }\end{array}$ & $\begin{array}{l}\text { Allows refinement to repre- } \\
\text { sent regional priorities, incor- } \\
\text { poration of regional data and } \\
\text { models, improved assessment } \\
\text { of resource response to fire. } \\
\text { Can be used to identify high } \\
\text { risk priority areas for further } \\
\text { analyses and potential invest- } \\
\text { ment in mitigation. }\end{array}$ & $\begin{array}{l}\text { Assessment too coarse to } \\
\text { identify specific manage- } \\
\text { ment responses, but alloca- } \\
\text { tion and mitigation strategies } \\
\text { within the region can be } \\
\text { developed. }\end{array}$ & $\begin{array}{l}\text { National goals/objec- } \\
\text { tives } \\
\text { Regional priorities } \\
\text { and existing risk as- } \\
\text { sessments } \\
\text { State Wildfire Risk } \\
\text { Assessments }\end{array}$ & $\begin{array}{l}\text { Evaluation of the } \\
\text { impact of alterna- } \\
\text { tive policy scenarios } \\
\text { on risk to regionally } \\
\text { identified priorities. }\end{array}$ \\
\hline Unit/Landscape & $\begin{array}{l}\text { Improves understanding of } \\
\text { threats to meeting desired } \\
\text { future conditions. } \\
\text { Provides solid link to fire } \\
\text { management plans. } \\
\text { Scenario analysis }\end{array}$ & $\begin{array}{l}\text { Must integrate risk reduction } \\
\text { opportunities with local/ } \\
\text { community priorities. } \\
\text { Best alternative still requires } \\
\text { weighting; direction on } \\
\text { appropriate weights are } \\
\text { typically not defined within } \\
\text { L/RMPa_a common chal- } \\
\text { lenge across scales of how } \\
\text { to articulate priorities across } \\
\text { non-commensurate assess- } \\
\text { ment endpoints. }\end{array}$ & $\begin{array}{l}\text { Existing L/RMP \& } \\
\text { FMPb (all of above) }^{\text {b }}\end{array}$ & $\begin{array}{l}\text { Informing planning } \\
\text { process (updating and } \\
\text { refinement) } \\
\text { FMP, L/RMP }\end{array}$ \\
\hline Event & $\begin{array}{l}\text { Develop risk-based manage- } \\
\text { ment strategies that con- } \\
\text { sider firefighter exposure and } \\
\text { potential resource losses and } \\
\text { benefits from wildland fire. }\end{array}$ & $\begin{array}{l}\text { Time sensitive nature and } \\
\text { community concern limits } \\
\text { consideration of full range of } \\
\text { losses and benefits. }\end{array}$ & $\begin{array}{l}\text { FMP and WFDSS } \\
\text { process }\end{array}$ & $\begin{array}{l}\text { Risk informed wildfire } \\
\text { management response }\end{array}$ \\
\hline
\end{tabular}

\footnotetext{
${ }^{a}$ Land/Resource Management Plan

b Fire Management Plan

${ }^{\mathrm{c}}$ National Environmental Policy Act

${ }^{\mathrm{d}}$ Community Wildfire Protection Plans

e Wildland Fire Decision Support System
} 


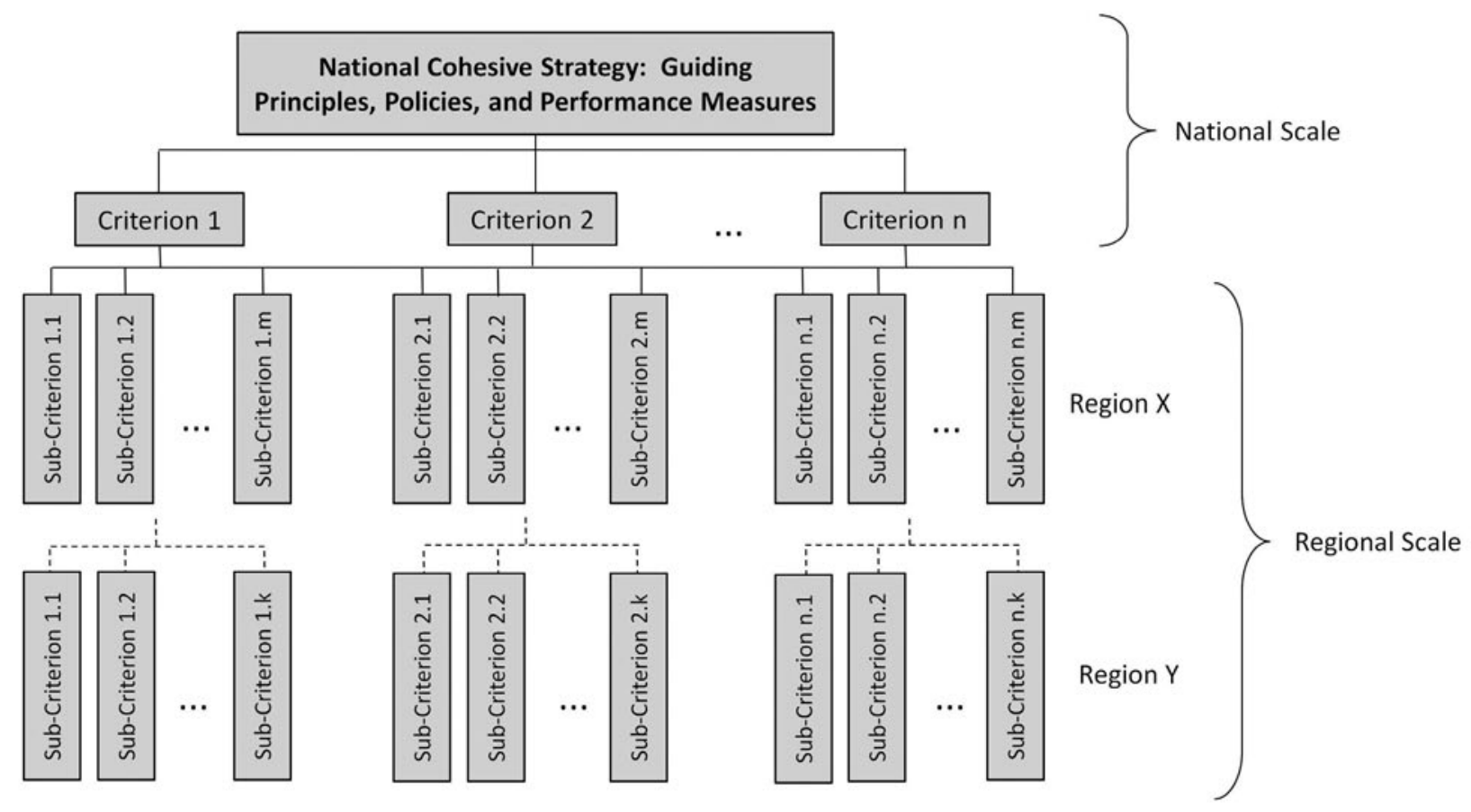

Figure 2-Conceptual multi-criteria analytical framework.

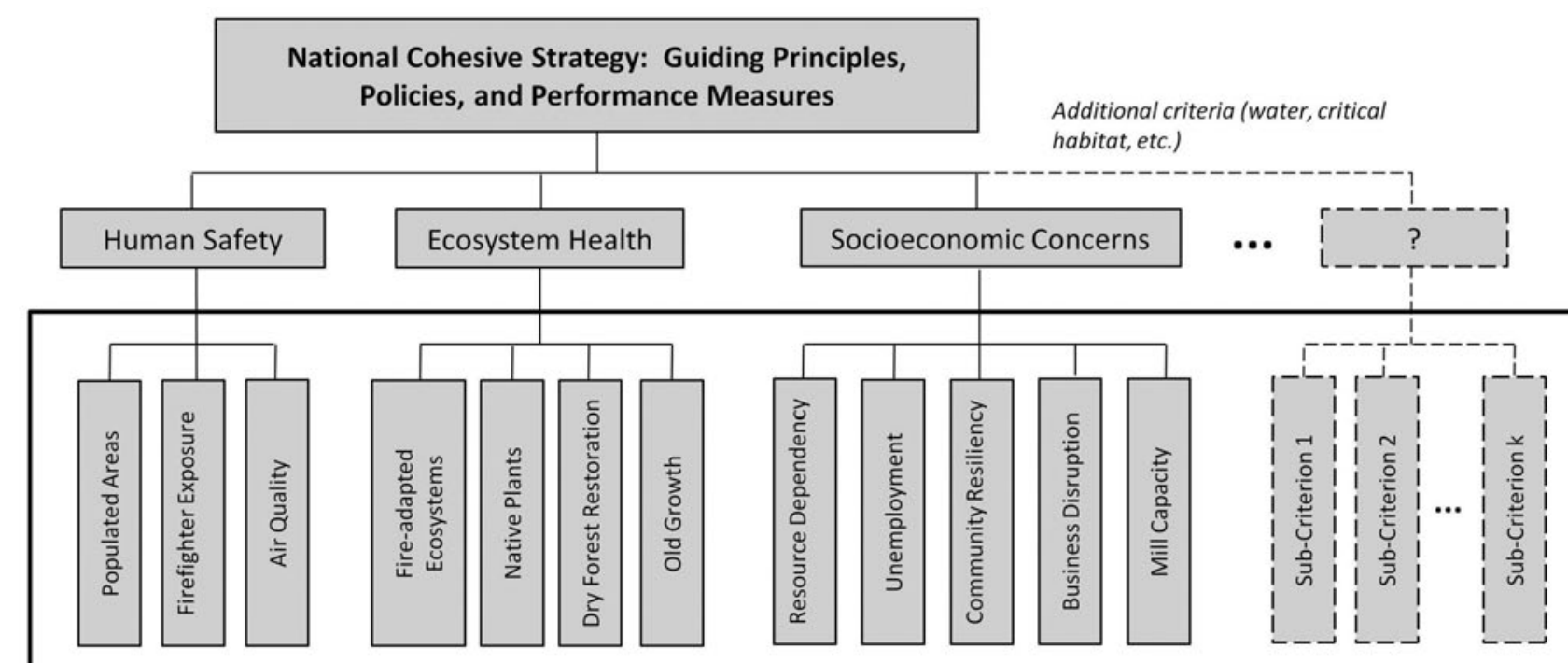

Sub-criteria relate to each nationally defined criterion (assessment endpoint). The specific nature, definition, and relative importance of these sub-criteria may vary across regions.

Figure 3-Hypothetical illustration of how national criteria and sub-criteria may be defined. A key design component of this hierarchical framework is the definition of risk-based performance measures that can aggregate up through the hierarchy. Regional differences emerge in definition of sub-criteria. 
Risk science was developed to help managers make decisions when outcomes are inherently uncertain and multiple choices are available (Morgan and Henrion 1990; Haynes and Cleaves 1999; Hubbard 2009). "Risk Management is the identification, assessment, and prioritization of risks followed by coordinated and economical application of resources to minimize, monitor, and control the probability and/or impact of unfortunate events" (Hubbard 2009, p. 10). Wildfire management is risk management in that it involves first analyzing both exposure and effects (in other words, likelihood and magnitude of potential beneficial/detrimental effects) and then developing appropriate management responses to reduce exposure or mitigate adverse effects (Fairbrother and Turnley 2005; Finney 2005). Ultimately, choosing among available options demands clarity in management objectives and, where multiple objectives are present, an understanding of management priorities.

In order to help meet the challenges of developing the Cohesive Strategy, we propose the use of comparative risk assessment as a rigorous basis for analyzing strategic alternatives. Risk assessment is a long standing and mature scientific approach to quantifying risk; comparative risk assessment simply extends the analysis to include the decision space available to managers and stakeholders to allow them to explore the tradeoffs between alternative courses of action. Taking this additional step requires understanding of preferences and risk tolerance. Risk assessments integrate information regarding the likelihood and magnitude of future events in order to synthesize a conclusion about risk that can inform decisionmaking (Sikder and others 2006). In the case of wildland fire, the ignition, spread, suppression, duration, costs, and ecological and economic impacts of future wildfires are not precisely known. Furthermore, fire managers often lack accurate measures of potential consequences to guide prioritization across fire-prone landscapes and resources at risk. The process of evaluating how risk to various resources changes in response to alternative management strategies (including no action) is crucial to risk-informed decisionmaking (for example, O'Laughlin 2005; Roloff and others 2005; Ager and others 2007a; Ager and others 2010b). In the absence of such risk assessments, decisions and management are likely to be less effective (Bar Massada and others 2009).

Wildfire risk has been used in a variety of ways (Bachmann and Allgöwer 2001; Schmoldt 2001; Finney 2005; Chuvieco and others 2010). For example, Hardy (2005) uses risk to refer to the probability of fire occurrence (i.e., the chance of a fire occurring via ignition or spread in a specific location). Other authors define risk not simply as whether a fire occurs but also as the likely behavior given that a fire does occur. In such cases, risk describes the probability of fire of a given flame length (for example, Ager and others 2010b). Additionally, some authors characterize risk as the product of wildfire probability and expected wildfire damages/benefits (for example, Bachman and Allgöwer 2000). As we demonstrate in Chapter 4, reducing risk to a single dimension in this manner is very useful, but it can create its own problems.

The quantitative framework put forward in this report is the probabilistic expectation of net resource value change (NVC) in response to fire introduced by Finney (2005). Mathematically, this is defined as:

$$
E\left(N V C_{j}\right)=\sum_{i} p\left(f_{i}\right) R F_{j}\left(f_{i}\right)
$$

where

$E\left(N V C_{j}\right)=$ expected net value change to resource $j$

$p\left(f_{i}\right)=$ probability of a fire at intensity level $i$

$R F_{j}\left(f_{i}\right)=$ response function for resource $j$ as a function of fire at intensity level $i$ 
The expected NVC is the product of burn probability at a given fire intensity (as measured by probability of a given flame length) and the resulting change in resource value, summed over all possible fire intensities. The components required to generate spatially explicit wildfire risk indices are: (1) burn probability maps generated from wildfire simulation models, (2) spatially identified resources, and (3) response functions describing the impact of fire on the resource(s) in question. In terms of the mathematical formulation, the spatial intersection of conditional burn probability $p\left(f_{i}\right)$ and resource values-at-risk quantifies exposure. The response function $R F_{j}\left(f_{i}\right)$ describes the response of the resource as a function of fire intensity, thereby quantifying the effects. Where uncertainty regarding fire effects precludes definition of response functions to quantify value change, other risk-based measures can be used to inform prioritization. Such measures include burn probability, conditional flame length probability given that a fire occurs, and expected area burned within a given geographic area or of a given resource type.

Our view of risk is consistent with the EPA risk assessment framework (EPA 1998), a widely used process that considers exposure to risk factors as well as the effects of exposure to risk factors. The EPA framework begins with problem formulation in which goals, objectives, and assessment endpoints are identified, along with potential linkages between risk factors and assessment endpoints. From there, the EPA articulates a three-step process for the quantification of risk: (1) exposure analysis explores the predicted scale and spatial/temporal relationships of causative risk factors, environmental predictors, and assessment endpoints and their properties; (2) effects analysis explores the response of valued resources to varying levels of the risk factors; and (3) risk characterization integrates information from exposure and effects components to formulate an informative conclusion about risk. The flow chart in figure 4 outlines the major steps of this risk assessment framework. Input from stakeholders, in our view of risk, is also reflected in preferences, priorities, and selected

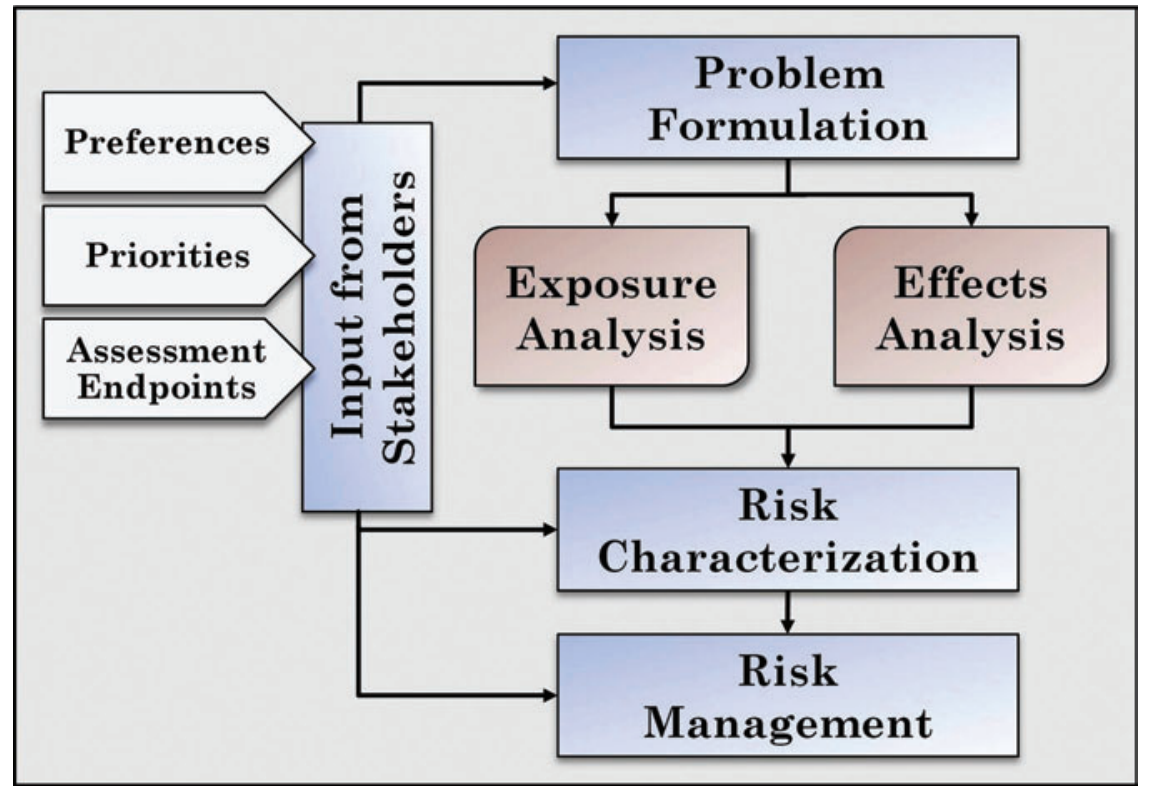

Figure 4-Risk Assessment Framework, modified from EPA (1998). 
assessment endpoints and informs problem formulation and risk characterization. Exposure analysis and effects analysis are the primary analytical components. Risk management incorporates information obtained from assessment to address various risk factors and to protect human and ecological values. Note that risk assessments, in and of themselves, do not necessarily reveal appropriate mitigation strategies. Other factors to consider are relevant laws and regulations, highly vulnerable communities, broader land and resource management plans, treatment opportunities, and likely effectiveness and negative consequences of various treatment alternatives. Further, publicly funded projects often consider socio-economic objectives such as rural economic development and supporting or subsidizing desired industries such as biomass energy development. In other words, risk assessments are a necessary but insufficient component to developing and deciding upon mitigation strategies. In subsequent chapters, we demonstrate the use of a set of models that have been developed specifically for wildland fire risk analyses. 


\section{Wildfire Risk Case Studies}

An important strength of the comparative risk framework is that it can be applied to management problems at a range of scales. To demonstrate this scalability, we provide four examples from our recent work: two local, one regional, and one national analysis. We envision that regional-scale analyses will form the basis of the early stage development, implementation, and monitoring for the Cohesive Strategy. The Forest and project examples will be particularly useful in later implementation phases of the Cohesive Strategy and illustrate a consistent application of risk assessment and management across scales. In this section, we begin with a brief discussion of the various fire models used in the referenced work followed by representative analyses conducted at the local, regional, and national scales.

\section{Fire Modeling}

Fire modeling is essential to actuarial risk assessment because historical fire data alone cannot sufficiently depict fire likelihood and intensity or the range of fire effects. In particular:

1. given the rarity of any particular acre burning, historical fire data cannot represent the full range of possible weather conditions, variability of ignition locations, intensities, and fire sizes;

2. the effect of fuel treatments on fires is spatially dependent and cannot be discerned from historical data or expert judgment; and

3. the variability of fire effects and probabilities at fine (for example, 100-m) scales is not represented by historical fire data. Estimating the likelihood of fire and impact to values (for example, home locations and wildlife habitat patches) is facilitated through spatially quantified estimates of burn probability and fire intensity at appropriate scales.

Through careful calibration with historical fire occurrence records, however, fire simulation modeling can be used to supply spatial details of fire behavior variation and probabilities.

Fire simulation consists of several components that have only recently been developed to a practical level. The first component, a fire growth model, must be developed to spread fire in two dimensions, burn over complex terrain and fuel patterns, and generate fire behavior information for all areas that are burned. The fire growth model used here makes use of a Minimum Travel Time algorithm (MTT, Finney 2002). The MTT model searches efficiently for the fastest fire travel paths from an ignition among grid points across the landscape. This produces fire growth with a minimal spatial distortion and records the fireline intensity associated with the arrival time and angle of contact. It represents behavior of surface fire, crown fire, and spotting as weather conditions change. To drive the fire growth model, we obtained spatial data on fuels and vegetation from the LANDFIRE dataset (www. landfire.gov).

The second major component of a simulation-based risk approach involves the analysis and synthesis of weather and ignition records for the purpose of representing the existing variability of fire seasons. The huge amount of variability in the sequence of weather and ignitions during the fire season means that each season is unique, and the historical weather records of 10 to 20 years are but a very small sample of potential variability. Thus, the ability to generate weather sequences for tens of thousands of seasons as a larger sample of the weather as it contributes to fire risk was afforded by a time-series analysis and modeling of the seasonal and daily trends in fuel moisture at individual weather stations (Finney and others 2011). Large fire ignitions were stochastically modeled based on the relationship between the probability of large fire occurrence and the fire danger rating index Energy Release Component (ERC, Andrews and others 2003). 
The simulation of fire risk components was performed for 134 Fire Planning Units (FPUs) covering the continental United States using a model called FSim (see Finney and others 2011). For each FPU, a single weather station was selected from available Remote Automated Weather Stations to represent the moisture trends and variability through the time-series analysis. Historical fire occurrence records from each FPU were summarized and logistic regressions were developed to predict large fire occurrence probability from ERC. For each day in each year of the simulation, ERC was obtained from the time-series model and fire occurrence probability was stochastically generated based on this ERC. Growth of each ignited fire was simulated for the subsequent sequence of weather days.

The model was run for 10,000 years in each of the western FPUs and 50,000 years in the eastern FPUs. Larger fires and higher burn probabilities in the West required fewer simulations to achieve complete coverage of fires and repeatable estimates of burn probability. At the end of each simulation, the burn probabilities by fire intensity were estimated by counting the number of times fires crossed each $270-$ by $270-\mathrm{m}$ (approx. 886- by 886-ft) cell with a given intensity. This estimates the variability of intensity related to weather and spread direction (backing, flanking, and heading) as well as the spatial complexity of burn probabilities. The results for each FPU were compared to historical summaries of average burn probability and fire size distributions (Finney and others 2011).

\section{Local-Scale Demonstration (Deschutes National Forest)}

Risk assessment at the National Forest scale can be used to address a range of fuel treatment planning issues, including assessment of the relative risk to locally valued resources and the effectiveness of treatments designed to mitigate those risks. Assessments at this scale could be categorized as mid-scale assessments, as National Forests constitute fairly sizeable landscapes. However, for the purposes of this paper and in contrast with national and regional assessments, we refer to them as "localscale." The example presented here was excerpted from a larger risk assessment study on the Deschutes National Forest in central Oregon (Ager and others, submitted). This work demonstrated the application of risk assessment to analyze the relative risk to human and ecological values. We addressed two questions of keen interest to Federal managers and policy makers:

- Are the wildfire risks to conservation and other Forest plan reserves more or less than land designations receiving fuel treatments?

- What is the relative wildfire risk to WUI areas compared to different land designations?

The analyses revealed spatial variation in wildfire risk that is useful in prioritizing fuels treatments and guiding other wildfire mitigation activities. The work also illuminated the conflict between biodiversity conservation efforts on Federally managed lands and the high wildfire risk on fire-prone landscapes. In this study, burn probability and conditional flame length were estimated with FlamMap and were used to examine the relative risk among land management allocations, conservation reserves, WUI areas, and other designations on the Forest and surrounding lands. Thus, the HVRs were tiered directly to Forest plan standards and land management plan designations. Selected outputs from this analysis (for example, figure 5) revealed wide variation among and within polygons belonging to specific land designations, providing a clear identification of priority targets for mitigation activities. Specific designations and conservation reserves showed markedly higher conditional flame lengths, such as spotted owl critical habitat and old growth forests (CHU, OLD). In contrast, the general forest matrix showed relatively high burn probabilities and lower conditional flame lengths. Most of the WUI areas showed lower burn probabilities and conditional flame lengths. Mapping of these results (not shown here) provides spatial identification of specific areas at risk. 


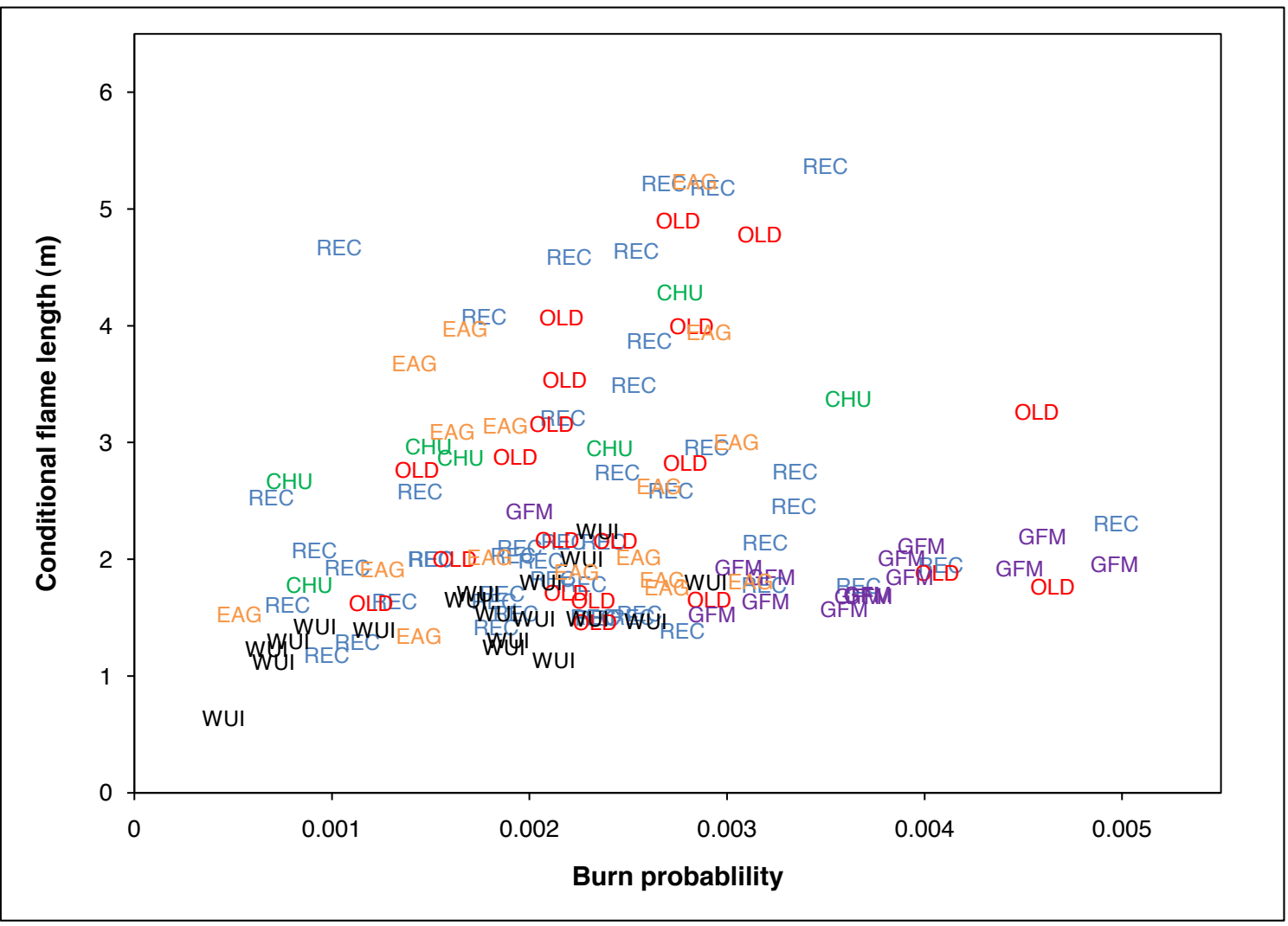

Figure 5-Example plot of burn probability versus conditional flame length for land management allocations on the Deschutes National Forest showing the relative wildfire risk among different management areas. The plot can be used for fuel treatment prioritization and monitoring of risk to key values at the National Forest scale. Legend: WUI (black) = wildland-urban interface, GFM (purple) = general forest matrix, EAG (gold) = eagle habitat, REC (blue) = recreation, $\mathrm{CHU}($ green $)=$ owl critical habitat, and OLD $($ red $)=$ old growth forests.

\section{Local-Scale Demonstration (Beaverhead-Deerlodge National Forest)}

A second National Forest example was obtained from the Beaverhead-Deerlodge National Forest where a wildfire risk assessment was conducted to determine the preand post-bark beetle wildfire risk to locally defined values. Highly Valued Resources and Assets (HVRA) listed in the Forest Plan are:

- Utility infrastructure - high-voltage power transmission lines and communication towers

- Residential and commercial buildings (wildland-urban interface [WUI])

- Municipal watersheds

- Vegetation resiliency and recovery - the Forest officials identified three vegetation types threatened by the exclusion of wildfire: whitebark pine, Douglas-fir/ ponderosa pine, and conifer-encroached rangelands

- Recreation infrastructure-ski areas, developed trailheads, interpretive sites, campgrounds

- 303(d)-listed streams

- Threatened and endangered species habitat

- Isolated fish populations

- Non-isolated bull trout and cutthroat trout

- Elk (winter range)

Resource specialists from the Forest developed response functions that related fire intensity level to the relative effect on the resource (its response to fire), scaled from -100 (greatest possible reduction of value) to +100 (greatest gain) (table 2). Resource 
Table 2-Defined value layers, response functions for each fire intensity level (FIL)a, and relative importance (social weights) for HVRA and Sub-HVRA (shown in parentheses) for the Beaverhead-Deerlodge National Forest, as presented by Scott and Helmrecht (2010).

\begin{tabular}{|c|c|c|c|c|c|c|c|c|c|}
\hline HVRA & Sub-HVRA & FIL1 & FIL2 & FIL3 & FIL4 & FIL5 & FIL6 & $\begin{array}{c}\text { Relative } \\
\text { Importance } \\
(\mathbf{R I})\end{array}$ & $\begin{array}{c}\text { Relative } \\
\text { Extent } \\
\text { (RE) }\end{array}$ \\
\hline Municipal watershed & Direct effects & 20 & 0 & -40 & -60 & -80 & -100 & $100(80)$ & 53.62 \\
\hline Municipal watershed & Indirect effects & 0 & 0 & 0 & -20 & -40 & -60 & $100(20)$ & 291.5 \\
\hline Residential structures & Low density & -10 & -30 & -50 & -90 & -100 & -100 & $100(70)$ & 6206 \\
\hline Residential structures & High density & -10 & -30 & -50 & -90 & -100 & -100 & $100(30)$ & 748.3 \\
\hline Utility infrastructure & Transmission lines & 10 & 10 & 10 & -40 & -80 & -100 & $100(95)$ & 60.86 \\
\hline Utility infrastructure & Communication towers & 10 & 10 & 10 & -40 & -80 & -100 & $100(5)$ & 0.02 \\
\hline Vegetation resiliency & Whitebark pine & 0 & 10 & 30 & 50 & 70 & 0 & $90(40)$ & 234.6 \\
\hline Vegetation resiliency & Encroached rangelands & 10 & 30 & 70 & 50 & 30 & 10 & $90(30)$ & 668.8 \\
\hline Vegetation resiliency & D-fir/Ponderosa pine & 40 & 60 & 20 & -20 & -60 & -80 & $90(30)$ & 4848 \\
\hline 303(d)-listed streams & Direct effects & 20 & 0 & -40 & -60 & -80 & -100 & $70(80)$ & 639.5 \\
\hline 303(d)-listed streams & Indirect effects & 0 & 0 & 0 & -20 & -40 & -60 & $70(20)$ & 24120 \\
\hline Rec. infrastructure & Ski areas & 20 & 10 & -20 & -40 & -60 & -80 & $70(60)$ & 10.26 \\
\hline Rec. infrastructure & High investment & 10 & -20 & -50 & -90 & -100 & -100 & $70(30)$ & 0.119 \\
\hline Rec. infrastructure & Normal investment & 10 & -20 & -50 & -90 & -100 & -100 & $70(10)$ & 0.167 \\
\hline TES (Grizzly habitat) & -- & 10 & 20 & 20 & 0 & -15 & -40 & $60(100)$ & 1560 \\
\hline Isolated TES fish & -- & 35 & 40 & 0 & -50 & -80 & -100 & $40(100)$ & 38.32 \\
\hline Non-isolated trout & -- & 35 & 40 & 0 & -35 & -60 & -85 & $10(100)$ & 553.9 \\
\hline Elk winter range & -- & 10 & 15 & 25 & -20 & -40 & -60 & $10(100)$ & 7321 \\
\hline
\end{tabular}

a Corresponding to 1 to $2 \mathrm{ft},>2$ to $4 \mathrm{ft},>4$ to $6 \mathrm{ft},>6$ to $8 \mathrm{ft},>8$ to $12 \mathrm{ft}$, and $>12 \mathrm{ft}$ flame lengths, as output by the FSim model.

staff elected to subdivide many of the key resources into two or more categories so that different response functions and relative importance values could be used. The threatened and endangered species resource was sub-divided into sensitive wildlife habitat and threatened and endangered wildlife habitat categories. The Municipal Watershed HVRA was divided into direct and indirect effects, with different response functions and different relative importance values for each. Direct effects on municipal watersheds refer to effects that take place in or very near the watercourse; indirect effects take place within the watershed but are removed from the watercourse. The response function designed by Forest staff indicates that high-intensity fire would result in a more adverse fire response near the watercourse (direct) than removed from it (indirect). Further, staff allocated 80 percent (shown in parentheses in table 2) of the importance of municipal watershed HVRA to the direct effects. This allocation coupled with the relative number of pixels of direct and indirect watershed effects determined the relative value per unit area of watershed.

In order to combine the individual wildfire threats to each key HVRA into a single overall measure of wildfire threat to all HVRAs, the staff and leadership team rated the key HVRAs in terms of their relative importance (value) to the Forest as a whole. The key HVRA(s) with the highest overall importance was assigned a value of 100 . Each remaining key HVRA was assigned an importance value relative to that maximum. These relative importance values were then divided by the area mapped to each HVRA (relative extent), resulting in relative importance per unit area. Therefore, an HVRA mapped with fewer pixels retains a higher importance value per pixel than one with many pixels where each would have less overall importance. The response function for each key HVRA was then multiplied by this weighting factor to produce an effective response function. 


\section{Regional-Scale Demonstration}

A regional prototype is being developed in the Forest Service's Pacific Northwest Region (Region 6) and considers multiple threats (climate change, insect and disease, and invasive plants) and values (carbon, critical habitat, etc.) to meet the needs of ongoing, Regionally specific assessments. Thus, the regional assessments can serve both local and national needs, the former having a scope beyond fire and fuels. The process leverages Regional datasets to the extent they are available. Specific questions that are being addressed in the Region 6 example are:

- Are there associations among threats like wildfire, insects, and climate change that form spatial patterns in the Region?

- Which human and ecological values are most associated with particular threats?

- How and where do management opportunities align with the occurrence of particular threat/value combinations?

- Where are restoration activities most needed, and are they associated with management opportunities?

- How can watersheds be ranked relative to the complete constellation of threats and values that face land managers?

These and other questions need to be addressed to develop regional options and performance measures for national tradeoff analyses. The initial regional-scale work has been funded in part by Region 6 and consisted of examining wildfire risk factors, such as burn probability and conditional flame length, for local HVR. Example outputs for SILVIS WUI (Radeloff and others 2005) areas are shown in figure 6. This type of plot, combined with additional information on management opportunities, can be used to develop investment strategies for prioritizing the allocation of funding.

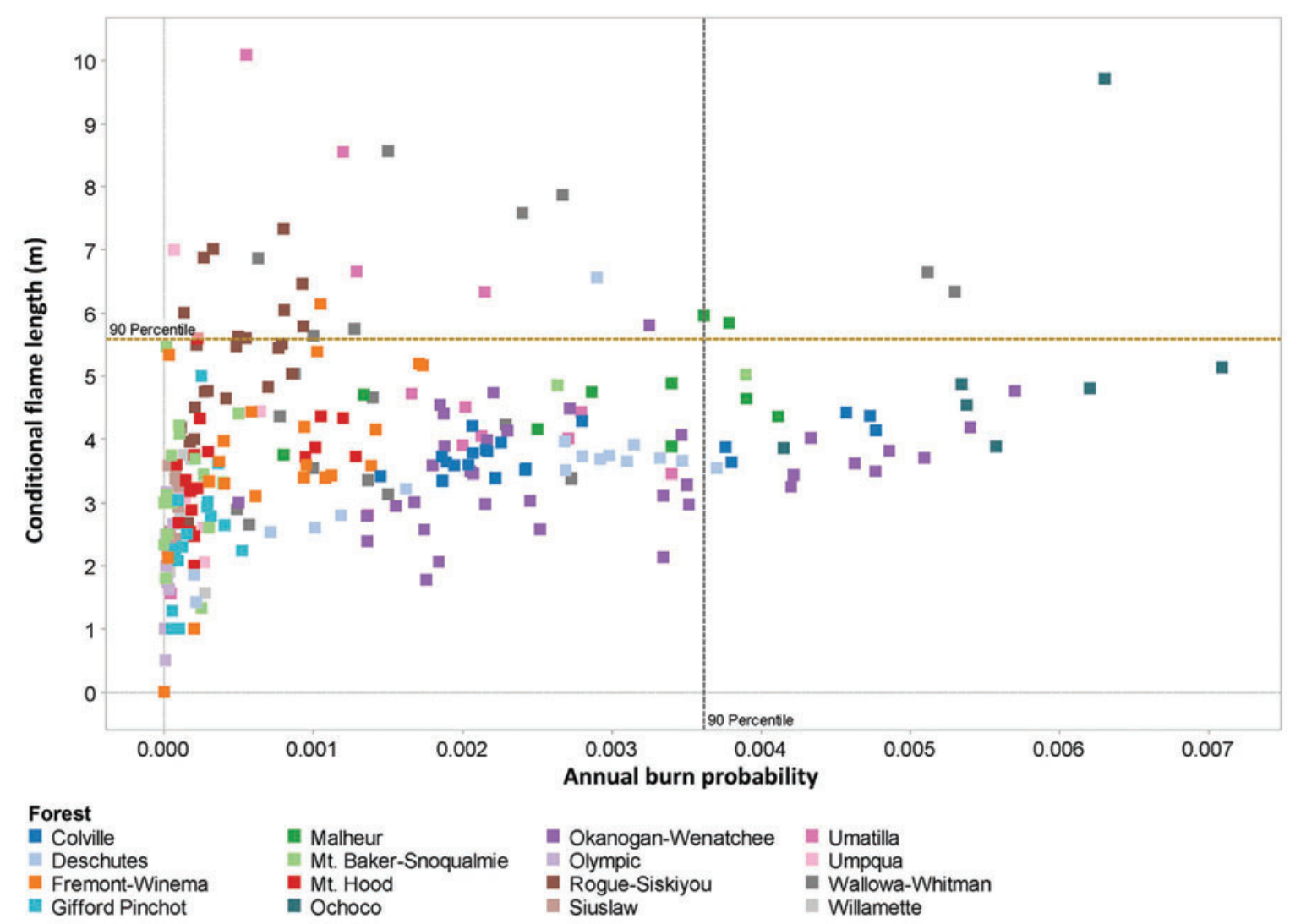

Figure 6-Scatterplot of average annual burn probability versus average conditional flame length (modified from Calkin and others 2011) for urban interface and intermix mapped by the SILVIS project (http://silvis. forest.wisc.edu/library/wuilibrary.asp) for the National Forests of Oregon and Washington. The plot shows relative risk, as measured by wildfire likelihood and intensity for each polygon, and can be used to prioritize mitigation efforts. Wildfire simulation outputs were obtained from Calkin and others (2010). 


\section{National-Scale Demonstration Overview}

"Wildland Fire Risk and Hazard: Procedures for the First Approximation" (RMRS-GTR-235; Calkin and others 2010) describes a quantitative, geospatial risk assessment framework that can be used to build national, regional, and sub-regional analyses. This assessment framework was first illustrated in a proof-of-concept analysis for the State of Oregon (Thompson and others 2010) and was later expanded to a national assessment (Thompson and others 2011) that was completed for WFLC. The work is intended to facilitate a baseline for monitoring trends in wildfire risk over time and to develop information useful in prioritizing fuels treatments and mitigation measures, and it is designed to support strategic planning by systematically portraying how fire likelihood and intensity influence risk to social, economic, and ecological values at national and regional scales. The methods and results for this assessment are only briefly described here; please refer to Calkin and others (2010) and Thompson and others $(2010,2011)$ for additional description.

The above-named project employed a risk framework that included:

- estimation of spatially explicit fire probability and intensity through the use of the Fire Program Analysis (FPA) large-fire simulation system (FSim) (Finney and others 2011);

- characterization of important resource values and assets (for example, municipal watersheds, endangered species habitat, and where people live);

- development of expert-defined response functions to quantify how important resource values and assets change under varying levels of fire intensity; and

- calculation and summary of risk at the FPU and geographic area (GA) level.

Figure 7 outlines the basic steps of the baseline assessment (mapped for the State of Oregon; the scale of analysis outlined by Calkin and others [2010]). The first step involved the identification and geospatial mapping of HVRs with assistance from 10 fire and fuels program management officials from the Forest Service, National

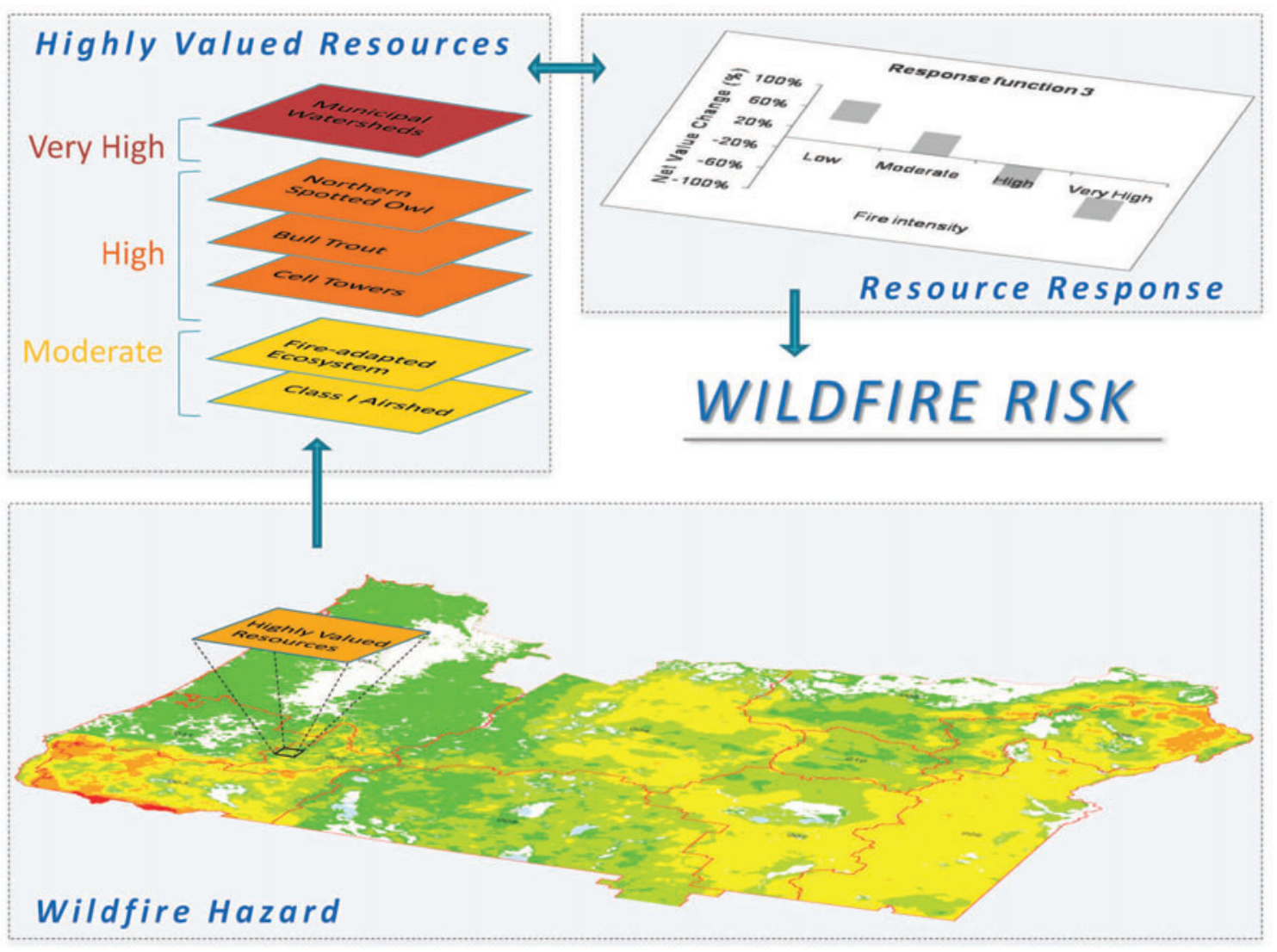

Figure 7-Illustration of the quantitative, spatial risk assessment process employed in the baseline risk assessment presented in RMRSGTR-235 (Calkin and others 2010). Wildfire hazard (measured as burn probability and conditional flame length distribution) and values-at-risk are mapped for every pixel on the landscape. This geospatial intersection of wildfire hazard and values-at-risk constitutes exposure analysis. Resource response functions quantitatively define the beneficial or detrimental effects of fire (effects analysis) to each resource contained within the pixel. Here, resource response varies as a function of fire intensity, measured via proxy as flame length. 
Park Service, Bureau of Land Management, Fish and Wildlife Service, and Bureau of Indian Affairs. Seven broad categories of HVRs were included in the baseline assessment: populated areas, fire-adapted ecosystems, fire-susceptible species, energy infrastructure, recreation infrastructure, municipal watersheds, and air quality.

The characterization of how these HVRs respond to fire of varying intensities entailed consultation with the panel of experts. A suite of generalized response functions were defined that translate fire effects into NVC to the resource in question, based upon flame length category (see formula 1). The response functions indicate relative $\mathrm{NVC}$ as a percentage of initial resource value for each flame length category. NVC is estimated using an area-based proxy called Total Change Equivalent (TCE). TCE aggregates pixel-based outputs and is defined as the equivalent area lost or gained for a particular HVR, measured here in hectares. TCE is calculated by multiplying a percentage coefficient (relative NVC) for each flame length category by the probability of fire at that flame length category, which in turn is multiplied by pixel area. As illustrated in figure 7, a given landscape pixel can house multiple HVRs, thus risk estimates entailed TCE computations for each pixel/HVR layer combination.

TCE as a spatial measure of risk enables commensurability across estimates of NVC but does not capture management priority or social worth ascribed to each HVR. An integrated approach considering the relative worth of multiple HVRs is necessary. Analyses performed to date have avoided attempts to monetize all resources (see Venn and Calkin 2009) and have instead relied on guidance from the fire and fuels program management officials to first qualitatively sort HVRs into three broad "value categories"- Moderate, High, and Very High. In this application, HVR layers were assigned to the following value categories: Moderate (Class I areas, Recreation sites and campgrounds, National trails, Fire-adapted ecosystems); High (Low-density population, Electronic transmission lines, Oil and gas pipelines, Energy generation plants, Cell towers, Ski areas, and Fire-susceptible species); and Very High (Non-attainment areas, High-density population, and Municipal watersheds).

Weights were then assigned to each category according to a simple ratio-scale technique (similar to the Simple Multi-Attribute Rating Technique) in which the weight of each successive category is a multiple of the previous category. Formula 2 displays how weighted TCE (wTCE) is calculated, where $\alpha_{i}$ is the weight assigned to the value category associated with HVR $i$ and where $n$ is the number of HVR layers. Sensitivity analysis considered three weight vectors: $(1,2,4),(1,3,9)$, and $(1,4,16)$, reflecting value differential factors of 2, 3, and 4, respectively. Figure 8 displays the allocation of these derived social weights for the weight vector $(1,3,9)$ within the construct of the multi-criteria hierarchical framework described in Chapter 3 (see also figure 3).

$$
w T C E=\sum_{i=1}^{n} \alpha_{i} T C E_{i}
$$

[formula 2]

Decision makers can experiment with various weight vectors and value category assignments to explore how changes affect the proportion of risk assigned to various HVR layers and how risk is distributed across the landscape. The relative weights assigned to resource value layers significantly influence risk measures assigned to specific locations and need to be carefully considered within risk assessment models at all scales. Chapter 7 discusses in more detail considerations related to articulation of relative priorities at various planning scales.

A key modification to the methods outlined in RMRS-GTR-235 includes an updated LandScan USA dataset (ORNL 2008) layer for human population and the likely impact of fire branding into populated areas from high-intensity fires. The 2008 LandScan USA dataset has many improvements over the 2006 dataset used in the First Approximation (Calkin and others 2010), including improved application of road and structure layers to identify populated areas (Bhaduri 2010, personal communication). 
To account for firebrands creating ignitions within populated areas, a movingwindow neighborhood was assessed for the high and very high burn probabilities (figure 9). The highest burn probability found within a 1 - by $1-\mathrm{km}$ (0.6- by $0.6-\mathrm{mi}$ ) neighborhood of a pixel (including the probability found in the pixel) was assigned the "firebrand probability" for that pixel. We used these new high and very high firebrand probability layers in place of the original outputs (of high and very high probabilities) for the population analysis. This allowed for the potential of a fire to affect populated areas within an unburnable fuel category (urban), which is located up to $1 \mathrm{~km}(0.6 \mathrm{mi})$ away from burnable fuels. The corresponding TCE for the populations (regardless of category) was calculated using a response function with strong loss (-80 percent) from fire at all intensities (Calkin and others 2010).

Two other modifications to the methods outlined in RMRS-GTR-235 (Calkin and others 2010) merit brief description. First, a noticeable trend in preliminary results was the very strong association between total mapped area and TCE values for fire-susceptible species (in particular sage-grouse [Centrocercus urophasianus] and Canada lynx [Lynx canadensis]). That risk (TCE) increased with mapped habitat area runs counter to the more intuitive notion of relative scarcity influencing risk and susceptibility of species loss. A useful alternative metric is the likely portion of habitat lost (in other words, TCE hectares/total hectares). Upon application of this metric, the relative ranking of most at-risk, fire-susceptible species changed dramatically. When considering TCE, the 10 most at-risk species are:

1. sage-grouse (Centrocercus urophasianus),

2. Canada lynx (Lynx canadensis),

3. northern spotted owl (Strix occidentalis caurina),

4. Mexican spotted owl (Strix occidentalis lucida),

5. Cape Sable seaside sparrow (Ammodramus maritimus mirabilis),

6. marbled murrelet (Brachyramphus marmoratus),

7. desert tortoise (Gopherus agassizii),

8. coastal California gnatcatcher (Polioptila californica californica),

9. peninsular bighorn sheep (Ovis canadensis nelsoni), and

10. Quino checkerspot butterfly (Euphydryas editha quino).

When looking instead at portion of habitat loss, many of these species lose salience relative to other species with smaller habitat extents but greater likelihood of loss. The top 10 list ranked by expected portion of habitat loss is:

1. Cape Sable seaside sparrow,

2. mountain yellow-legged frog (Rana muscosa),

3. San Bernardino Mountains bladderpod (Lesquerella kingii ssp. bernardina),

4. Quino checkerspot butterfly,

5. Vail Lake ceanothus (Ceanothus ophiochilus),

6. arroyo toad (Bufo californicus),

7. thread-leaved brodiaea (Brodiaea filifolia),

8. Mexican flannelbush (Fremontodendron mexicanum),

9. coastal California gnatcatcher, and

10. spruce-fir moss spider (Microhexura montivaga).

The four most influential species, as ranked by TCE, end up falling to ranks 15 , 25,23 , and 29 , respectively, when ranked by expected proportion of habitat loss. The Cape Sable seaside sparrow, by contrast, increases in salience, geographically ascribing high risk to areas of interior southern Florida with frequent fire. These results suggest decoupling fire-susceptible species from the integrated TCE calculations and presenting information on expected habitat loss separately (see Thompson and others [2011] for more details). 


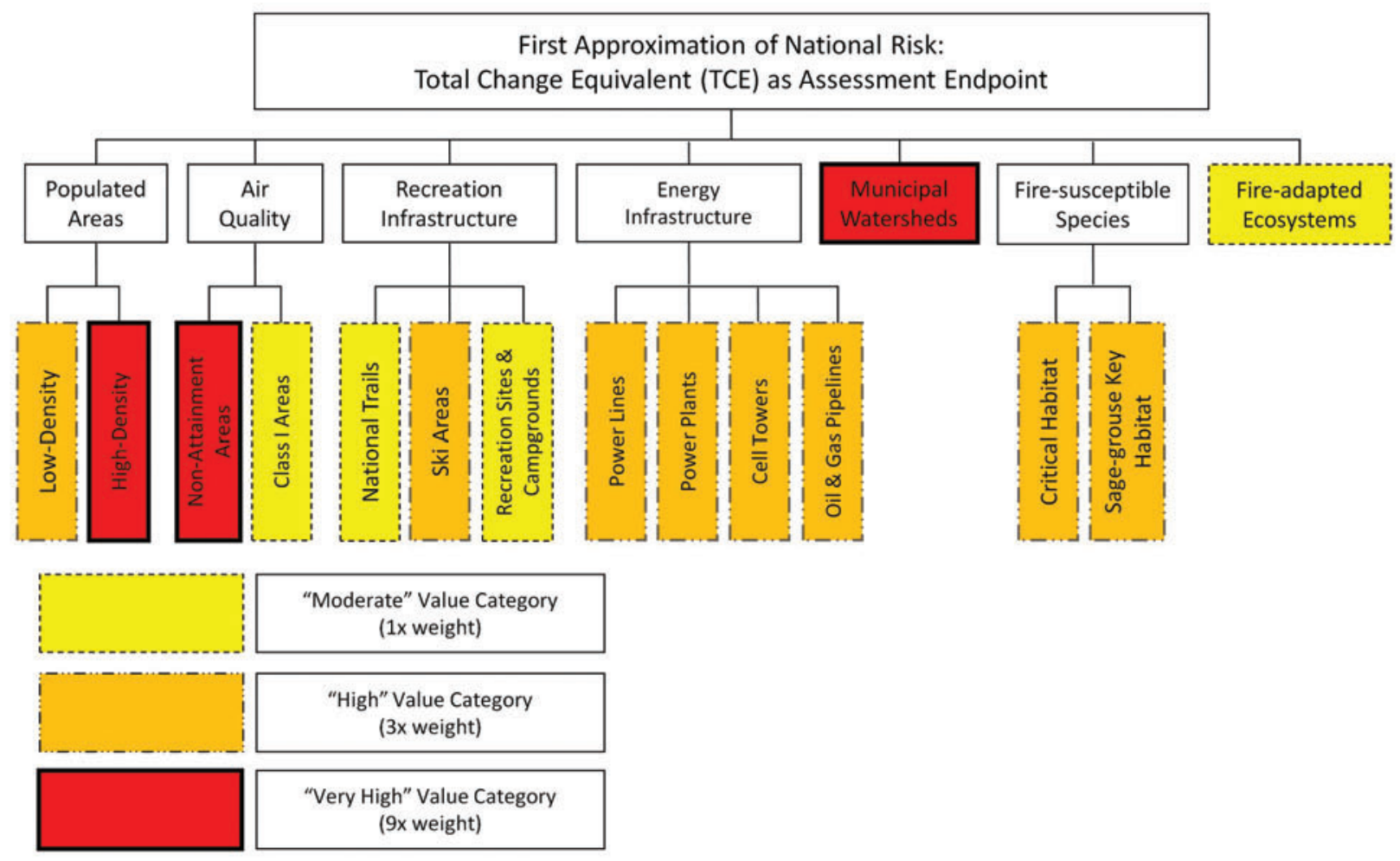

Figure 8-Allocation of social weights within the hierarchical multi-criteria structure for assessing risk in the First Approximation (Calkin and others 2010) using the (1,3,9) weight vector.

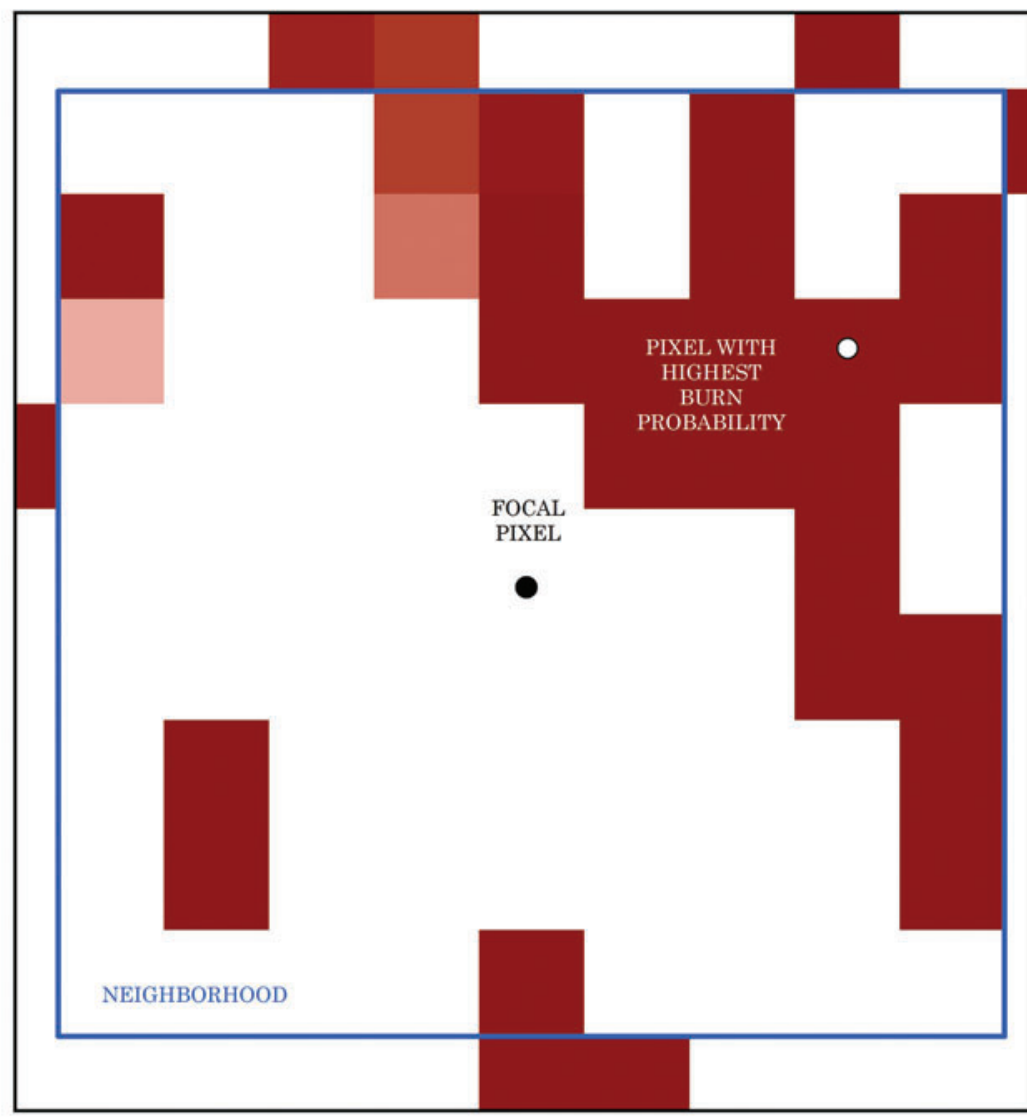

Figure 9-Illustration of the moving-window approach to account for fire branding and subsequent increase in burn probability for pixels with otherwise non-burnable fuel types up to $1 \mathrm{~km}$ away.

$>0.1-1.0 \quad \square>0.0001-0.001$
$>0.01-0.1 \quad \square>0.00001-0.0001$
$>0.001-0.01 \square$ Unburnable Fuels / No Burn Probability


A second modification to TCE calculations was required to adjust for the temporal extent of air quality impacts. Although smoke issues are very important and can result in significant health and economic impacts (Kochi and others 2010), particularly in highly populated areas, smoke impacts last only a short duration (days to weeks) relative to the impacts to other resource types. Omission of this temporal component may inflate the risk associated with wildfire in non-attainment areas and Class I areas. Thus, results were adjusted by a factor of $1 / 52$ based on the rationale that the human health and safety issues associated with smoke only last for, on average, one week per year.

\section{National Results Summary}

Results are summarized at the GA and FPU level ${ }^{2}$. (Detailed results are included in an internal document that can be made available by the authors.) Results for national burn probability and conditional flame length for the 134 FPUs are shown in figures 10 and 11. Conditional flame length is a probabilistic expectation of flame length, conditioned upon a fire occurring.

Several patterns are noticeable on the national maps of burn probability and conditional flame length. First, burn probabilities are generally higher in the western half of the country, with the notable exception of southern Florida. Fires can grow much larger in the West because of the continuity of wildland vegetation and comparatively dry climate. These probabilities are only weakly related to the rate of ignitions (see figure 35 in Chapter 6) since most ignitions do not result in much area burned. Second, flame lengths tend to be much greater in the western United States and along the extreme edge of the east coast because of the potential for crown fire caused by conifer forest and fuel structure. Low conditional flame lengths predominate in the eastern half of the country. Third, artifacts of the FPU-level analyses are visible as abrupt transitions between some FPUs. This occurs because of the assumptions in the current formulation of the model, namely that weather is constant throughout each FPU and ignitions are uniform and random throughout each FPU. These issues will be remedied in future versions of the simulation by use of gridded weather and large fire ignition density data that allow weather and ignitions to vary within FPUs.

Table 3 displays total TCE (expected NVC measured in hectares) for each HVR layer, broken down by geographic area and value category. These results present TCE values with the air quality adjustment described above and with expected habitat loss presented separately. Within the Moderate value category, the Northwest, Great Basin, Southwest and Northern Rockies all anticipate significant benefits to fire-adapted ecosystems. In the High value category, the Southern Area, California, and the Southwest expect substantial losses to energy infrastructure and low-density built structures. In the Very High value category, even greater losses are expected to moderate- and highdensity built structures and, to a lesser extent, to Municipal watersheds; California and the Southern Area expect the greatest loss. With respect to habitat loss California, the Southern Area, and the Southwest comprise the largest extent of expected loss.

Figure 12 compares geographic area share of national weighted TCE using the $(1,3,9)$ weight vector. The Southern Area (37.93 percent) and California (34.95 percent) dominate the overall picture, followed by the Southwest ( 8.79 percent). These rankings remained consistent across the alternative weight vectors considered in the sensitivity analysis, suggesting that results are robust and should not substantially differ under alternative preferences. To reiterate, the information presented in figure 12 should be evaluated simultaneously with the information on fire-susceptible species presented in table 3 . The top three GAs by wTCE (SA, CA, and SW) are also the top three areas of high expected loss to fire-susceptible species (although not exactly by rank; table 3), providing an aligned picture of integrated risk.

\footnotetext{
${ }^{2}$ To facilitate interagency planning, the continental United States is divided into multiple Geographic Area Coordination Centers for the purposes of incident management and mobilization of resources (http://gacc.nifc.gov); these centers are referred to in this report as geographic areas (GAs). Fire Program Analysis further divides the landscape into Forest Planning Units (FPUs), defined for the purpose of cooperative fire management planning and implementation.
} 


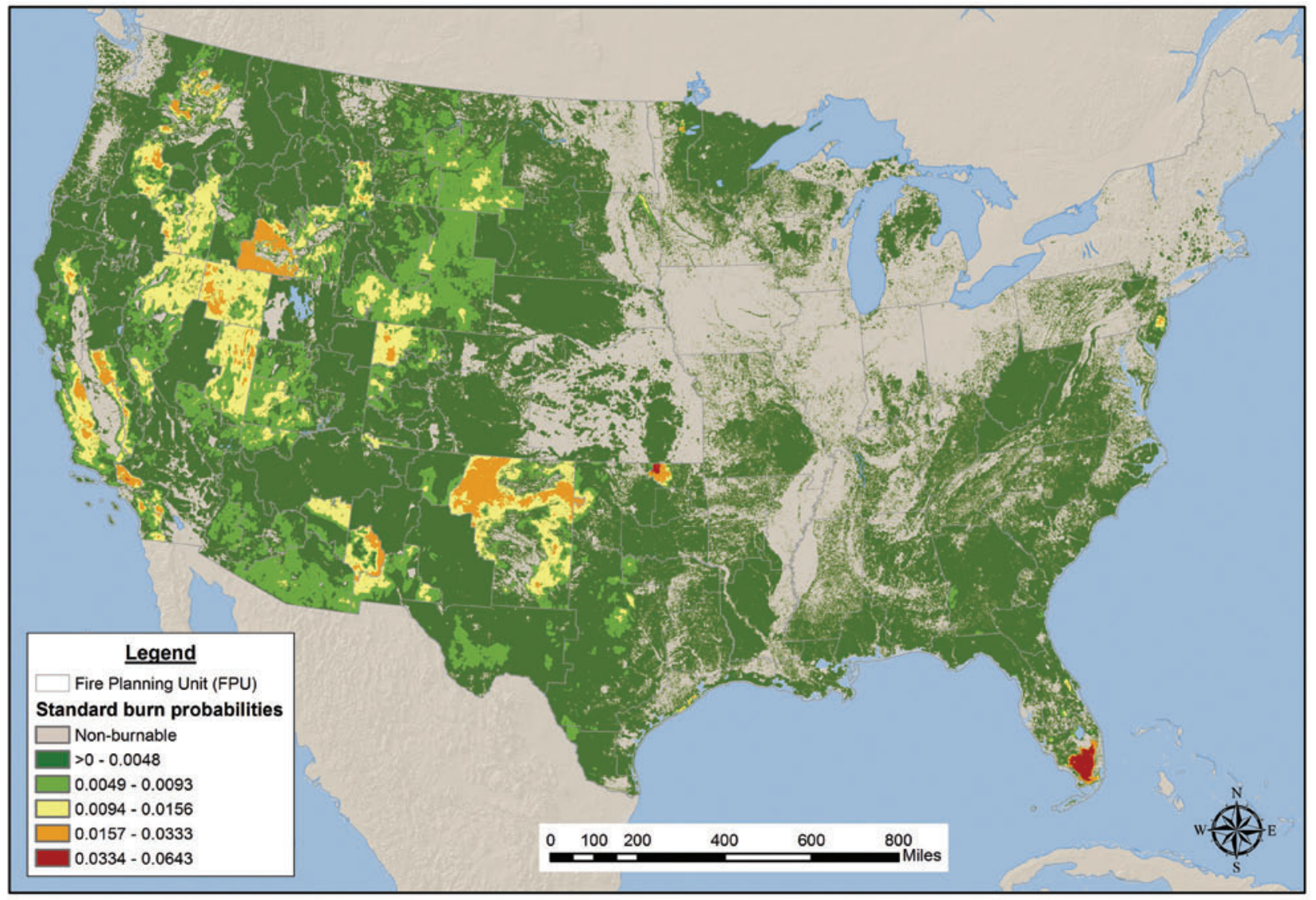

Figure 10—National map of burn probability from FSim modeling.

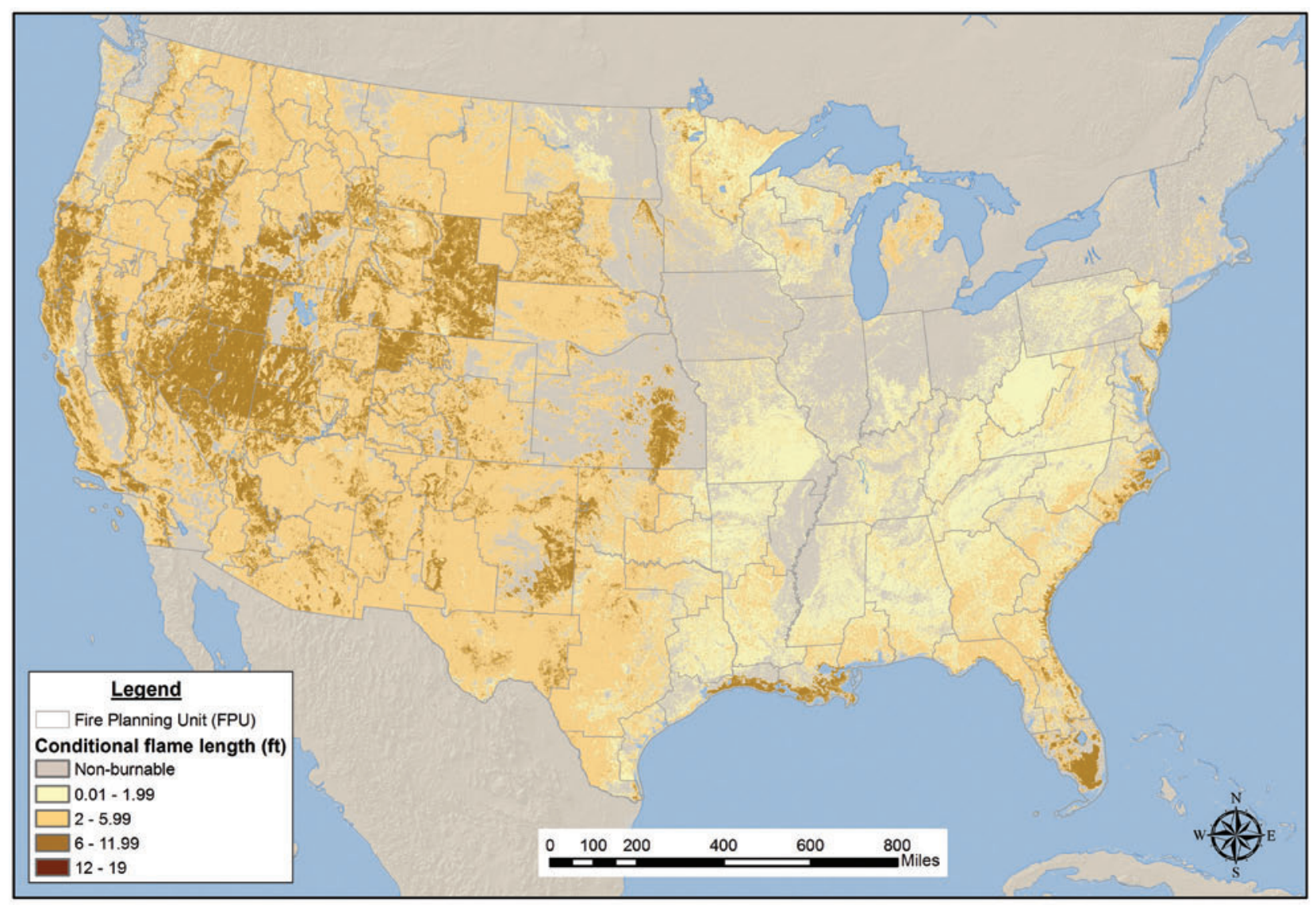

Figure 11-National map of conditional flame length for the 134 FPUs. 
Table 3-TCE measured in hectares by HVR layer for each Geographic Area across value categories. HVR layers "Low density" and "Mod/High density" refer to populated areas. Legend: CA = California, EA = Eastern Area, GB $=$ Great Basin, NR $=$ Northern Rockies, NW = Northwest, $\mathrm{RM}=$ Rocky Mountain, SA = Southern Area, SW = Southwest.

\begin{tabular}{|c|c|c|c|c|c|c|c|c|c|}
\hline & & \multicolumn{8}{|c|}{ Geographic Area } \\
\hline & & CA & EA & GB & NR & NW & $\mathbf{R M}$ & SA & SW \\
\hline \multirow[t]{4}{*}{ Moderate } & Class I areas & -17 & -1 & -4 & -25 & -9 & -1 & -102 & -9 \\
\hline & Ecosystems & 336 & 659 & 3420 & 2867 & 5832 & 686 & 578 & 3018 \\
\hline & National recreation & -46 & 0 & -5 & -4 & -7 & -1 & -114 & -4 \\
\hline & Total & 273 & 658 & 3410 & 2837 & 5816 & 684 & 362 & 3005 \\
\hline \multirow[t]{4}{*}{ High } & Energy & -831 & -176 & -208 & -51 & -102 & -208 & -2004 & -374 \\
\hline & Low density & -1245 & -693 & -336 & -397 & -300 & -513 & -3512 & -1073 \\
\hline & Ski areas & -3 & 4 & 6 & 7 & 4 & 2 & 2 & 0 \\
\hline & Total & -2079 & -865 & -538 & -441 & -398 & -719 & -5514 & -1447 \\
\hline \multirow[t]{4}{*}{ Very High } & Non-attainment areas & -869 & -20 & -22 & -2 & 0 & -3 & -70 & -62 \\
\hline & Mod/High density & -5211 & -1105 & -488 & -428 & -550 & -404 & -6851 & -1853 \\
\hline & Watersheds & -4952 & -155 & -921 & -716 & -1142 & -679 & -3972 & -879 \\
\hline & Total & -11032 & -1280 & -1431 & -1146 & -1692 & -1086 & -10893 & -2794 \\
\hline \multicolumn{2}{|c|}{ Total \% habitat lost } & $9.26 \%$ & $0.01 \%$ & $0.19 \%$ & $0.13 \%$ & $0.50 \%$ & $0.15 \%$ & $5.40 \%$ & $1.21 \%$ \\
\hline
\end{tabular}

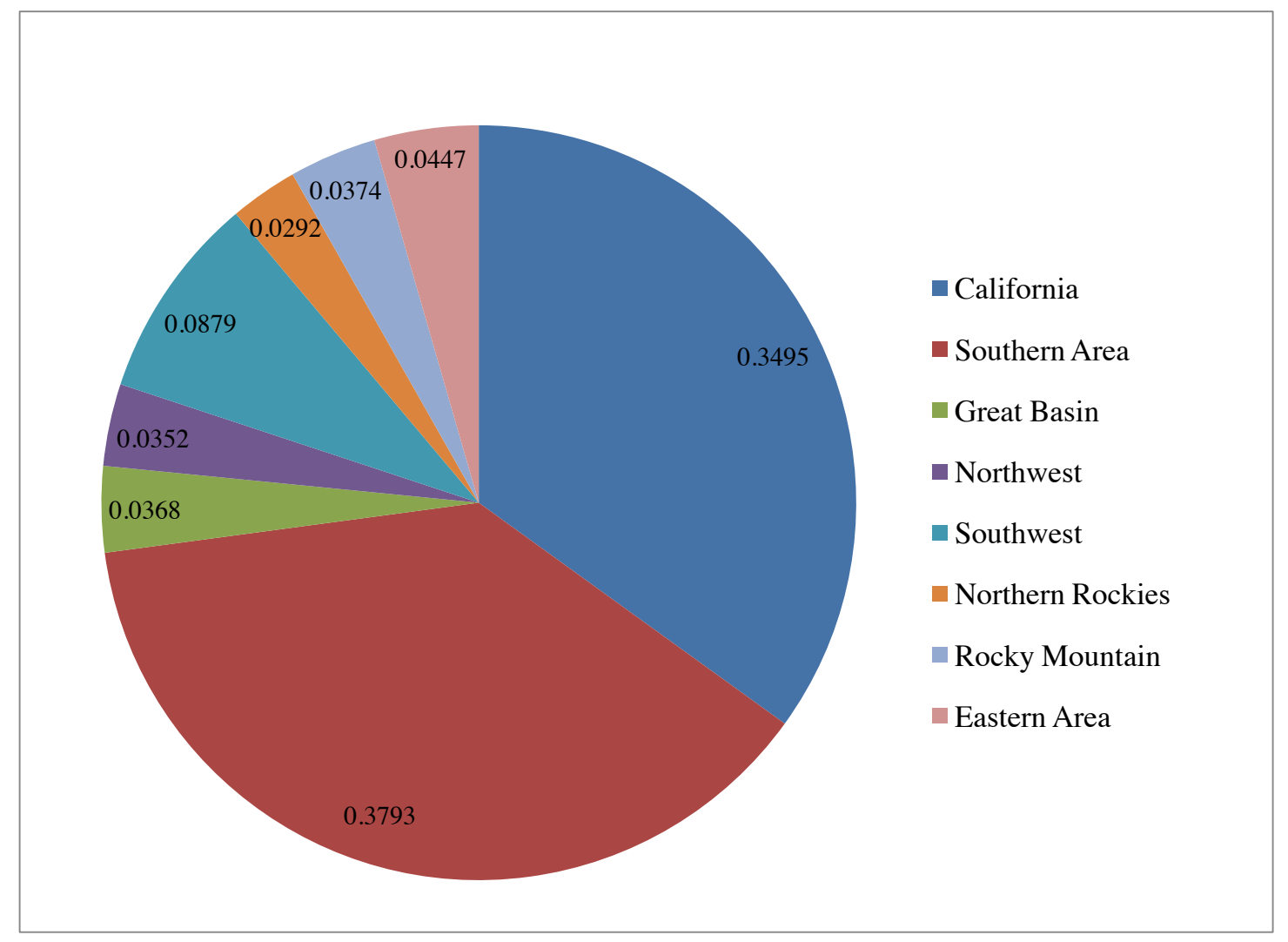

Figure 12-Geographic Area share of national weighted risk (wTCE) for the modified scenario using the (1, 3, 9) weight vector (figure from Thompson and others [2011]). 


\section{Comparative Risk Mitigation (Exploring Options for Reducing Risk)}

Our discussions of risk in the preceding chapters have generally focused on current levels of risk or simple conceptualizations of how risk is affected by both natural factors (weather, fuels, and topography) and management actions. Broader management options that might be expected to affect those risks were implied but were not specifically analyzed in our discussion. It is instructive to think about the types of options that do exist, how they might be analyzed in the next phase of the development of the Cohesive Strategy, and what available information might be brought to bear.

To facilitate this discussion, we refer to the simple conceptual model in figure 13 and the four basic options to mitigate wildfire risk:

- Invest to prevent human caused ignitions

- Invest in fuels treatment

- Invest to build capacity in fire response

- Invest to protect values exposed to risk

We speak to each of these below, but the real work is in trying to understand how they might best be applied together. Because of the complexity involved in understanding the effect of fuel treatments and the degree to which that option has been examined, we explore it more fully than the other options.

To begin to understand how each option might play out, it is necessary to (1) establish a historical point of reference, (2) develop an analytical capacity to examine the relative effectiveness of each option, and (3) project conditions into the future. Fortunately, there are numerous completed and ongoing assessment and planning efforts that provide a good start on having the tools and information needed. Some of these are referenced above, including the FPA (http://www.fpa.nifc.gov) effort that focuses on investment effectiveness among Federal agencies. The analytical system

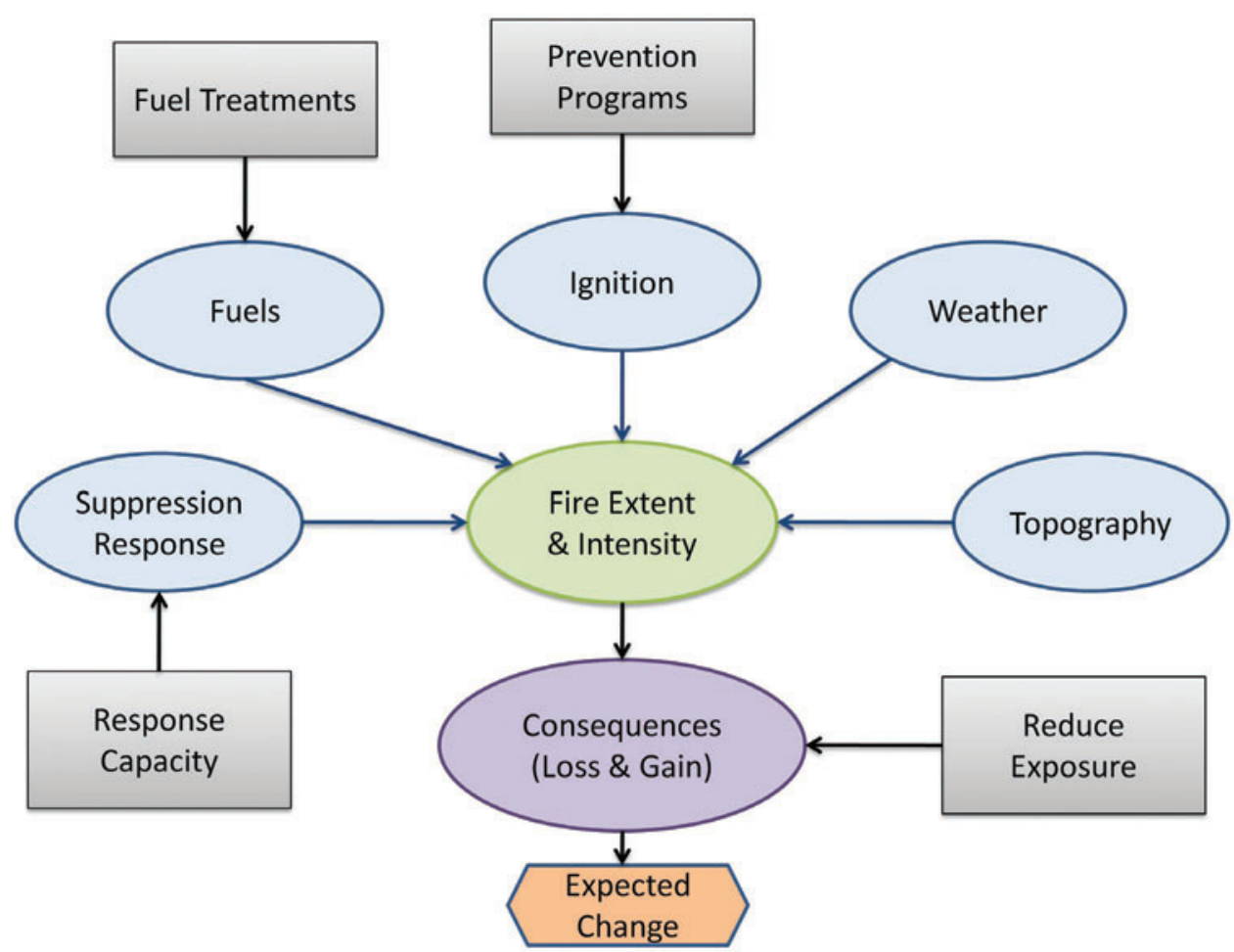

Figure 13-A simple conceptual model of wildfire, including the five principal contributing factors, consequences, and management options (blue bubbles) designed to either change wildfire extent and intensity or to alter risk by changing the degree of exposure experienced by valued elements of the landscape. 
designed and built to support FPA has the capacity for modeling effectiveness of fire prevention programs, investments in preparedness resources, and landscape fuels treatments in affecting various performance measures tied to the probability and intensity of areas burning within the analysis area and the suppression costs associated with responding to wildfires. FPA is not the only modeling framework available to tackle these issues, but it is remarkable in its level of detail, extensive accounting, and analysis features.

One of the more critical datasets used by FPA is the historical fire occurrence data compiled by Federal and State agencies. FPA analysts use these data to determine the location and cause of wildfire ignitions; the data also provide a basis for model calibration. The FPA dataset has some known issues associated with data accuracy and completeness, especially regarding fires on non-Federal lands. Updated versions of the dataset will correct some problems related to duplicate records and missing or inaccurate location information, but the updated data will likely still miss many fires that occurred historically. We use the FPA records for fires occurring from 1999 to 2008 here for illustrative purposes, recognizing that improved and more comprehensive data may become available that could change our results.

As a point of reference, approximately 447,000 recorded wildfires occurred across the United States between 1999 and 2008 and burned over 28 million ha (69 million acres). Although the Southern GA led all regions with number of recorded wildfires (41 percent of total), most of the area burned was located in western states, with over 7 million ha (18 million acres) in Alaska alone (which tends to experience fewer but larger fires on average). The 10-year historical average for the conterminous 48 states is close to the roughly 2 million ha (5 million acres) of simulated wildfires used to generate the burn probability map shown above in figure 10. Dividing the area burned in a 10-year period by the land area of each state produces an area-adjusted map of historical burning that corresponds well to the simulated burn probability map (figure 14).

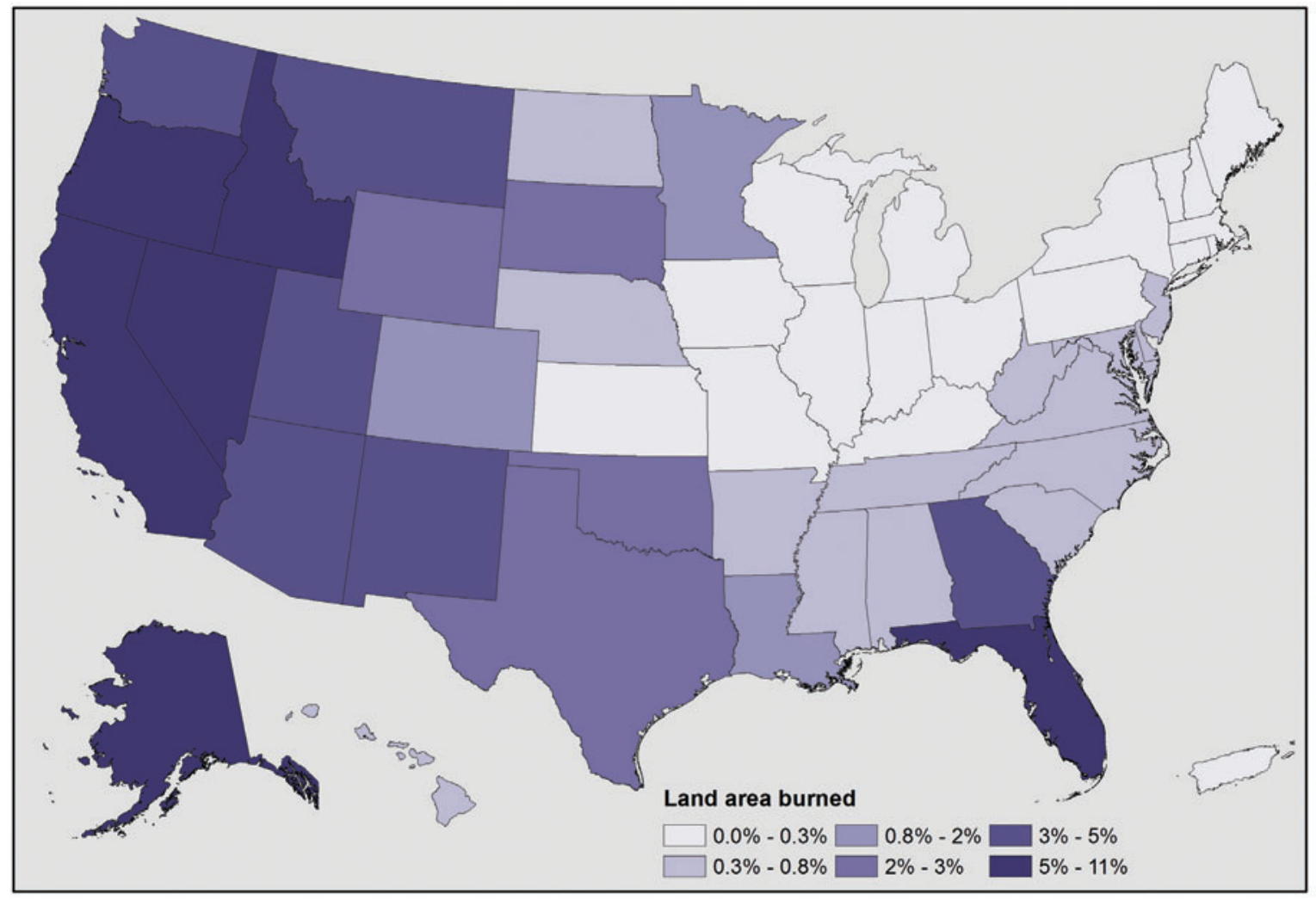

Figure 14-Cumulative area burned in each state from 1999 to 2008 . Areas are normalized by dividing the area burned by the total land area in each state. 
Understanding current risk is not the same thing as projecting future risk, however, and major challenges must be overcome in order to produce credible estimates. Three of the more difficult factors to predict are (1) changes in vegetation from factors other than wildfire, (2) changes in population and development patterns that could expose more lives and property to wildfire effects, and (3) the feedback effects of fires in one year on fire occurrence and behavior in following years. Add to this backdrop of uncertainty the additional questions about future climate and it is clear that any future projections will include a healthy dose of uncertainty. Rigorous examination of this uncertainty is an essential component of a risk-based assessment process.

The FPA analysis process was not designed to assess the impact of future changes in vegetation, climate, or WUI areas. Future improvements in the FPA system may remedy these shortcomings, but other avenues of modeling these issues should be explored for the immediate future. These are areas of active research and development in agencies such as the USDA Forest Service and U.S. Geological Survey (USGS), and results are promising. Models such as LANDIS, a spatially explicit forest succession model, and Vegetation Dynamics Development Tool (VDDT) target some of these issues and have been used at smaller scales to examine interactions among fire and landscape changes (Sturtevant and others 2009a, 2009b). Application of these models in future Cohesive Strategy analyses is possible, especially for regional analyses that focus on particular landscapes that have been previously examined.

\section{Option 1. Invest to Prevent Human-Caused Ignitions}

There is an old adage that the best way to stop a wildfire is to make sure it never starts. Wildfire prevention programs form an important component of any comprehensive wildfire management strategy, ranging from the familiar "Smokey Bear" public education campaign to focused law enforcement. Prevention efforts target those sources of human ignitions that can be avoided, including arson, debris burning, campfires, smoking, and off-road vehicle use. The degree to which humancaused ignitions contribute to wildfire is substantial. Nationwide, human ignitions (everything except lightning) accounted for nearly 75 percent of all wildfire starts, yet only 30 percent of the area burned. This disparity is due to geographical differences in wildfires; the western states experience larger fires dominated by lightning ignitions, while smaller wildfires in most eastern states are human caused (figure 15).

Despite a long and storied history of fire prevention programs in the United States, scholarly analysis of the effectiveness of these programs is scarce. A recent article by Prestemon and others (2010) is a notable exception, in which the authors remarked, "Although a common belief is that wildfire prevention education is worthwhile, there is a striking absence of studies documenting its effectiveness." One of the more commonly used tools for estimating the effects of prevention programs is the Risk Assessment and Mitigation Strategies (RAMS) model, which was developed in the mid 1990s using expert opinion. Briefly, the RAMS model uses a combination of effectiveness factors and preventability factors to calculate the expected reduction in human ignitions given a prescribed mix of program elements such as patrols, signs, law enforcement, and public contact. The degree to which fire can be prevented varies by specific cause. FPA incorporates RAMS in its suite of models and caps the preventability levels by cause. For example, no more than 7 percent of arson fires can be prevented within FPA, while 16 percent of fires started by debris burning and children can be prevented. Given the limited validation efforts to date regarding RAMS, sensitivity analysis is recommended.

For illustrative purposes, we use the maximum preventability factors and historical fire information from FPA to calculate the upper limit for expected change in ignitions and area burned. Nationwide, we estimate that 9.4 percent of the reported ignitions from 1999 to 2008 could have been prevented, which would have reduced the expected area burned by 3.4 percent. The differences among states are dramatic, again, depending on whether fires are predominately human caused. Normalized by land area within each state, the greatest gains in terms of ignitions per square mile are found 
in high-frequency states such as Georgia, New Jersey, South Carolina, and Florida (figure 16). In terms of relative change in the number of ignitions, many eastern states exceed the national average, while western states dominated by lightning-caused ignitions show relatively small benefit from reduced ignitions (figure 17). Further analyses at the county level would show similar variation among counties within many states, such as California, with a mix of urban and wildland areas.

A comparison of these national results with the empirical results of Prestemon and others (2010) from Florida suggests that the limits on preventability imposed by the RAMS model within the FPA project may seriously underestimate the benefit of prevention programs in some areas. Using a sophisticated empirical model, the authors show that increased investment in wildfire prevention education (WPE) could result in reductions in preventable ignitions upward of 80 percent, with associated reductions in area burned resulting in a more modest 10 percent or less (figure 18). Prestemon and others (2010) go further in their analysis, incorporating estimates of change in net value estimating that the marginal benefits of averted wildfire damages are 35 times the investment in WPE in Florida with reduced suppression costs accounting for 15 percent of the estimated benefit.

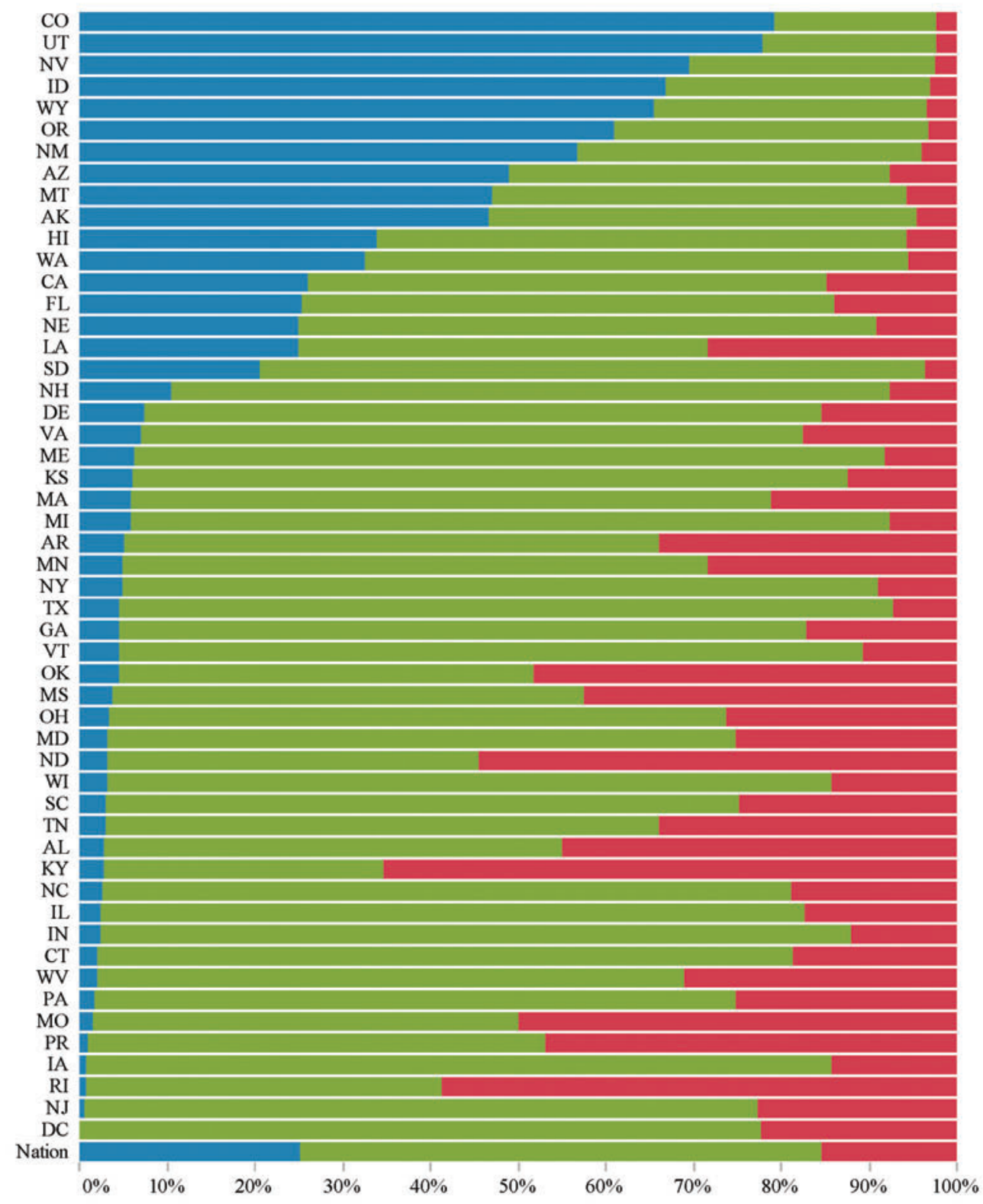

Figure 15-Historical distribution of reported cause of wildfire ignitions by state (1999 to 2008). 


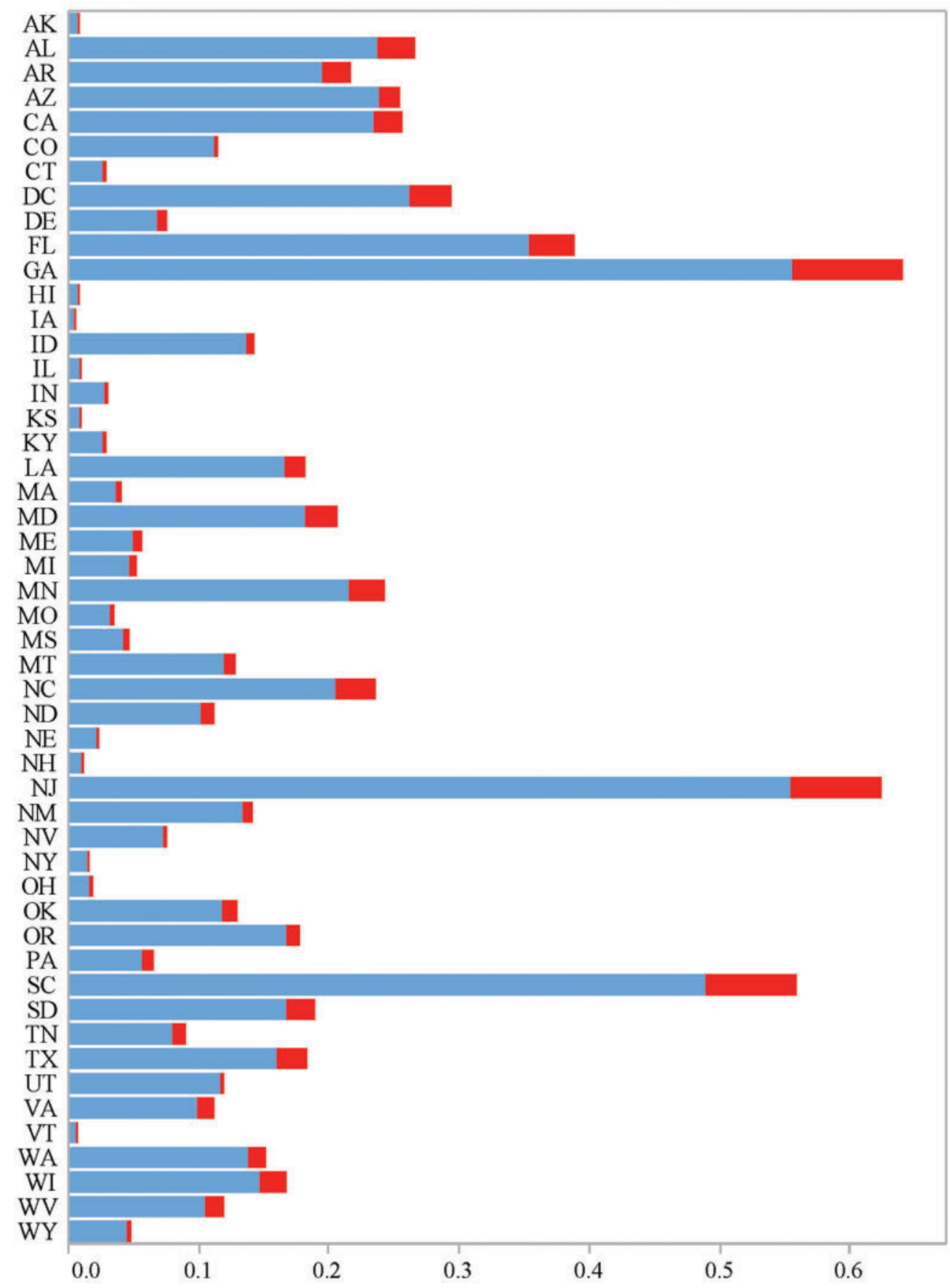

Prevented

Recorded fires/sq_mi

Figure 16-Reported number of fires per square mile in each state (1999 to 2008). Area in red represents the upper limit on the number of preventable fires resulting from a fully implemented prevention program. 


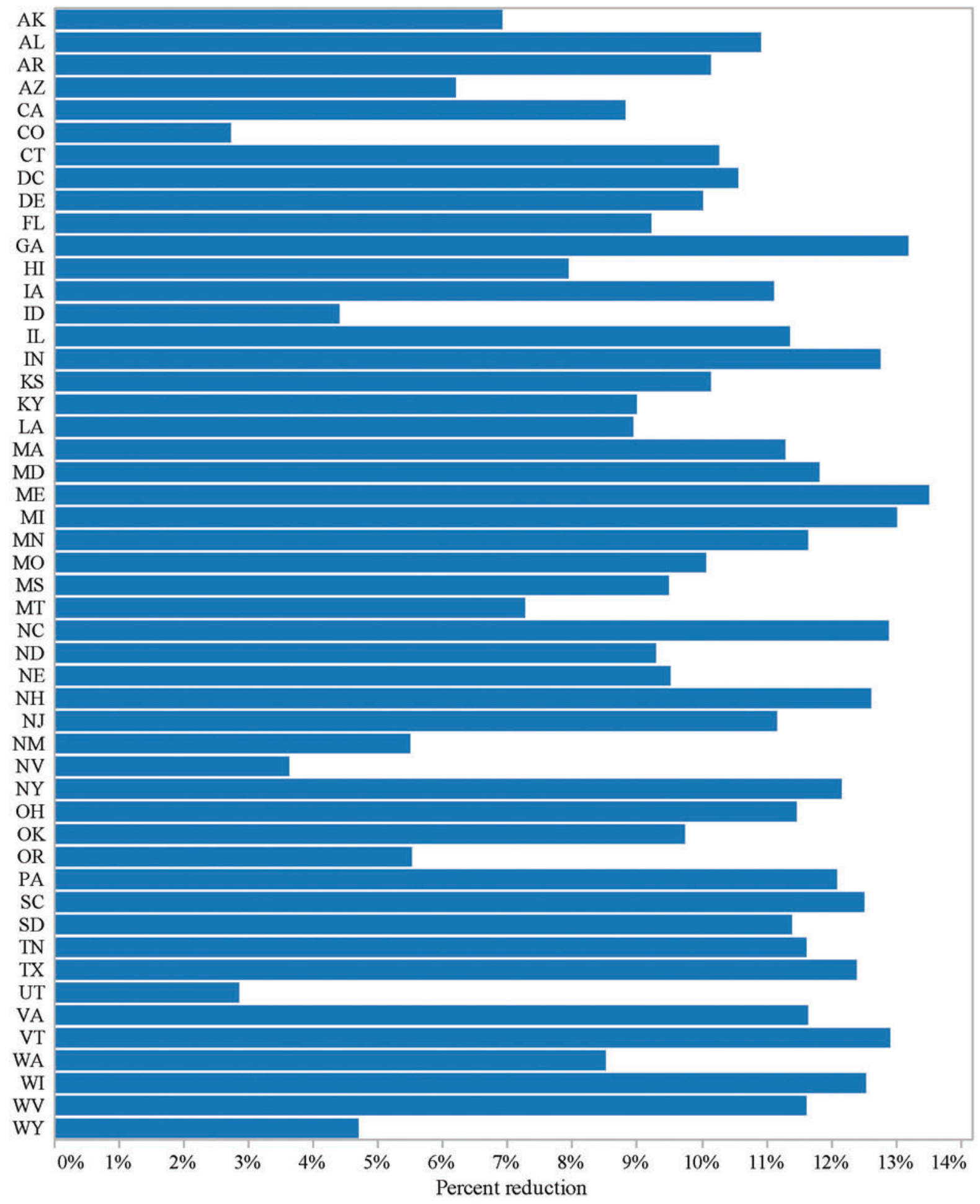

Figure 17-Percent reduction in human-caused ignitions by state in full prevention scenario. 


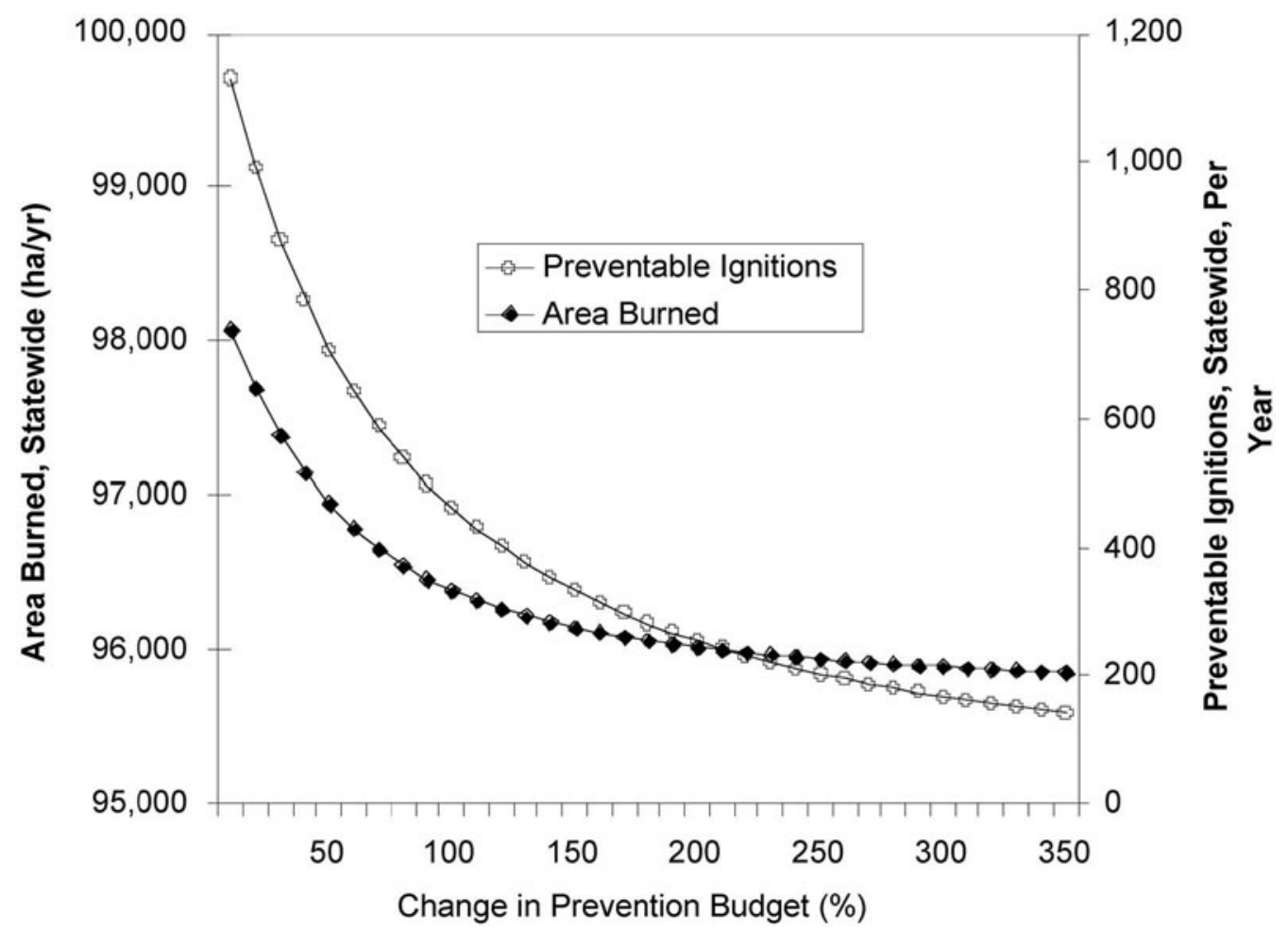

Figure 18-Counterfactual effects on annual area burned and the annual number of expected wildfires obtained by simultaneously changing all wildfire prevention education efforts statewide in Florida, 2002 to 2007, across a range of possible percentage increases (from Prestemon and others [2010]).

\section{Option 2. Invest in Fuel Treatments}

The purpose of national fuel management activities in the United States are described by the broad goals stated in the National Fire Plan. These goals are: reducing the risk of catastrophic fire, protecting communities, reducing fuel hazards, reducing wildfire acres and costs, and restoring fire-adapted ecosystems (USDA and USDI 2002).

Investing in fuel treatments requires that these broad policy goals be translated to guide field-level projects based on a local problem analysis and have standards for evaluating the success or failure of the project. In addition, for the objectives to be met and for benefits to be realized from fuel management investments, a supporting analysis must be developed to physically relate cause and effect, essentially evaluating how the benefit is physically derived from the management action (in other words, fuel management). Finney and Cohen (2003) outlined steps that can help translate broad policy-oriented goals to field-level actions:

1. Identify the specific problems to be addressed by fire/fuels management.

2. Identify the cause of these problems as relating to fuels or fire behavior.

3. Describe the desired outcome of the treatment measure (in other words, how much change is needed).

4. Identify the appropriate scale of treatment needed to effectuate the desired outcome.

5. Describe the specific cause and effect relationship between the desired outcome and the proposed treatment(s).

Finney and Cohen (2003) further suggested that all of these goals can be collapsed into the single broad category of "fire risk management," meaning that fire 
risk is managed, not eliminated, but the associated social and ecological impacts are mitigated.

What is needed to examine fuel treatment investment for a revised Cohesive Strategy is a fire risk management strategy that can guide each step at the field level and meet the broad policy objectives. Although there are many new detailed studies on fuel treatments (Finney and others 2007; Schmidt and others 2008; Vaillant 2008; Ager and others 2010b; Graham and others 2010) and some overview papers (Reinhardt and others 2008; Collins and others 2010) none has offered a translation of the main fuel management goals into a risk-based framework consistent with the goals of the revised Cohesive Strategy. We suggest that at the field level, risk assessment procedures, as outlined earlier in this document, can assist in the steps to inform fuel treatment strategies in terms of treatment location, amount, type, and spatial patterns. Fire likelihood, intensity, and potential effects can be combined with spatial patterns of values, fire management objectives, and fire regime to determine fuel treatment and overall fire management strategies (figure 19). The risk assessment determines the expected mix of intensity and likelihood of wildfire, while the spatial pattern of values determines the interaction of the aforementioned wildfire risk factors with values perceived to be at risk. Fire management objectives determine the extent to which long-term risk management emphasizes restoring natural fire regimes or suppression to protect HVRs. Example scenarios covering a range of fuel treatment strategies and fire restoration management objectives are shown in figure 20.

Development of a wide range of case studies to illustrate this risk-based fuel treatment taxonomy is in progress. The following sections describe studies completed to date that show how risk assessment methods can be applied to examine fuel treatments with respect to the process outlined in Finney and Cohen (2003) and the broad goals of fuel management. The analyses presented below are largely linked with the risk assessment examples presented in the previous chapter and range from projectscale analyses to national assessments. Following, we describe relevant results to a small number of these studies.

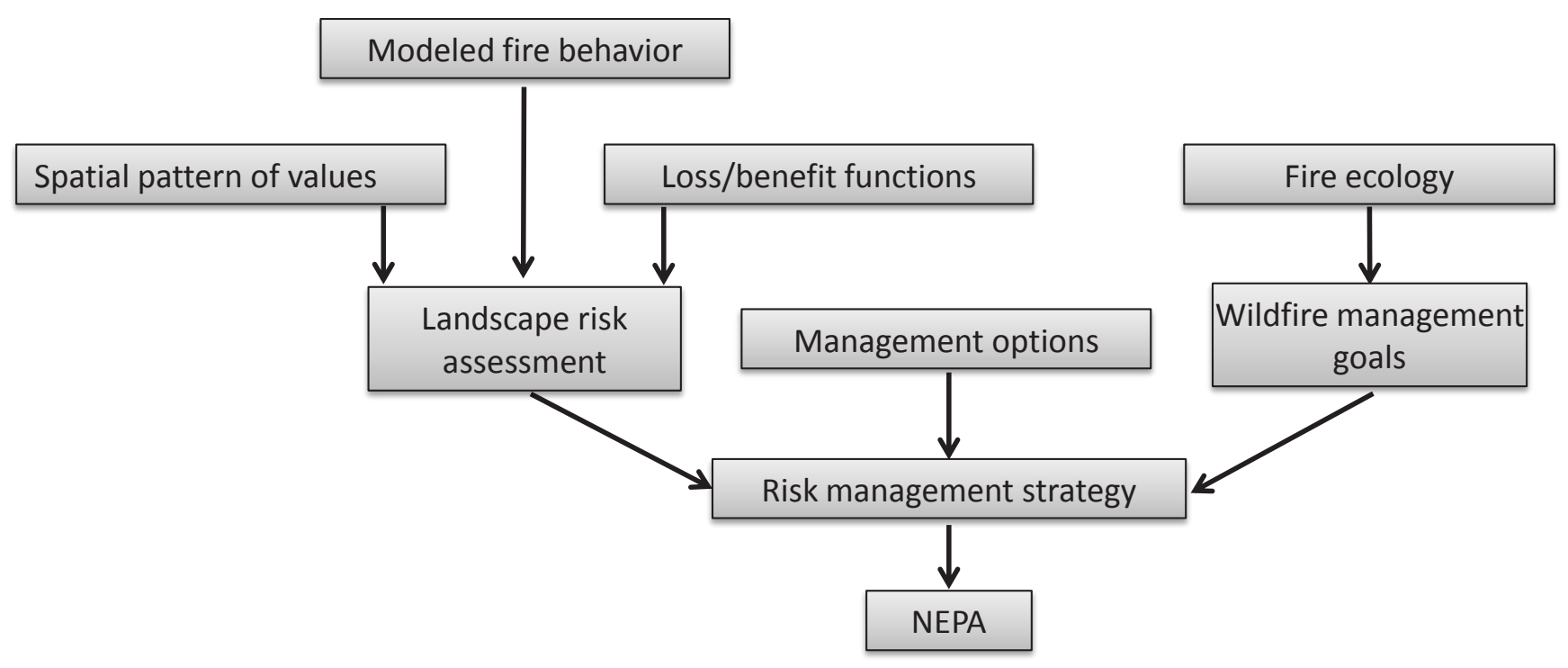

Figure 19-Combining risk analysis with management opportunity and ecological conditions with respect to fire determines coordinated landscape fuel treatment strategies. 


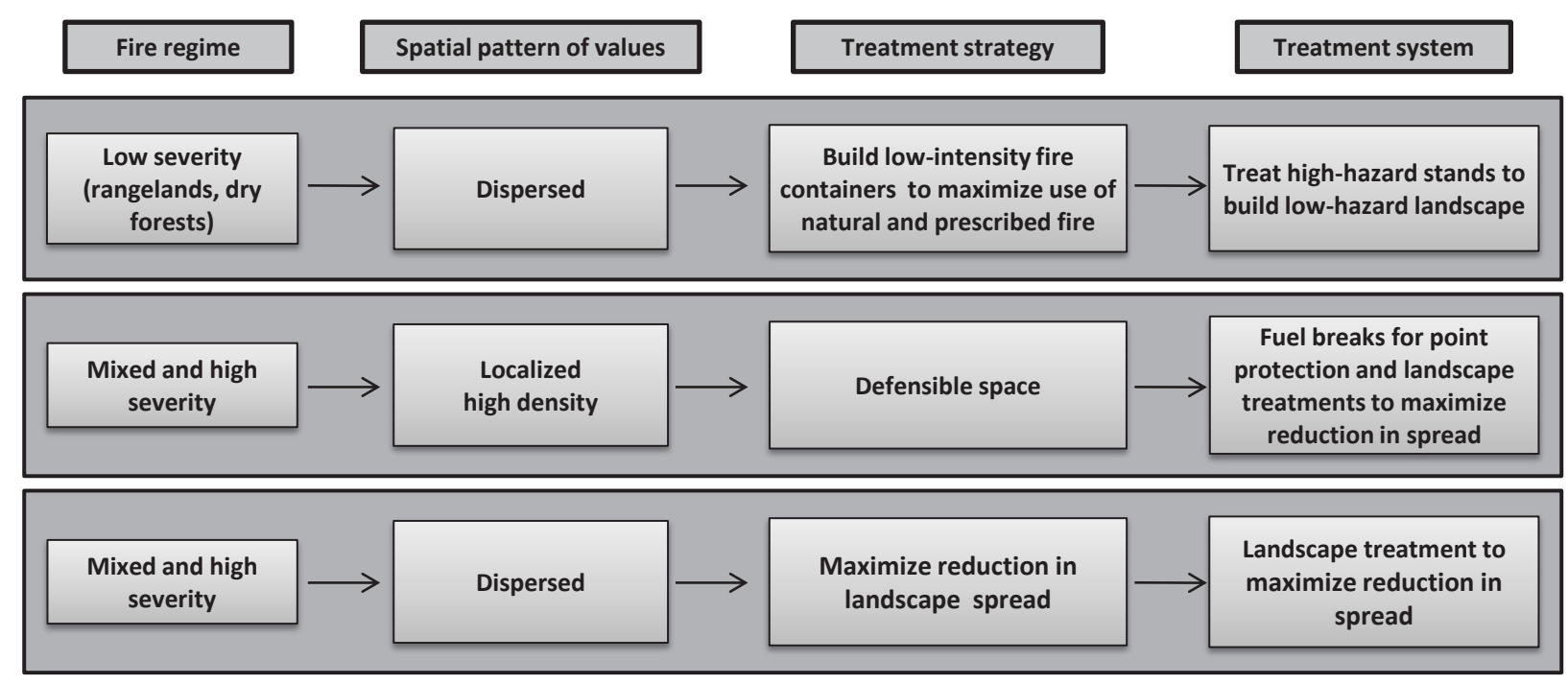

Figure 20-Taxonomy of fuel treatment strategies showing example scenarios that are driven by fire management objectives, spatial patterns of values, and fire regime.

\section{Project-Scale Fuels Treatment}

Ager and others (2010b) applied risk analysis to examine tradeoffs between landscape restoration (as measured by old growth mortality) and protection of structures within a wildland urban interface in eastern Oregon. The treatment strategies were evaluated by simulating 10,000 wildfires with random ignition locations and calculating burn probabilities by $0.5-\mathrm{m}$ (1.5-ft) flame length categories for each $30-\mathrm{m}(98-\mathrm{ft})$ pixel in the study area. The burn conditions for the wildfires were chosen to replicate severe fire events based on $97^{\text {th }}$ percentile historic weather conditions. The burn probabilities were used to calculate wildfire risk profiles for each of the 170 residential structures within the WUI and to estimate the expected (probabilistic) wildfire mortality of large trees (diameter $>53 \mathrm{~cm}$ or 21 inches) that are a key indicator of stand restoration objectives. Expected wildfire mortality for large trees was calculated by building flame-length mortality functions using the Forest Vegetation Simulator and subsequently applying these functions to the burn probability outputs. Results suggested that treatments on a relatively minor percentage of the landscape (10 percent) result in a roughly 70 percent reduction in the expected wildfire loss of large trees for the restoration scenario (figure 21). Treating stands near residential structures resulted in a higher expected loss of large trees but relatively lower burn probability and flame length within structure buffers. Substantial reduction in burn probability and flame length around structures was also observed in the restoration scenario where fuels treatments were located 5 to $10 \mathrm{~km}$ (3 to $6 \mathrm{mi}$ ) distant (figure 22). The study demonstrated tradeoffs between ecological management objectives on wildlands (represented by large, fire-resilient trees) versus protection of structures.

\section{Forest-Level Fuels Treatment}

A fuel treatment priority map for the Deschutes National Forest was used to simulate fuels treatment and examine change in wildfire risk. The treatment scenario called for 64,000 ha (approx. 26,000 acres) of treatments in the general forest management areas. The ratio of the burn probability after and before the treatments was used to examine change in wildfire likelihood (figure 23). The analysis suggested large reductions in burn probability to conservation and other reserves. For instance, the likelihood of a fire in the old growth reserves was 30 percent of the pre-treatment conditions. The effect of treatments on both burn probability and fire size for specific reserves, like old growth, show large reductions post treatment (figure 24). 
a) SDEN expected loss

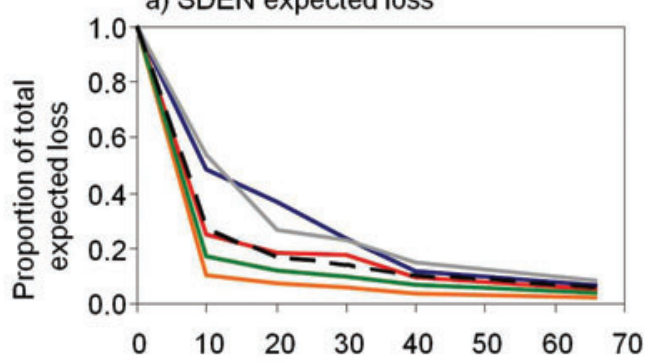

c) SDEN conditional expected loss

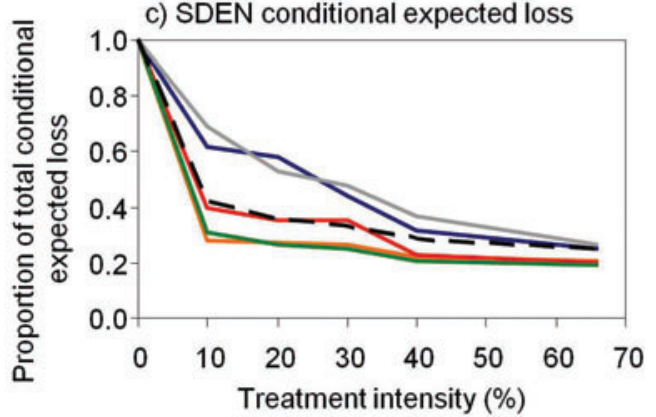

b) RDEN expected loss

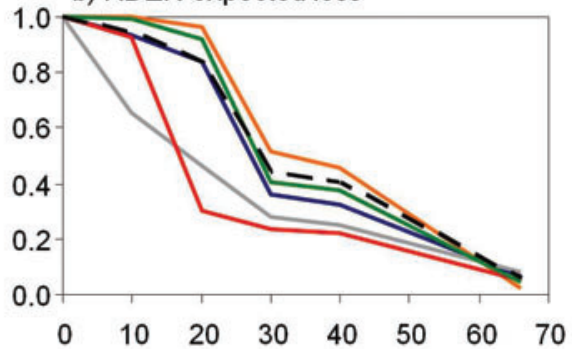

d) RDEN conditional expected loss

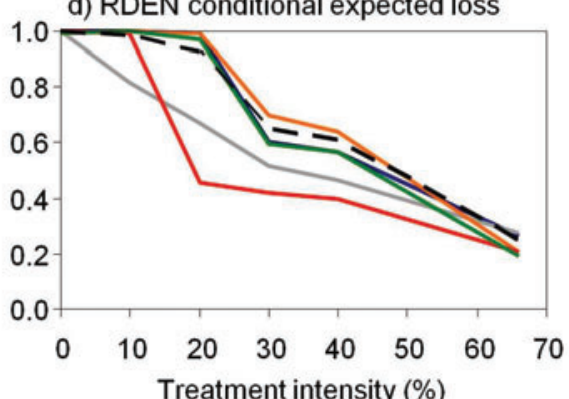

Figure 21-Graph from Ager and others (2010b) showing the expected and conditional loss of old growth as a function of six treatment intensities and two fuel treatment scenarios. The graphs suggest that treatments in the WUI (residential density, RDEN scenario) are relatively ineffective at reducing expected loss of large trees, compared to treatments in the adjacent wildlands (stand density, SDEN scenario) where stands were thinned to promote forest restoration objectives. DF $=$ Douglas-fir, $\mathrm{PP}=$ ponderosa pine, $\mathrm{WL}=$ western larch, ES = Engelmann spruce, $\mathrm{SF}=$ subalpine fir.

a) SDEN

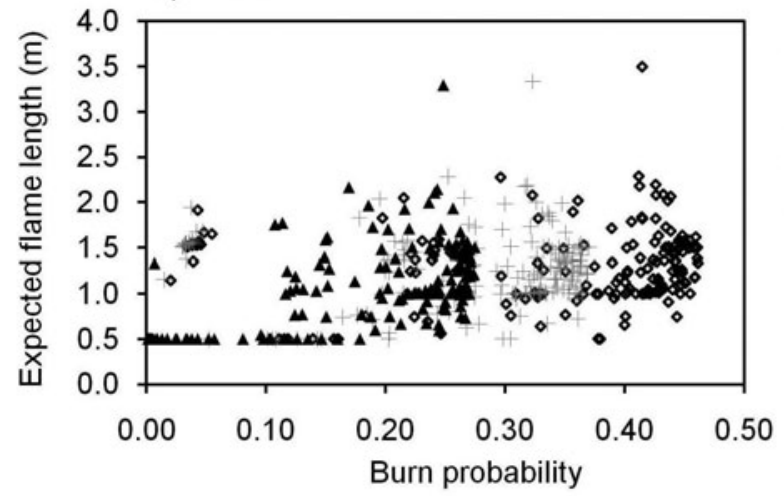

b) RDEN

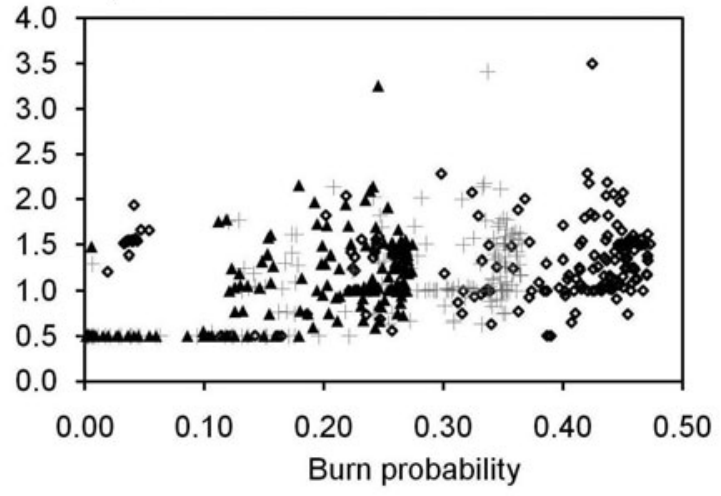

$\diamond$ No Treat + Treat $20 \% \quad \Delta$ Treat $66 \%$

Figure 22-Graph from Ager and others (2010b) showing burn probability and expected flame length values for individual structures in the Mt. Emily wildland urban interface area in northeastern Oregon. The stand density (SDEN) and residential density (RDEN) scenarios used different spatial treatment priorities emphasizing fire resiliency in the wildlands versus protection of structures in the WUI. Points represent average values for all pixels within a $45.7-\mathrm{m}$ (150-ft) radius around each structure. The figure suggests that burn probability and, to a lesser extent, flame length can be reduced around structures when fuel treatments are located outside the interface to address forest restoration and create fire-resilient forests. 


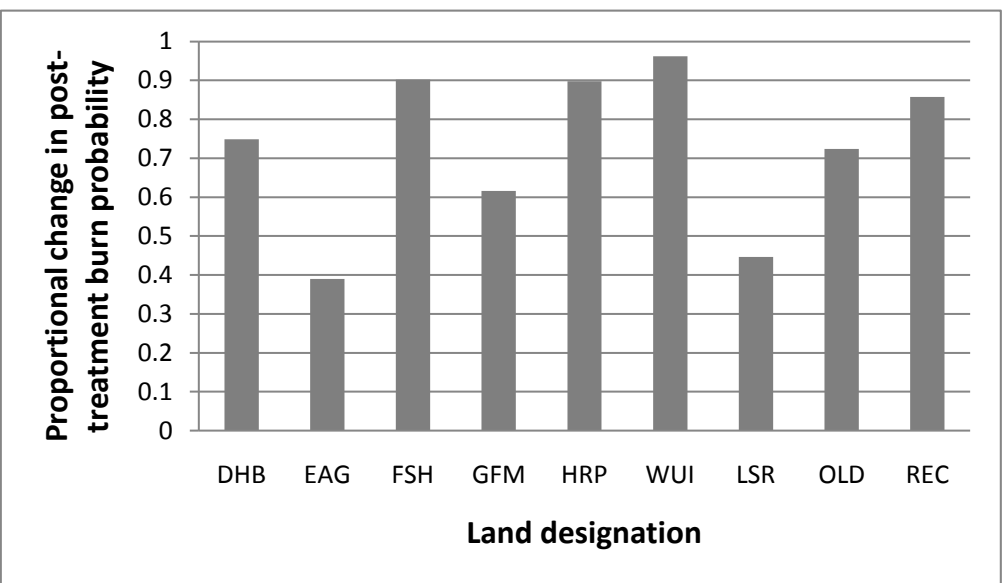

Figure 23-Proportional change in burn probability resulting from treatments by management land designation on the Deschutes National Forest. Treatments were applied to about 20 percent of the forested land area. The graph suggests that burn probability to the old growth management area (OLD) was about 30 percent of the pre-treatment level. Legend: $\mathrm{DHB}=$ deer habitat, $\mathrm{EAG}=$ bald eagle habitat, $\mathrm{FSH}=$ aquatic conservation areas, GFM = general forest matrix, $\mathrm{HRP}=$ potential owl nest sites, $\mathrm{WUI}=$ wildland urban interface, LSR = late-successional reserves, $\mathrm{OLD}=$ old growth forests, $\mathrm{REC}=$ recreation .

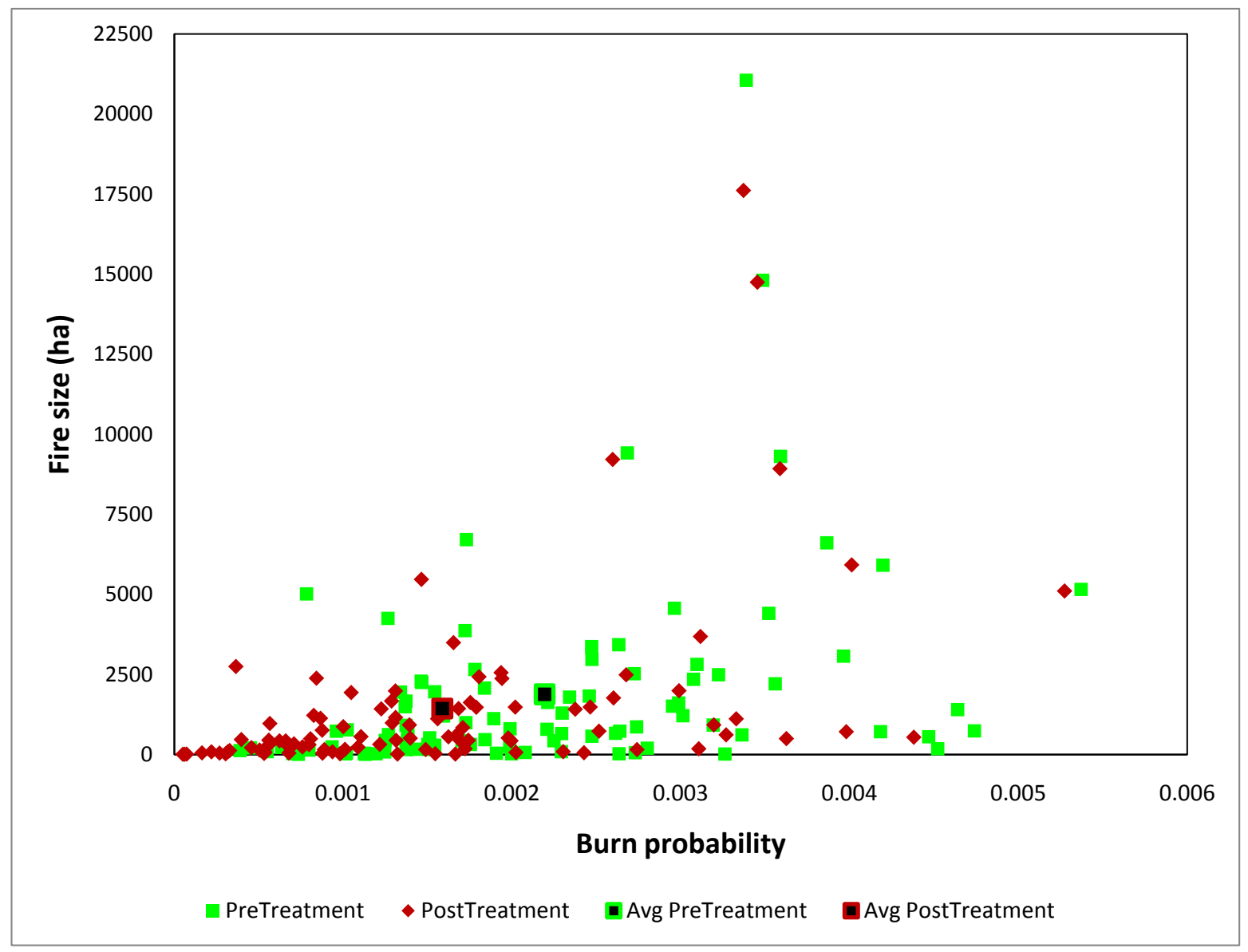

Figure 24-Change in burn probability and fire size to old growth management units on the Deschutes National Forest after simulating treatments on approximately 20 percent of the forested area. Treatments were not placed inside the old growth units. 


\section{National Fuels Treatment}

Despite the complexities described earlier in the chapter, it is informative to examine how broad-scale applications of fuels treatments might affect risk using basic models with simplified assumptions. Fuel treatment scenarios were modeled spatially but very generally for each FPU as part of the FPA process. The methods consisted of first soliciting treatment prescriptions by fuel and vegetation type from local fire planners in each FPU. These prescriptions contained details on changes to surface fuel models and canopy characteristics that constitute treatments applicable to current LANDFIRE fuel type descriptions (FPA 2009). Then, an automated procedure applied these prescriptions to specific stands throughout the FPU until a total of 15 percent of the FPU landscape was treated. The random placement of treatment units meant that the local percentage of treatment within the FPU would vary from this average figure. The treatment effect was realized by running the FSim model for a treated landscape using identical simulation settings as for the standard landscape. The contrast between risk metrics for each landscape illustrates the magnitude of possible changes resulting from this treatment level and random placement strategy.

The FPA fuel treatment scenario resulted in modified burn probability (figure 25) and conditional flame length (figure 26) across the country. Intersecting these posttreatment fire metrics with HVR layers and resource response functions (as was done previously in Chapter 4) enables estimation of changes in TCE and expected habitat loss. A range of response to fuel treatment is expected due to the arrangement of fuels relative to values-at-risk, the effectiveness of treatments in reducing fire spread and intensity in certain fuel types, and variation in how the individual FPUs defined the

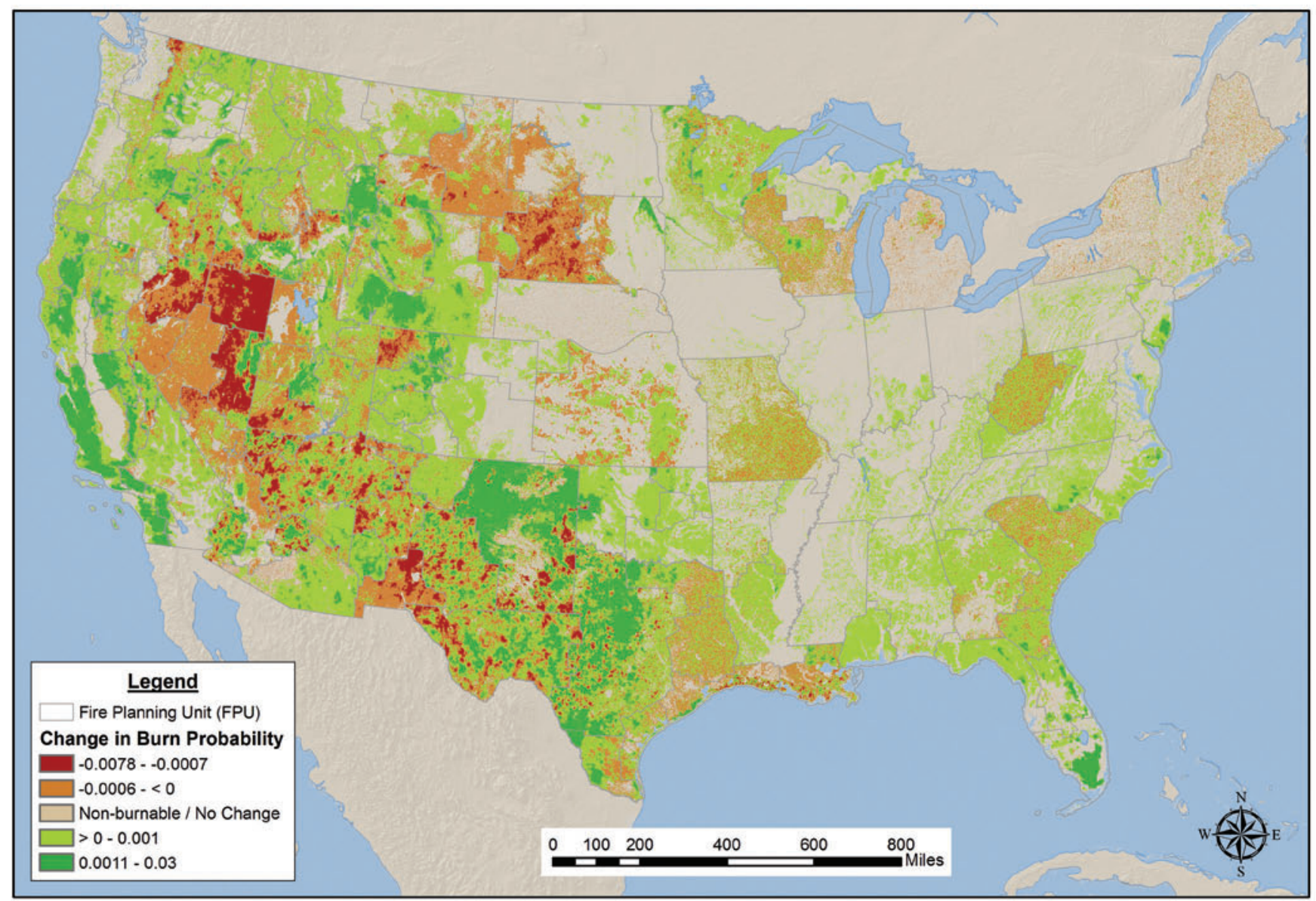

Figure 25-Changes in simulated burn probability resulting from fuels treatments on 15 percent of each FPU (standard run minus treatment run). Red and orange colors indicate increases in burn probability with treatment, whereas green colors indicate reductions of burn probability (positive difference). 


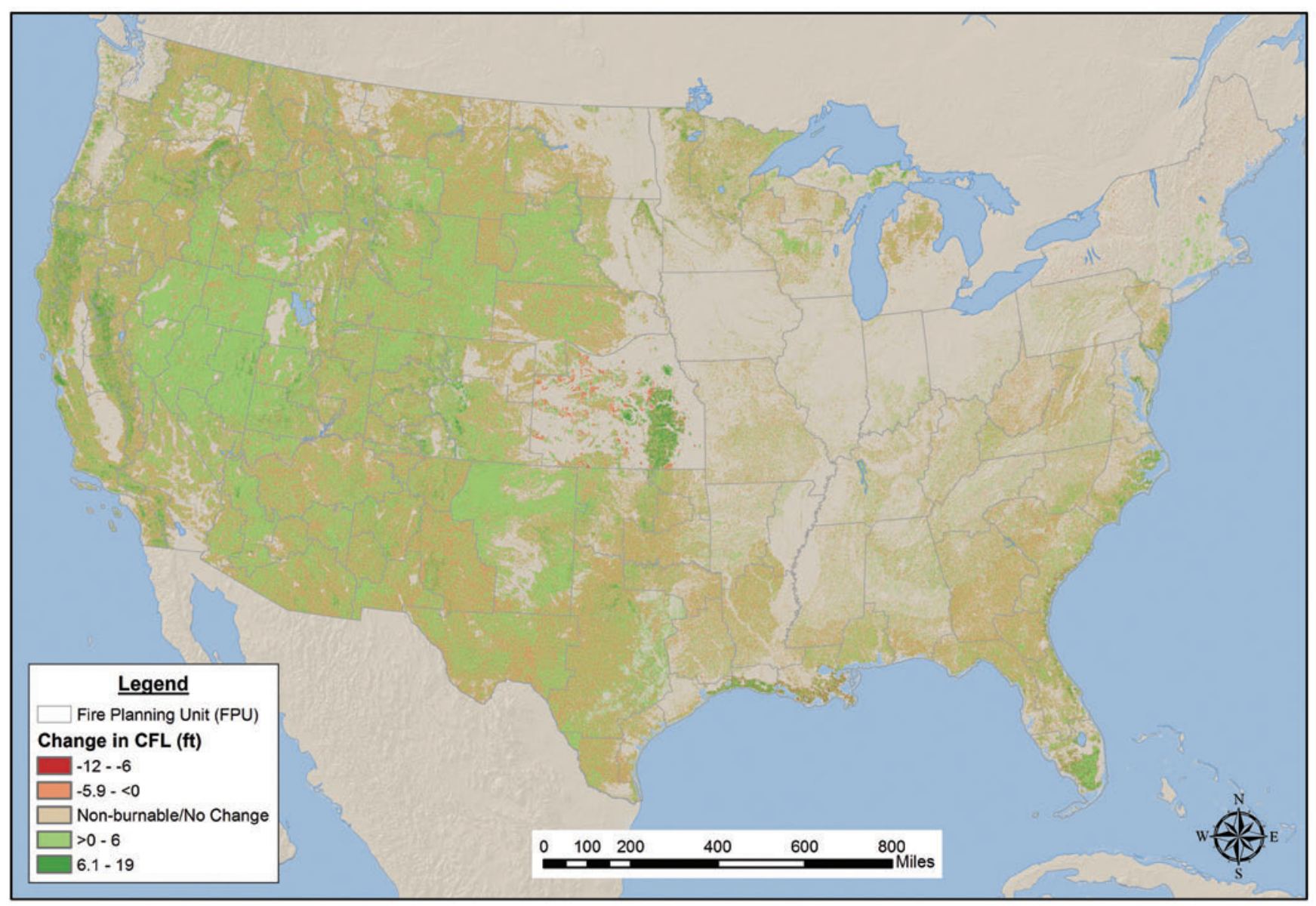

Figure 26-Changes in simulated conditional flame length after 15 percent of the landscape was treated. Results suggest most of the country experiences reductions in flame length (green). Red-shaded areas suggest increases in flame length following application of treatment prescriptions.

treatment prescriptions that were evaluated. Given that the spatial implementation of fuel treatment prescriptions was done for broad-scale FPA purposes and was not spatially strategic, results could be considerably improved if the analyses and simulations were done at the project level (as previously demonstrated).

The changes in burn probability and conditional flame length (resulting from these treatments) suggest that substantial reductions in both are possible in many of the western FPUs. A few exceptions to this occur in the Great Basin and Dakotas where flame length reductions are associated with increases in burn probability. Further analysis is necessary to discover how much of the variation in burn probability and intensity is related to vegetation response to treatment as compared to the range of treatment prescriptions that were individually defined at the FPU level.

Estimating changes in risk by looking at both burn probability and flame intensity is highly informative but computationally demanding. If we simplify further and assume that risk is proportional to area burned, we can examine the potential magnitude of changes in risk from fuels treatments using statistical approximation.

We fit a statistical model using FSim simulation results generated for all FPUs during the FPA analysis that was completed in 2010. This model uses a series of matched simulations to derive statistical relationships that use the fire spread inherent in a particular location, the weather conditions during a wildfire, and the extent of fuel treatment in the area surrounding the fire ignition point to estimate the expected size of each simulated wildfire. The statistical model fits the simulated data reasonably well in most FPUs $\left(\mathrm{r}^{2}>0.75\right)$, with exceptions in some eastern states with highly fragmented fuel patterns $\left(0.45<\mathrm{r}^{2}<0.75\right)$. The simple statistical model has a general 
tendency to underestimate observed FSim fire sizes due to the highly skewed distribution of the observed data, but on net, it gives total area burned estimates that agree well with FSim results.

Using the statistical model, we then estimated the expected fire size for each of the wildfires simulated with FSim. Fires with expected values greater than 20.2 ha (50 acres) were used in a subsequent analysis with fixed levels of fuels treatments between 5 and 50 percent in 5-percent increments. The net result was a dataset based on more than 55 million simulated fires across the conterminous United States. Both FSim and the statistical model tend to estimate average fire sizes that exceed historical averages; therefore, reported average fire sizes were adjusted to match historical averages by geographic area to provide reasonable comparisons.

The results demonstrate a curvilinear decline in adjusted mean fire size with increasing treatment levels for all GAs (figure 27). Declines are most noticeable in California and the Northwestern GAs (comprised of Oregon and Washington), and are least apparent in the Great Basin and Rocky Mountain geographic areas ${ }^{3}$. Multiplying the mean fire sizes by the historical mean number of fires greater than 20.2 ha (50 acres) provides an estimate of the extent of reductions in area burned that might be expected from varying levels of fuel treatment. The largest changes in area burned were observed in California, Southern, Northwestern, and Southwestern GAs (figure 28), which is consistent with our change in risk estimates previously presented. The Great Basin, which has the largest number of hectares burned, shows essentially no change due to fuel treatments. Closer examination of this geographic area shows that some FPUs actually show increases in area burned with fuel treatments, which counteracts those FPUs with more common responses. Although not

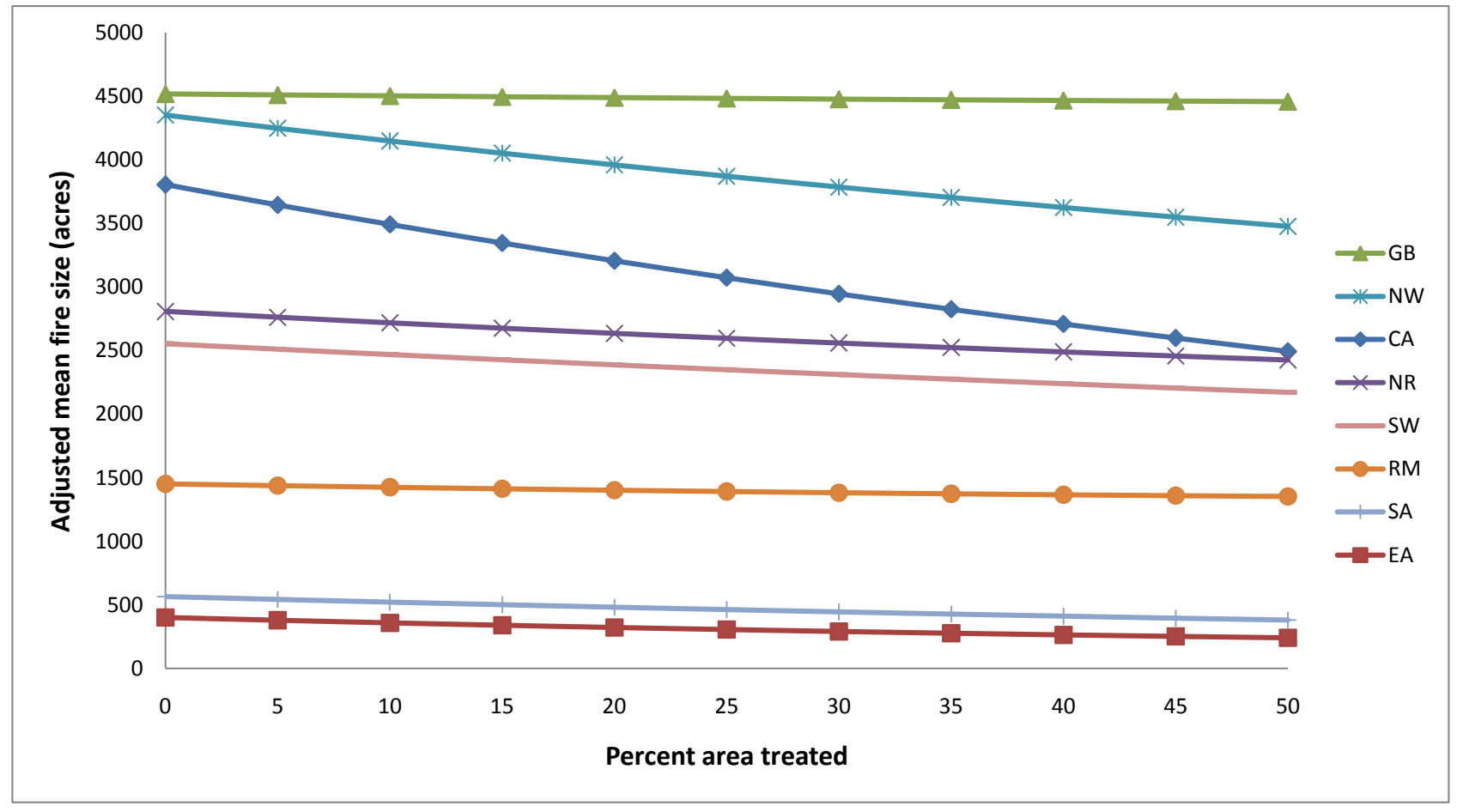

Figure 27-Changes in the adjusted mean fire size with increasing levels of fuel treatment, by geographic area. Legend: GB $=$ Great Basin, NW = Northwest, $\mathrm{CA}=$ California, NR $=$ Northern Rockies, $\mathrm{SW}=$ Southwest, $\mathrm{RM}=$ Rocky Mountain, $\mathrm{SA}$ $=$ Southern Area, $\mathrm{EA}=$ Eastern Area.

\footnotetext{
${ }^{3}$ All of the observed trends are statistically significant, but such significance is rather academic given the very large sample sizes involved in this analysis and the fact that estimates are derived mathematically without sampling error. Thus, we focus on practical significance rather than strict statistical interpretation.
} 


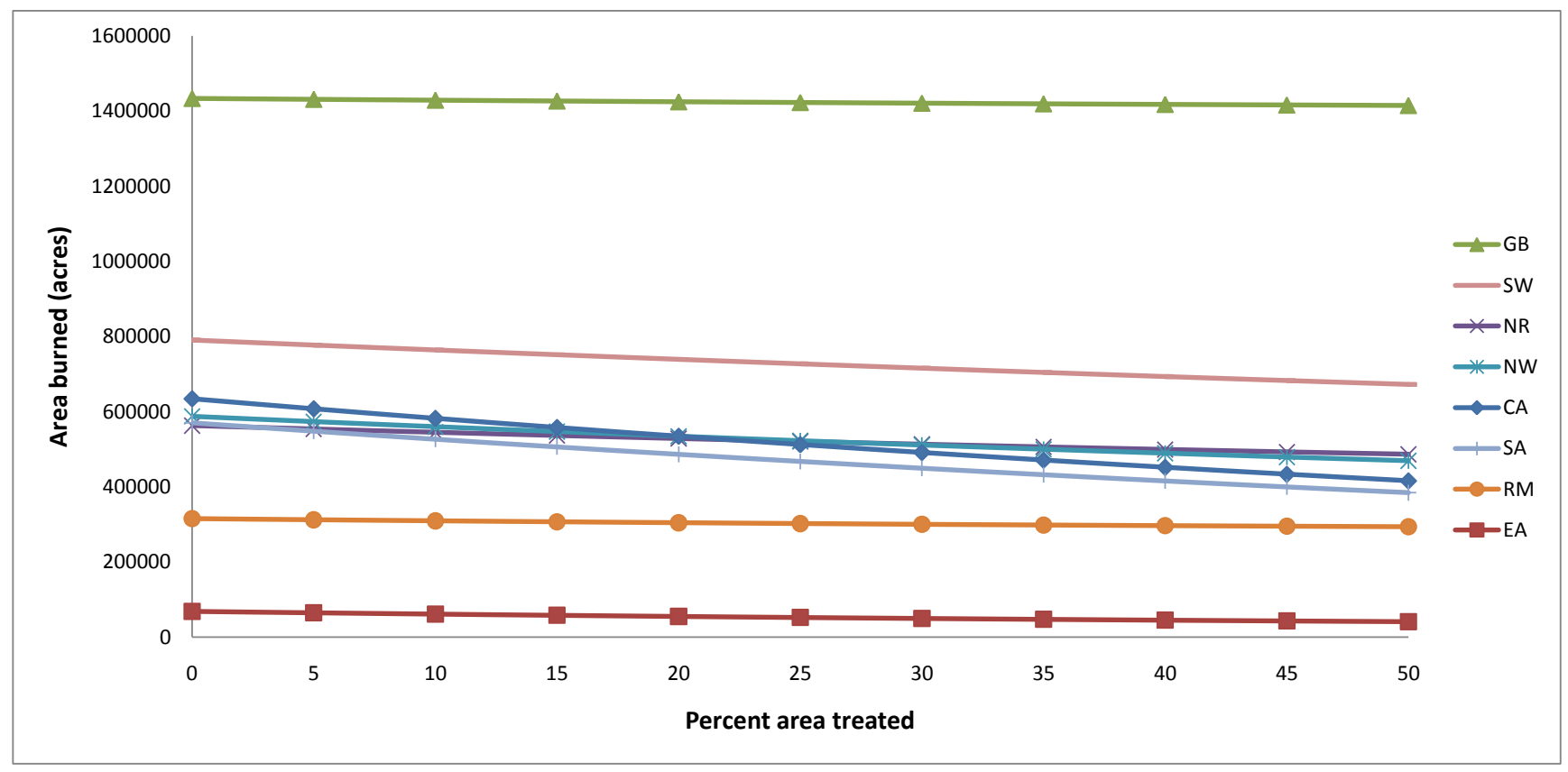

Figure 28-Expected changes in the annual area burned for varying levels of fuels treatments for each geographical area. Values are estimated by multiplying the mean fire size from figure 27 by the historical mean number of fires greater than 20.2 ha (50 acres). Legend: $\mathrm{GB}=$ Great Basin, SW $=$ Southwest, NR = Northern Rockies, NW = Northwest, CA = California, $\mathrm{SA}=$ Southern Area, $\mathrm{RM}=$ Rocky Mountain, $\mathrm{EA}=$ Eastern Area.

readily apparent in the graphs due to the small absolute change, the largest relative change (-40 percent) occurred in the Eastern GA. Overall, the results do not suggest wholesale fuels treatments across the United States without further analysis. For example, treating 50 percent of the landscape (a huge investment) results in only a 16 percent decline in area burned. (Please note that this analysis only looks at fires greater than 20.2 ha [ 50 acres] and does not include the effect of fuels treatments on initial response effectiveness.)

\section{Option 3. Invest to Build Capacity in Fire Response}

Analyzing investments in wildfire response can be very complicated. In addition to all of the issues mentioned previously regarding complexities of fire behavior, one must address interactions among the distribution of available resources, the performance of those resources on the fire, the dispatch logic used to send resources to a fire, and multiple operational constraints. FPA includes a highly detailed Initial Response Simulator that addresses many of these issues but is designed to only simulate responses in the first 18 hours following discovery of a wildfire. The levels of detail within the model and data requirements have created problems in its implementation that are just now being resolved. Thus, we do not have credible results from FPA to use at this point, but we expect to deliver useful results from FPA during the next phase of Cohesive Strategy development.

Once a wildfire has escaped initial containment efforts, further complications arise as resources are drawn from remote locations, fire behavior becomes difficult to predict, and even the objectives of the suppression response may change from day to day depending on circumstances that are not easily understood, much less modeled. The analytical system used in FPA does not directly simulate extended suppression or containment. Rather, it uses an empirically derived relationship between weather and suppression effectiveness (Finney and others 2009) and calculates suppression cost as the output of the model using relationships developed by Gebert and 
others (2007). Ongoing research directed at better understanding the management context and decision processes used in large fire suppression may lead to more reliable models that can capture the principal factors influencing performance-however it might be measured.

Lacking models for evaluating response capability, there is little we can offer in the sense of quantitative analysis. One observation that may be useful, however, is that the GAs of the Intermountain West (Great Basin, Northern Rockies, and Rocky Mountains) show relatively little response to increases in either prevention or fuel treatments relative to other areas. This suggests that these areas might benefit more by focusing on response capability rather than on fuel treatments and should use prevention funds only in targeted areas where human ignitions are problematic (for example, in heavily used recreation areas). The tradeoffs between suppression response and fuels treatments can be seen by examining the equivalency between number of fires and average fire size as affected by percent area treated. Figure 29 depicts the number of fires greater than 20.2 ha $(50$ acres) that would need to be averted in order to achieve the same level of reduction in area burned across the GA, which would be expected under given levels of fuel treatments. For the Great Basin, if 4.2 fires were averted, the reduction in area burned would match a 50 percent treatment strategy. In contrast, 330 fires would need to be averted in the Southern area to accomplish the same reduction, due to the smaller size of those fires.

We recognize that these simple calculations ignore many of the complexities that we've previously noted regarding the fact that number of fires and area burned are not readily substitutable due to the values exposed in each circumstance. More sophisticated analyses at local and regional levels should provide a richer interpretation and reveal important nuances. We also recognize that areas responsive to fuels treatments may also benefit from increased response capacity.

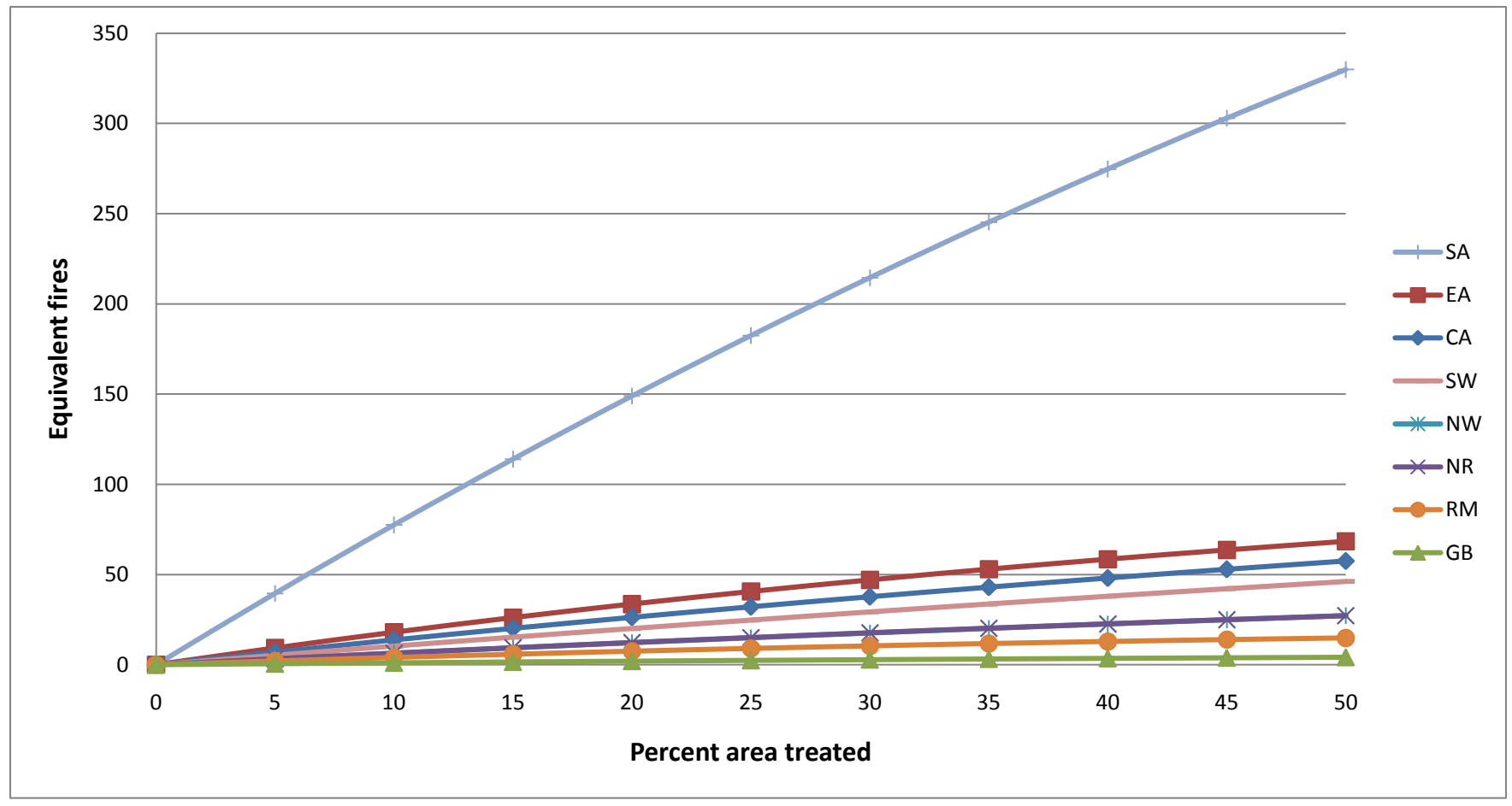

Figure 29-Equivalency between the number of fires averted and percent area treated for each geographic area. Each point on the line represents a level of fire reduction that could be obtained by either averting $y$ number of fires or treating $x$ percentage of the landscape. Legend: $\mathrm{SA}=$ Southern Area, $\mathrm{EA}=$ Eastern Area, CA = California, $\mathrm{SW}=$ Southwest, NW $=\mathrm{Northwest}, \mathrm{NR}=$ Northern Rockies, $\mathrm{RM}=$ Rocky Mountain, $\mathrm{GB}=$ Great Basin. 


\section{Option 4. Invest to Protect Values Exposed to Risk}

The motivation behind options designed to lessen values-at-risk is relatively simple. If one cannot change the likelihood of a wildfire occurring, one might instead focus on lessening the chances that a given fire will have negative consequences. Such thinking motivates many of the activities focused on homeowners in the WUI. Owners are taught to actively manage areas adjacent to their homes to reduce the chances of wildfires reaching the structure and are encouraged to prepare emergency supplies and evacuation plans that can be implemented at a moment's notice. Similarly, important cultural or archaeological sites may be managed in ways that offer passive resistance to wildfires. Species conservation plans can be designed to manage risks by ensuring that no single event has the capacity to eliminate large blocks of the population or critical habitat.

Analyzing such options seems easy at first glance, but it becomes increasingly difficult the better it is understood. In our analytical framework, reducing the exposure to risk is as simple as changing the response functions or benefit/loss values. This presumes, of course, that the appropriate values are addressed in the analysis to begin with, and that the initial response functions accurately capture changes in value. Neither presumption is likely to go unchallenged. A second problem concerns the sensitivity of the response function to management actions. In our prototype risk analyses, we have used stylized response functions that only crudely capture the effects of fire at varying intensities on values of concern. If the function is derived with little or no empirical basis to begin with, any change in that function could seem arbitrary without extensive quantitative analyses to support it. Furthermore, the signal to noise ratio in the response function may be very weak, and much of the change in the function due to proposed management actions may not rise to the level necessary to overcome the noise.

The net result of these considerations is that any action short of major shifts in policies or broad-scale changes in management is probably best left to local analyses that can be appropriately scaled to capture the relevant changes.

\section{General Observations on Analyzing Options}

We recognize that our discussion of options provides only a cursory look at the issues and complexities that are involved in decisionmaking at multiple levels - from Federal executives to the homeowner. Our point is not to examine these options comprehensively, but rather to illustrate the types of information that could help inform rational discussion of the Cohesive Strategy and to reinforce the notion that risk assessment provides a sufficiently flexible and powerful framework for addressing these complexities. Although we focused on each option independently, in reality, the Cohesive Strategy must include mixes of all of the options. Finding the right balance is a daunting task that must include all stakeholders - a task that should not simply be delegated to analysts. Additionally, there are a number of cross-cutting issues that we have not addressed that will undoubtedly require consideration in future phases of the Cohesive Strategy, including:

- Social equitability —who pays and who benefits from the different options?

- Constraints on management activities and funding to support them.

- How are impacts beyond the local community (for example, smoke and carbon sequestration) best factored into the risk equations? What is the appropriate balance between local and national interests?

- How can traditional knowledge and cultural traditions best be used to define and achieve desired outcomes?

- How do we best utilize opportunities for learning (in other words, adaptive management)? 


\section{Other Related Efforts}

\section{Relation to the Previous Cohesive Strategy and Policy-Moving Beyond FRCC}

The previous Cohesive Strategy (2002)_ “A Collaborative Approach for Reducing Wildland Fire Risks to Communities and the Environment: 10-Year Comprehensive Strategy Implementation Plan"_-defined a collaborative framework with goals, implementation outcomes, performance measures, and implementation tasks (USDA and USDI 2002). This strategy documented principles, a strategy for implementation, and accountability by evaluating performance, and it outlined three guiding principles: prioritization of communities and high-priority watersheds, collaboration among governments and stakeholders, and accountability through performance measures and monitoring (USDA and USDI 2002). Prioritization emphasizes that WUI treatments are first and that treatments outside the WUI should concentrate on sites where vegetation supports fires that threaten values. The prioritization process also identifies areas-at-risk by adopting a method to categorize WUI areas into those at high, medium, low, or insignificant risk from wildland fire. This is done at the state level using at least four criteria: (1) likelihood of fire occurrence, (2) assessment of fuel condition, (3) values being protected, and (4) fire protection capabilities. The strategy emphasizes prioritization of treatments to specific fire condition classes and fire regimes but states that data are not available to further refine potential treatment areas outside of the WUI.

Fire regime is a way of describing the characteristics of fire in given vegetation types. Typically, fire regime includes information about the frequency and severity of fire, but it can also contain information about the extent, intensity, and seasonality of fire (Agee 1994). The FRCC system was devised as a way of describing the possible departure from the historical or natural fire regime (Barrett and others 2010; Hann and Bunnell 2001; Hardy and others 2001; Holsinger and others 2006) and includes information about vegetation, fuels, and fire regime (frequency and severity). The FRCC contains three classes based on the departure from the natural fire regime, with the highest (category 3 ) being the most departed (Barrett and others 2010).

The construct of risk management has been put forward by interagency leadership (for example, WFLC and the Fire Executive Council) to address the repeated concerns identified by Federal oversight agencies. As a matter of policy, the Forest Service has embraced a risk-informed management paradigm (FEC 2009). Further, the U.S. Department of the Interior and USDA Forest Service identify risk management as a guiding principle for all fire management activities (USDA and USDI 2011). The revised wildland fire policy directs managers to employ a risk-based decision support process for wildfire management decisions and documentation (FEC 2009).

The new risk-based Cohesive Strategy is a transition from a stand-scale measurement of ecological condition with respect to fire (FRCC) to a landscape-scale measurement of risk that incorporates quantitative estimates of potential wildfire impacts on values of concern. Risk factors such as burn probability and expected flame length have direct analogies to fire regime and condition class. For instance:

- Fire regime is the combination of burn probability and conditional flame length. However, fire regimes are measures of ecological potential rather than the existing fire behavior.

- Risk science contributes additional information compared to the FRCC stratification, especially with respect to the design of fuel treatment strategies. Wildfire risk can be used to quantitatively measure the potential effects of fuel treatments, while change in condition class by fire regime is only a qualitative indicator.

- While the change in condition class from treatments can be summed for a landscape, the effect of the fuels treatments on the arrangement of fuels as it affects wildfire spread and intensity is not represented. Moreover, the effect of fuels 
treatments on fire behavior outside treatment units is not reflected in analyses of FRCC.

- FRCC is focused on ecological condition and does not span human and ecological values.

- FRCC does not address GAO and Office of Inspector General reports calling for risk-based measures.

To help understand how the classification of vegetation and wildfire risk in the previous Cohesive Strategy compares to the risk in the national assessment, we examined average FRCC departure index with wildfire risk as measured by TCE, burn probability, and conditional flame length at the FPU level. The LANDFIRE FRCC departure index (www.landfire.gov) measures the need for restoration/fuels treatments according to three departure index classes. These classes represent the amount (percentage) that current vegetation has departed from historical conditions (Barrett and others 2010; Holsinger and others 2006). To compare the mean FRCC departure percentages with mean risk values for each FPU, we derived the mean FRCC departure by assigning a class midpoint value to each pixel and calculating the mean of these midpoint values for each FPU (figure 30). As might be expected, there was little correspondence between TCE and the departure index since HVRs are not considered in the latter. However, larger departure indices were associated with higher flame lengths (figure 31) and, to a lesser extent, higher burn probability (figure 32), demonstrating some relationship between risk factors and the LANDFIRE departure index.

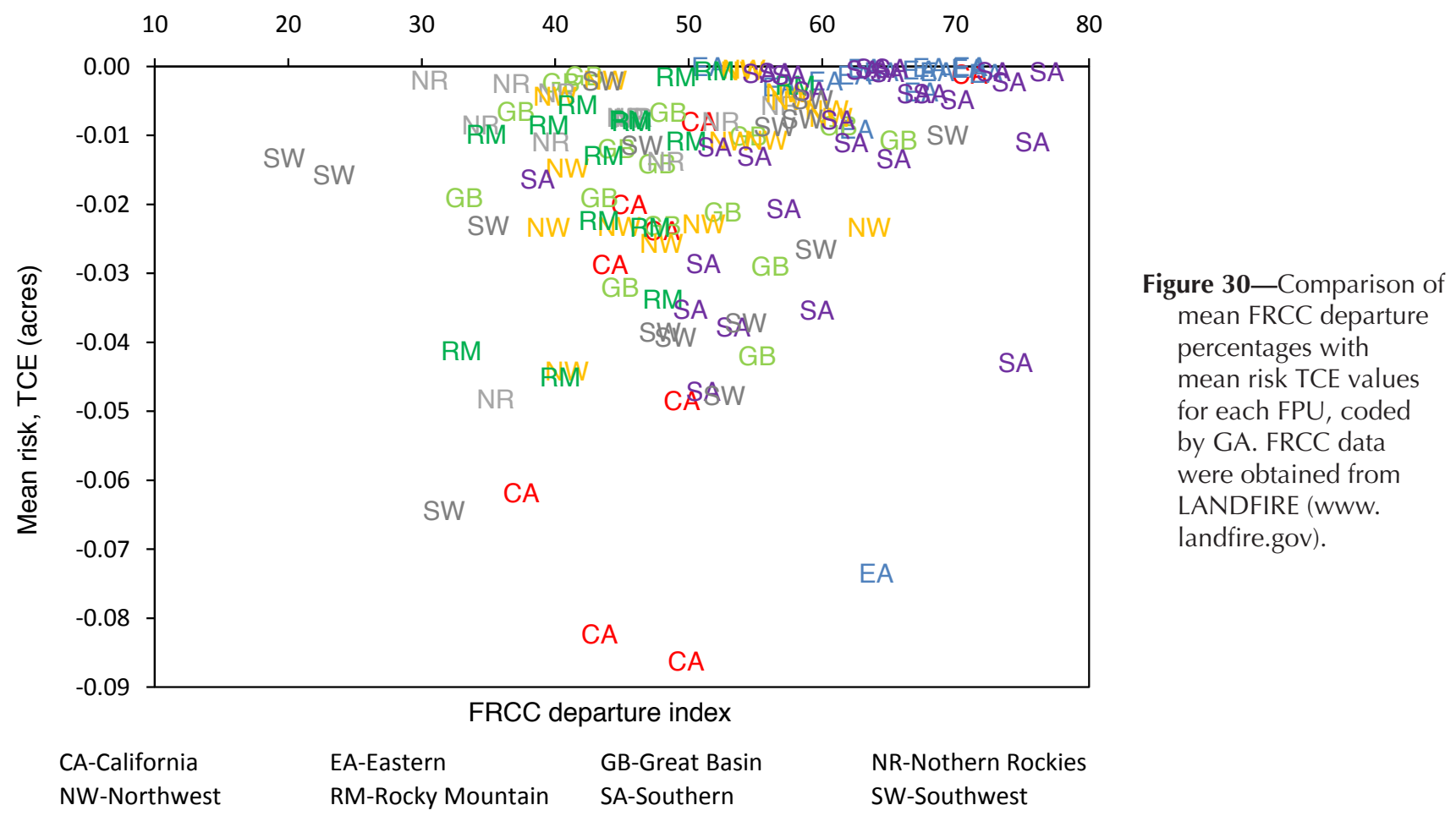




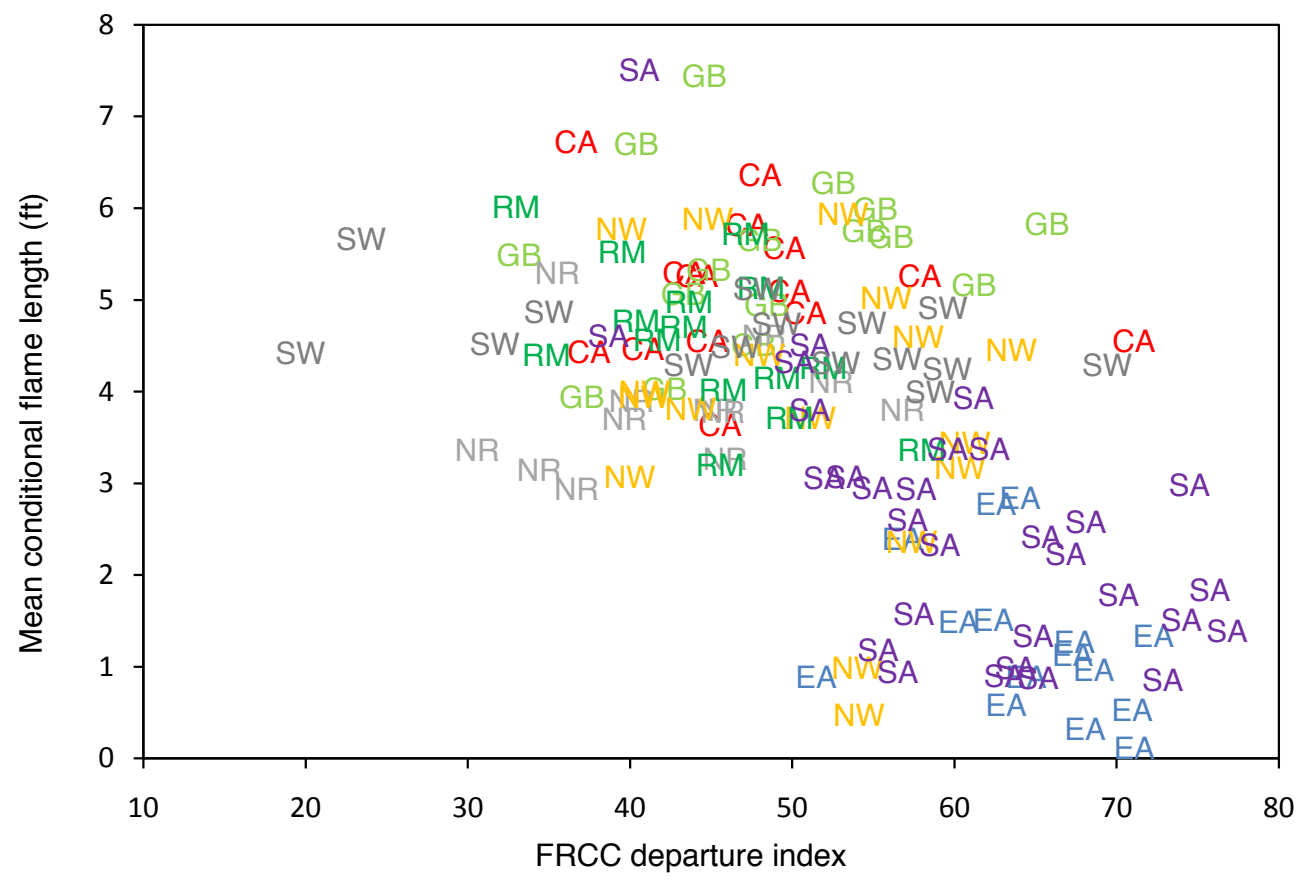

CA-California NW-Northwest

$\begin{array}{lll}\text { EA-Eastern } & \text { GB-Great Basin } & \text { NR-Nothern Rockies } \\ \text { RM-Rocky Mountain } & \text { SA-Southern } & \text { SW-Southwest }\end{array}$

Figure 31-Comparison of mean FRCC departure percentages with mean conditional flame length values for each FPU, coded by GA. FRCC data were obtained from LANDFIRE (www. landfire.gov).

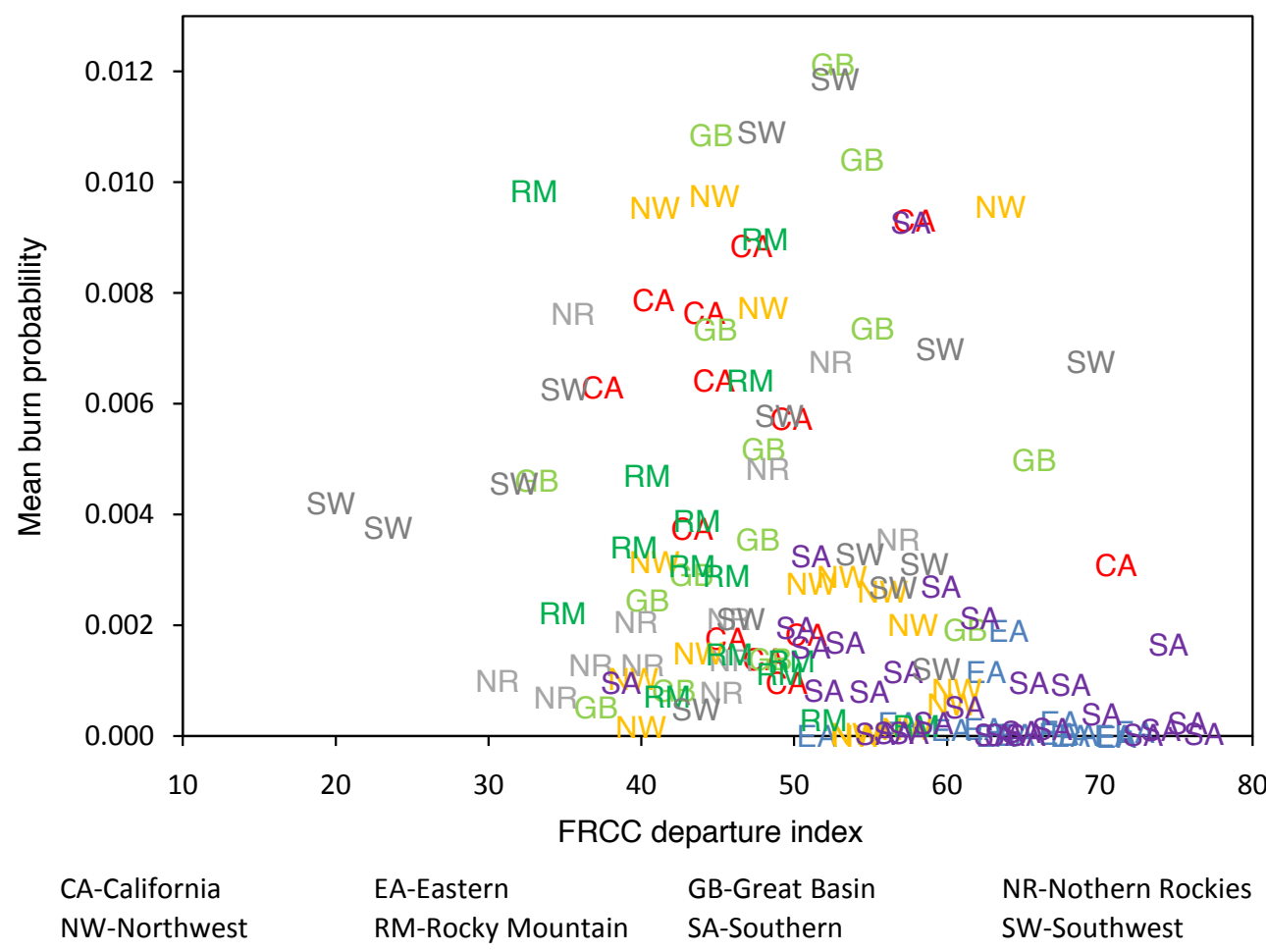

Figure 32-Comparison of mean FRCC departure percentages with mean burn probability values for each FPU, coded by GA. FRCC data were obtained from LANDFIRE (www. landfire.gov). 


\section{Wildfire Ignition and its Relation to Risk}

Most of the State and Regional Assessment products include ignition components. There have been a number of investigations into quantifying wildfire risk as a function of ignition probability using fire occurrence data (Martell and others 1989; Preisler and others 2004; Mercer and Prestemon 2005; Brillinger and others 2006; Syphard and others 2006, 2007, 2008; Preisler and Westerling 2007). Moreover, many of the existing wildfire risk assessment models contain components that measure the spatial probability of an ignition. Figure 33 shows annual ignition density for the United States for fires greater than or equal to 20.2 ha (50 acres). Figure 34 shows annual ignition density for fires greater than or equal to 121 ha (300 acres). The SWRA (http://www.southernwildfirerisk.com/) uses Fire Occurrence Areas data in the Wildland Fire Susceptibility Index (WFSI) model to portray ignition likelihood. It is important to note the difference between wildfire risk and occurrence. The respective analyses give vastly different depictions of wildfire risk. While relevant to emergency fire response and firefighting infrastructure, ignition locations or densities depict only localized impacts from nearby ignitions and not from fire spread or area burned. This is because where fire sizes are large, burn probability can be relatively high, even though ignition probability is low. As the distribution of fires tends toward large events, the relationship between ignition and burn probability becomes more diffuse - fires spread long distances and burn locations distal to the ignition. Figure 35 depicts the ratio of ignition density (number of ignitions per hectare per year) and burn probability from historical fire records. High values in eastern areas and the Northwest coast imply high numbers of ignitions but low area burned.

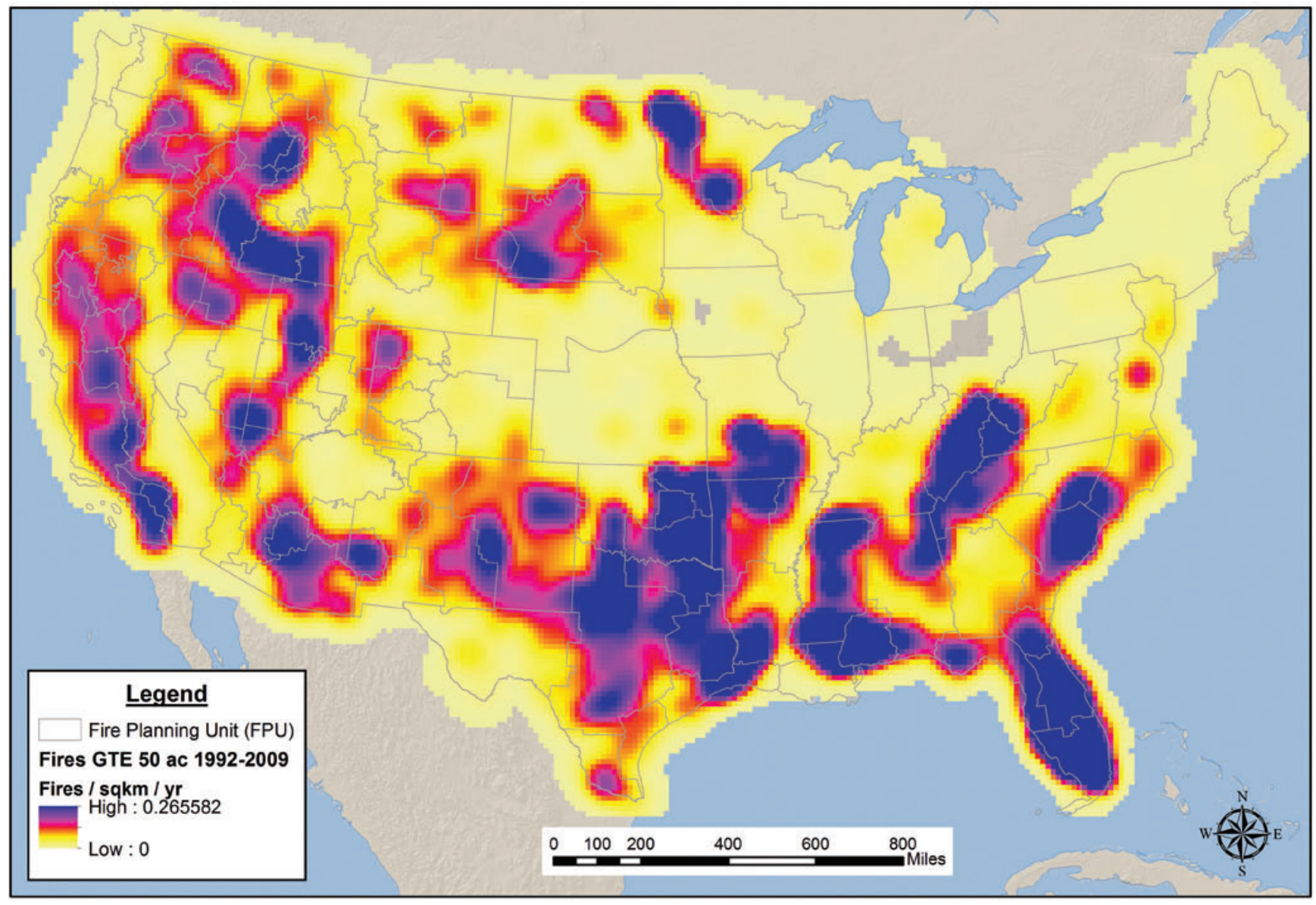

Figure 33-Annualized ignition density, measured in number of ignitions per square kilometer per year, for fires greater than or equal to 20.2 ha (50 acres). 


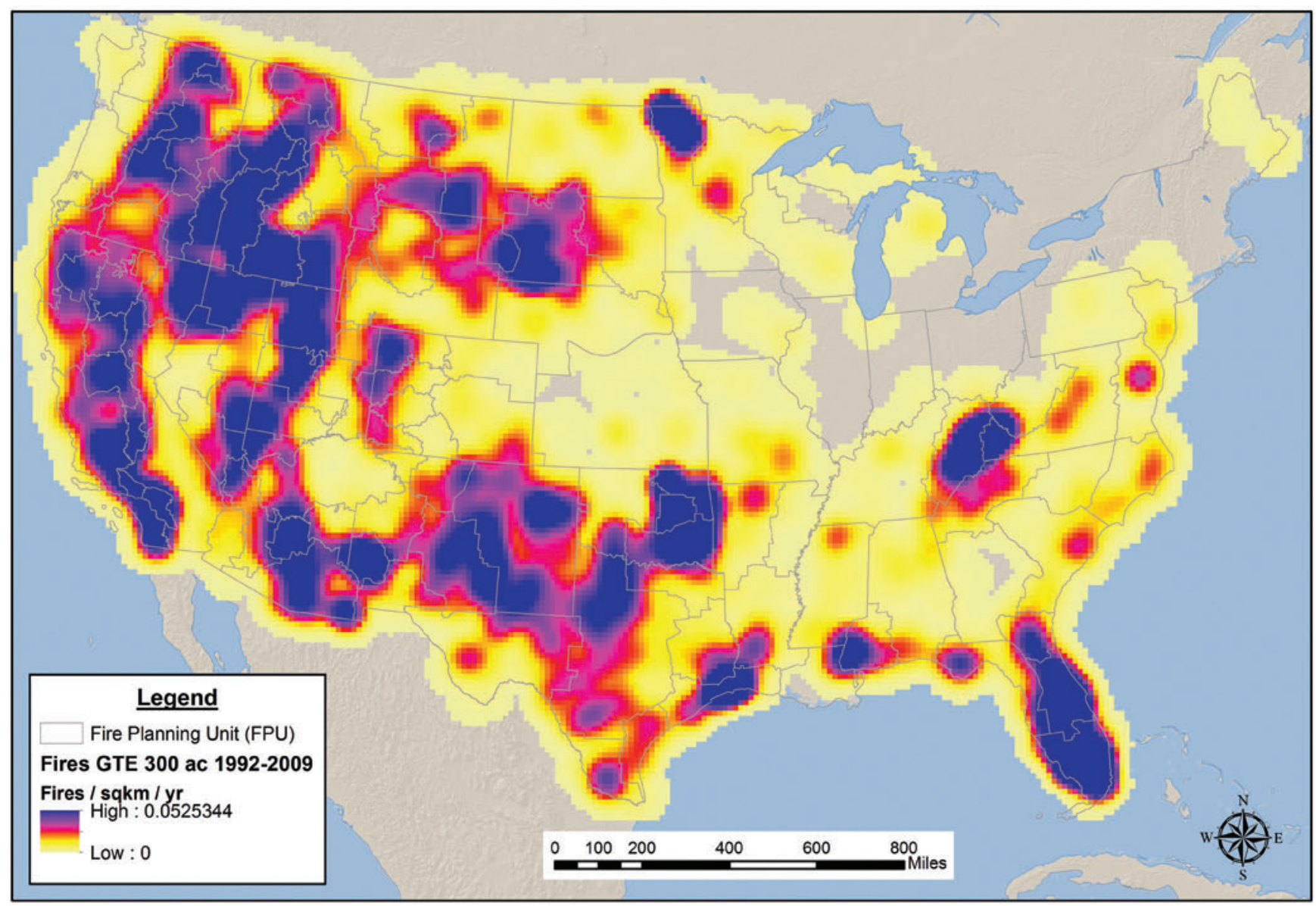

Figure 34-Annualized ignition density (number of ignitions per square kilometer per year) for fires greater than or equal to 121 ha (300 acres).

Correlations between fire ignition events and landscape features are often found to be significant, although the variables depend on whether ignitions are human versus lightning caused. Ignition indices are important components in WFSI (as in the Southern Wildfire Risk Assessment) and initial attack systems, such as the initial attack module in the FPA System. However, ignition indices are just one component in a broad risk-based framework that includes all aspects of fire management.

Our method for simulating burn probabilities and fire behavior relies on random uniform ignitions from within the area of an FPU. These ignitions represent "large" fires - (fires that are larger than a locally determined size), which are relatively rare because they occur only after initial attack fails and the fire grows in area substantially beyond the ignition point. Statistical relationships that determine the number of large fire ignitions are taken from historical occurrences of large fires in relation to an index of fire danger from the National Fire Danger Rating System. Thus, the probability and numbers of historical large fire occurrences can be predicted by the daily value of fire danger expressed by ERC. At present, the methods simulate ignitions at random spatial locations, partly because large fires are so rare and densities are so low across very large areas. Improvements may be possible where there are historically steep changes in large fire ignition density within the area bounded by a single FPU. In these cases, improvements in representing large fire occurrence and behavior would likely occur at finer scales within the FPU. 


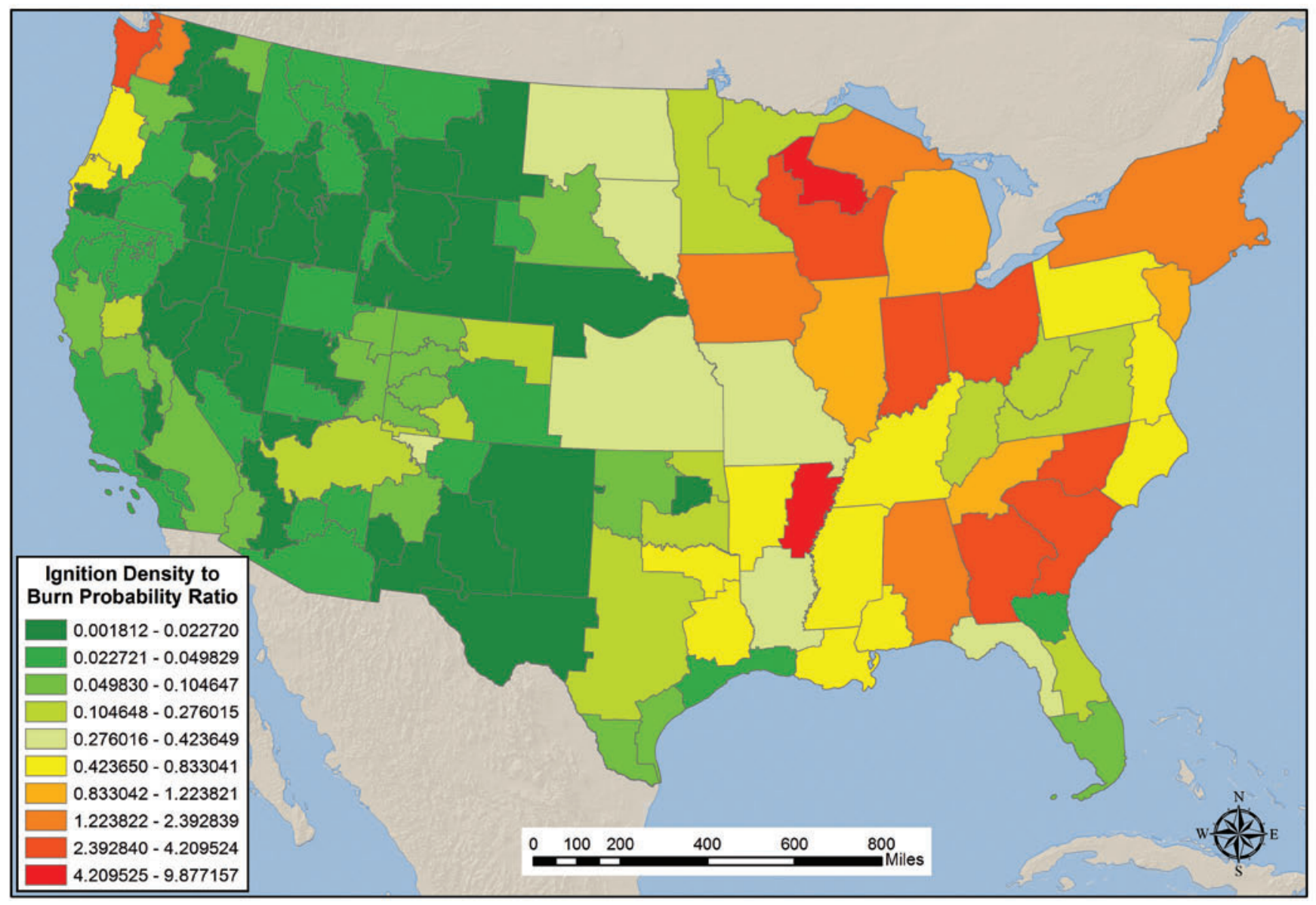

Figure 35-Ratio of ignition density (number of ignitions per hectare per year) to burn probability from historical data (1992 to 2009). High values shown in red and orange indicate many ignitions, but little area burned.

\section{Carbon and Emissions}

A high-profile component that was not addressed in the national risk assessment (Calkin and others 2010) was the effect of wildfire on carbon stocks. Understanding the implications of wildfire on carbon stocks is of growing interest to scientists and policy makers. Since the ability of fire management to influence carbon stocks is poorly understood, carbon emissions were not included in the first approximation of the national risk assessment. However, given the significance of the issue to policy makers, we used techniques developed for the First Approximation to explore the potential to use fire simulation output to estimate expected carbon emissions.

The effects of Federal fuel treatment programs on long-term carbon storage and emissions are not well known. Public forests contain a relatively large amount of stored carbon, and their management has a significant impact on the U.S. forest carbon balance. From a carbon perspective, fuel reduction projects can reduce the potential for emissions by removing surface and canopy biomass, leaving a forest landscape that burns with a lower intensity if a fire occurs (Finney and Cohen 2003; Hurteau and others 2008; Reinhardt and others 2008; Bonnicksen 2009; North and others 2009; Stephens and others 2009). When fuel treatments result in lower spread rates and intensity, carbon emissions are reduced during wildfire events as well as after, due to the reduction in decomposition of dead trees. However, fuel management activities remove substantial carbon from the forest, much of which is not fixed in wood products, and generate carbon emissions from use of gasoline during treatment activities as well as from prescribed fire and the decay of non-merchantable material. Clearly, when a wildfire encounters a fuel treatment, the potential carbon benefit is strongly dependent on the balance between carbon removed in the fuel treatment and 
the degree to which the wildfire behavior is moderated. Both positive (Finkral and Evans 2008; Hurteau and others 2008; Bonnicksen 2009; North and others 2009; Stephens and others 2009) and negative (Krankina and others 2008; Mitchell and others 2009) carbon outcomes have been reported in prior studies that examined stand-level fuel treatments and fire behavior. In most studies, the effect of fuel treatments on avoided wildfire emissions was insufficient to generate a net carbon benefit because most of the post-wildfire carbon remains on the site in dead trees.

However, key assumptions in all of these studies are: (1) carbon effects from fuel treatments are contained within the spatial extent of the treated stands, (2) wildfires are assumed to burn the treatments shortly after their implementation (in other words, burn probability $=1.0$ ), and (3) wildfire occurrence is independent of the spatial arrangement of fuels, topography, and other factors that are known to drive wildfire probability (Parisien and Moritz 2009). It is well documented, however, that fuel treatment effects on large fires can extend well beyond the boundary of treated areas through reduction in rate of spread and probability of crown fire (Finney and others 2007). In addition, empirical data suggest burn probabilities in the range of 0.001 to 0.10 in western U.S. National Forests (Finney 2005), meaning the likelihood of a fuel treatment burning soon after implementation is low. Moreover, simulation studies suggest 100 fold differences over short distances $(<5 \mathrm{~km}$ or $3 \mathrm{mi})$ in the likelihood of burning on typical forest landscapes in much of the interior western United States (Ager and others 2007b). Thus, a full accounting of carbon effects from forest management activities requires an approach that captures fire spread and intensity over large landscapes and the probabilities of wildfire. Such an approach is possible by employing burn probability modeling to quantify the expected carbon within a quantitative wildfire risk framework such as described in this report. The potential carbon change from fuel treatments can be quantified as the expected difference in the treated and non-treated scenarios. A further summation over time could be added to capture the temporal dynamics of emissions and sequestration. Using this approach, landscape effects of fuel treatments are considered in the calculation of carbon stocks and emissions, the probability of a treated stand burning is included in calculations, and the effects of fuel treatments extend beyond the stands in which they are implemented.

This process has been completed for a 65,000-ha (approx. 160,000-acre) project area on the Fremont-Winema National Forest (Ager and others 2010a) and for the 650,000-ha (1.6 million acre) Deschutes National Forest. We are now scaling up the approach to estimate expected carbon emissions at a national scale using FPA fire modeling outputs from the large-fire simulation system (FSim, Finney and others 2011), Fuel Loading Models (FLMs, Lutes and others 2009), and a national tree-list dataset (Drury and Herynk 2011). FSim outputs to be used include estimated burn probabilities for six different flame length categories ( 0 to $0.6,>0.6$ to $1.2,>1.2$ to $1.8,>1.8$ to $2.4,>2.4$ to 3.7 , and $>3.7 \mathrm{~m})^{4}$ on a 270 - by $270-\mathrm{m}$ (886- by $\left.886-\mathrm{ft}\right)$ grid spanning the continental United States. We estimate the amount of carbon in surface fuel under a no-fire scenario using FLMs, which provide median biomass weights in forested areas for duff, litter, and woody fuel in four size categories $(1 \mathrm{hr}, 10 \mathrm{hr}, 100 \mathrm{hr}$, and logs), and total above-ground biomass in shrublands and grasslands. Standing carbon and emissions will be calculated for each grid cell in forested areas using the FVS with inputs that include the national tree-list and the FLMs, and carbon lost to consumption will be calculated for each of the six flame lengths (Seli and others 2008). In shrublands and grasslands, carbon consumption will be estimated using a set of combustion factors. These figures for carbon under no-fire and six different intensity scenarios will be used to estimate expected carbon and emissions as follows:

$$
E\left(C_{S}\right)=\sum_{i} p\left(f_{i}\right) R F_{c}\left(f_{i}\right)
$$

[formula 3]

\footnotetext{
${ }^{4}$ Corresponding to 1 to $2 \mathrm{ft}$, $>2$ to $4 \mathrm{ft}$, $>4$ to $6 \mathrm{ft}$, $>6$ to $8 \mathrm{ft}$, $>8$ to $12 \mathrm{ft}$, and $>12 \mathrm{ft}$ flame lengths, as output by the FSim model.
} 
where

$E\left(C_{S}\right)=$ expected carbon

$p\left(f_{i}\right)=$ the probability of a fire of intensity level $i$

$R F_{c}\left(f_{i}\right)=$ the carbon "response function," equivalent to the amount of carbon predicted to remain after a fire of intensity level $i$

$i=$ intensity levels $0 \mathrm{~m}$ (no fire), $0.61 \mathrm{~m}(2 \mathrm{ft}), 1.22 \mathrm{~m}(4 \mathrm{ft}), 1.83 \mathrm{~m}(6 \mathrm{ft}), 2.44 \mathrm{~m}$ $(8 \mathrm{ft}), 3.05 \mathrm{~m}(10 \mathrm{ft})$, and $6.10 \mathrm{~m}(20 \mathrm{ft})$, representing the flame length categories

$$
E\left(C_{e}\right)=\sum_{i} p\left(f_{i}\right) R F_{\boldsymbol{e}}\left(f_{i}\right)
$$

where

$E\left(C_{e}\right)=$ expected emissions

$p\left(f_{i}\right)=$ the probability of a fire of intensity level $i$

$R F_{e}\left(f_{i}\right)=$ the carbon emissions "response function," equivalent to emissions from burning at intensity level $i$

Expected carbon and emissions will be calculated for each pixel and may also be summed for the local, regional, or national scale.

This framework allows for evaluation of expected carbon and expected emissions under different fuel treatment scenarios. Current landscape data (FLMs and tree-list) provide expected carbon and emissions under current conditions. Local fire managers have worked with FPA to create sets of proposed fuel treatments for each of 134 FPUs spanning the continental United States, and these treated landscapes were used as inputs to FSim to provide a set of burn probabilities for the landscape under a treatment scenario. Expected carbon and emissions will be calculated for this treatment scenario, with tree lists altered to reflect mechanical thinning and prescribed fire treatments. The results of the fuel treatment scenario will be compared with those from current conditions to determine where and how carbon storage differed due to fuel treatments. It is expected that the landscape in and adjacent to fuel treatments will show reduced burn probabilities due to reduced rate of spread in the treated areas, resulting in a carbon benefit in these areas.

This methodology can be used to evaluate a set of alternative treatment landscapes to determine which is most beneficial in terms of stored carbon and reduced emissions (Finney and others 2007). The approach is scalable to the project, Forest, or regional scale, as demonstrated by Ager and others (2010a).

\section{Relationship to Existing State and Regional Wildfire Risk Assessments}

The quantitative risk assessment process described within this document shares important similarities and differences with the state and regional assessments (for example, the SWRA, the Westwide Wildfire Risk Assessment [WWRA], and the individual State Forest Resource Assessments [SFRA]). One difference deals with modeling fire likelihood and intensity. The baseline national risk assessment described in this report relies on FSim, a mechanistic simulation model that calculates burn probabilities by simulating wildfire events over many "seasons" based on historical weather-fire frequency relationships. The model allows for more realistic assessment of effects of treatment and disturbance on fire likelihood (fuel changes affect fire within the neighborhood of the event) and thus, is particularly useful for project-level planning. Regional assessments, such as SWRA and WWRA, use instead a simplified model with an index of probability rather than a true probability and do not model landscape fire spread in order to simplify the procedures. The SWRA relies on expert system models that integrate a variety of factors into a broad risk index score. 
The fire behavior models implemented by the current work and the regional risk assessments are almost identical. Surface fire and crown fire models that produce spread rates and flame lengths for each cell of a landscape are the same. Differences arise in relation to fire growth - that is, the spatial processes of spreading fire and representing the area burned by fires that start in a given location. Our process relies on fire growth modeling to grow fires in two dimensions from an ignition location. Fires grow for a series of weather conditions (fuel, moisture, and wind) generated from observations at local weather stations and produce burned area and variability in flame length on cells that are burned. The regional risk assessments estimate burned area by converting modeled spread rate to fire size based on historical relationships. Thus, spread between cells of a landscape is not part of the regional risk assessment methods, and fire behavior variation (for example, flame length) comes from heading fire only (not backing or flanking). Fuel treatment analysis is more difficult if fire growth is not simulated because off-site impacts and effects of spatial patterns of fuel types are not captured.

State assessments (SFRAs) contain significant and important resource values that should be considered within risk assessment models. Unfortunately, our examination of their data revealed that the state assessments have not used consistent approaches to define HVRs. For example, Jim Wolf (WWRA Project Manager) and David Buckley (WWRA Technical Lead) reviewed the current state of the western SFRAs and concluded that, "Outputs for each state are not readily comparable" and, "While it was hoped that a single layer might be available that identified "priority forest landscapes' for each state, this is not the case. Numerous layers are used to derive these priority areas" (Wolf and Buckley 2010).

Given the relative ease of interacting fire likelihood and intensity with HVRs through the use of response functions, it would not be too difficult to quantify risk to the important values identified within the state assessment (the primary challenge is to identify what information is available to establish an appropriate response function). However, given the variety of values identified across states and the range of approaches to map these resources, integration of multiple states into a regional assessment is problematic. Therefore, a key lesson for implementation of the Cohesive Strategy is to ensure coordination across assessments at various scales to promote consistency and cohesiveness.

Additional sources to consider in wildland fire risk assessment are the Community Wildfire Protection Plans (CWPP), which provide critical information regarding community priorities and partnerships that can be brought to bear for project-level planning. However, the lack of consistency among approaches to define measured wildfire potential and resource priorities limits the relevance of CWPPs to regionaland national-scale planning efforts. This is in part because county officials have not yet had access to advanced wildfire projection models such as FSim. Also, it is not surprising that priority resource layers are inconsistent among communities since a primary focus is for the plans to fit the needs of the communities that develop them.

\section{Similarities and Differences with HFPAS Planning Efforts}

There are several key similarities between the FY11 HFPAS analytical framework and the Analytical Protocol proposed here for use within the Cohesive Strategy. Both approaches are spatially explicit, multi-criteria decision support models that consider fire behavior and values-at-risk; and both employ FSim generated products. The approaches can similarly describe model outputs in aggregate and by component-for instance, describing what proportion of the overall score/risk is attributed to issues related to smoke, WUI development, and high fire hazard. Further, both rely on a decisionmaking body to articulate preferences across potentially non-commensurate resources.

However, there are also important distinctions to recognize. The risk-based approach within the Cohesive Strategy retains pixel-specific burn probability and conditional flame length probability. In contrast, the FY11 HFPAS analysis 
algebraically combines flame length probabilities to derive a total wildfire potential (WP) score as follows:

$$
W P=\sum_{i} w_{i} p\left(f_{i}\right), w=\left\{\begin{array}{l}
1 \\
2 \\
4
\end{array}\right\}, i=\left\{\begin{array}{l}
1(0-1.22-m) \\
2(>1.22-2.44-m) \\
3(>2.44-m)
\end{array}\right\} \quad \text { [formula 5] }
$$

where

$p\left(f_{i}\right)=$ probability of a fire at intensity level $i$

$W_{i}=$ relative weight or importance factor for fire at intensity level $i$

Another key distinction is the lack of interaction (or a "crosswalk") between wildfire and resources within HFPAS - in other words, the lack of resource-specific response functions that vary with fire intensity. The HFPAS model scores wildfire potential independent of consequences to resources, and these independent scores are then aggregated into a composite index according to a logic model with userdefined weights. The risk-based framework, to the contrary, explicitly considers the response of each resource to fire at the scale of the individual pixel. This approach attempts to better capture the heterogeneous nature of resource response to fire, including potential benefits to fire-adapted ecosystems. This difference is potentially magnified when using the frameworks to evaluate alternative fuel treatments. In both models, the fuel treatment effect is captured with fire behavior simulations from FSim. The risk assessment approach also captures how the interaction of this altered fire behavior changes consequences to the resource.

\section{Comparison of Wildfire Risk Measures with National Insect and Disease Risk Map}

Multiple disturbances such as forest insects and wildfire can be considered competing risks in that both impart a probability of mortality to forests and related damages. Several elements in the Flame Act speak to the assessment of wildfire risk in relation to other wildland threats. Nationally consistent datasets on wildland threats are not available for many threats of interest. One exception is the Forest Service, 2006 National Insect and Disease Risk Map (NIDRM, Krist and others 2007). The NIDRM was driven by 188 models that attempted to predict how individual tree species would react to various mortality agents. The models, in turn, were the interactions of predicted agent behavior with known forest parameters, in this case, the predicted basal area loss from 2005 to 2020. It is important to note that in comparison to wildfire risk, as defined in this report, the NIDRM considers only tree mortality and not secondary effects on other HVRs of concern. We compared outputs from the wildfire risk simulations with the NIDRM at the FPU level by averaging the outputs from both models. The results revealed several key findings.

At the FPU scale, there was a weak but positive relationship between conditional flame length and basal area loss; and again, there was wide variability in the individual values by FPU. Plots of conditional flame length (figure 36) and burn probability (figure 37) versus basal area loss also revealed wide variability among FPUs and some clustering of FPUs by GA. From the graphs, it is possible to identify individual FPUs and, to a lesser extent, GAs where both wildfire and insect-disease risks are relatively high compared to the average. 

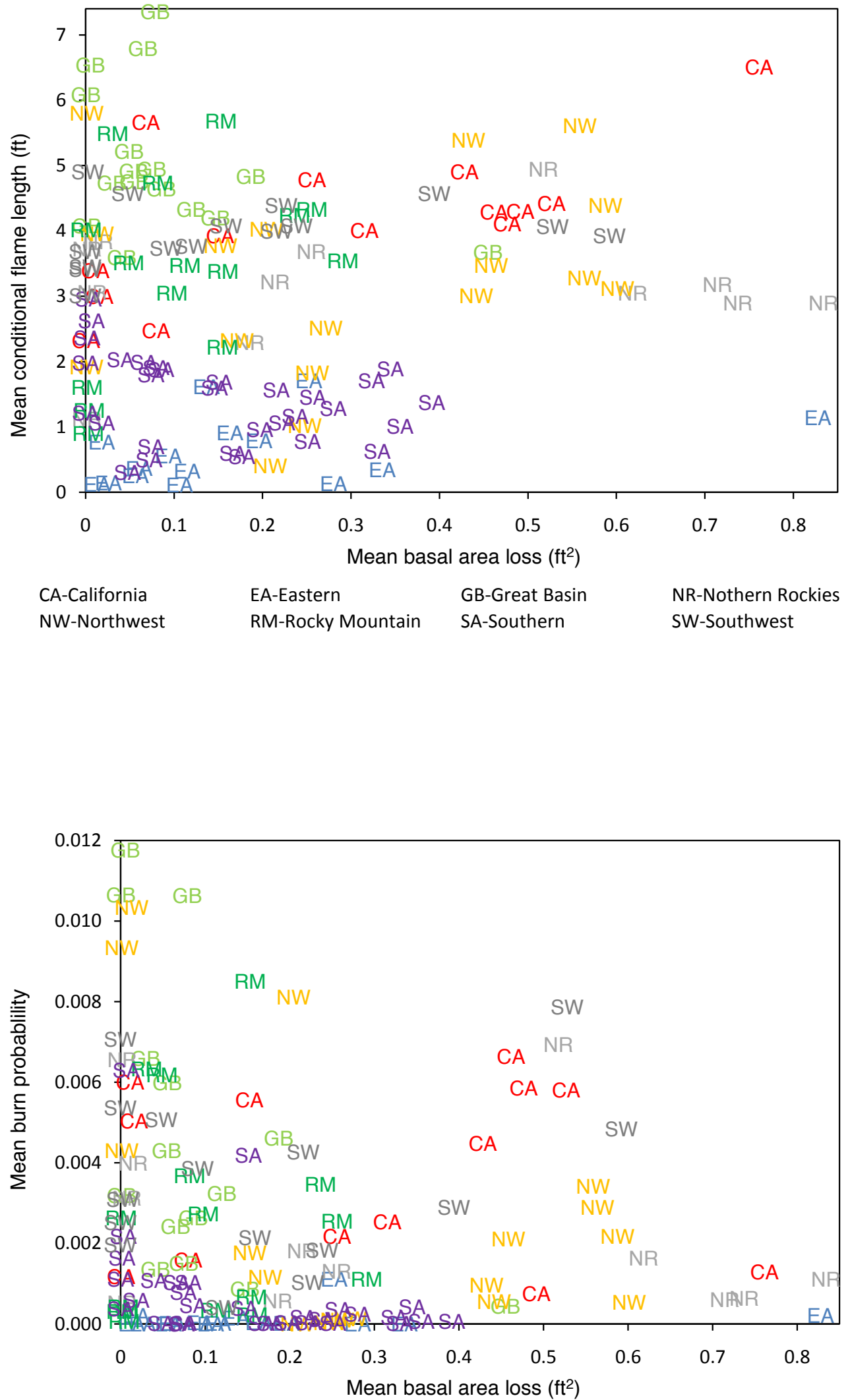

CA-California NW-Northwest
GB-Great Basin SA-Southern
NR-Nothern Rockies SW-Southwest
Figure 36-Scatter plot of conditional flame length versus predicted basal area loss from insects and disease by FPU. The latter data were obtained from the Forest Service National Insect and Disease Risk Map (Krist and others 2007).
Figure 37-Scatter plot of burn probability versus predicted basal area loss from insects and disease by FPU. The latter data were obtained from the Forest Service National Insect and Disease Risk Map (Krist and others 2007). 


\section{Science Limitations}

\section{Defining and Measuring Risk}

In this document, risk is viewed as a composite measure of the probability of a set of possible outcomes and the consequences associated with each outcome (Gadow 2000; Finney 2005). That is, risk is a two-dimensional measure that includes both the probability and magnitude of a potential loss or gain. For example, consider the two probability distributions shown in figure 38-A, which represent the uncertainty in area burned annually under two scenarios. Both distributions have a mean value of 2 million ha (5 million acres) burned, but the wider spread in the curve for Scenario 1 suggests greater uncertainty in what the actual value in a given year will be. Now suppose that the losses, both economic and ecological, are not a simple linear function of area burned but instead increase in a curvilinear fashion as shown in figure 38-B. Combining the probability functions for figure 38-A with the response function in figure 38 -B produces the resulting risk profiles shown in figure 38-C. These profiles suggest even greater separation between Scenario 1 and 2, whereby Scenario 1 has a higher expected loss in addition to greater uncertainty. Bringing the response function into the risk profile improves the understanding of the full consequences of wildfire while allowing for a rigorous decomposition of the problem into more readily accessible components. For example, the components of wildfire risk calculations can be analyzed separately (for example, ignition probability, burn probability, conditional flame length, and area burned above/below an intensity threshold) and then integrated into a single profile.

Limitations of this work, therefore, are that it does not capture the variability around the expectation and it does not capture the full risk profile. Although a full risk profile is preferred for many comparative risk assessments, reducing risk to a single index can aid risk comparisons across complex landscapes where the sheer numbers of probability distributions can be overwhelming.

Another limitation relates to how the effects of fire are modeled with resource response functions. In the current implementation, responses are modeled at the pixel level assuming independence across pixels in terms of resource response. Some resources, such as critical habitat, are sensitive to the spatial extent of individual events. For example, high-intensity wildfire on 5 percent of critical habitat at 10 different sites is likely to influence population dynamics in a very different way than high-intensity wildfire on 50 percent of critical habitat at one site. Similarly, the effect of wildfire on watersheds is dependent upon the spatial patterns of burn severity. Incorporating spatial information to guide a resource response function definition greatly increases the complexity of the modeling effort required. Nevertheless, it is technically possible with the current fire simulation models to generate fire intensity patterns that pertain to each fire. More complicated fire-level response functions would then have to be developed. For other resources, the question is not driven by modeling constraints so much as it is by knowledge constraints-for instance, the processes surrounding structure ignition are not well understood and are difficult to model (Cohen 2008). Existing knowledge bases (for example, Fire Effects Information System [FEIS 2011]) should help scientists develop response functions using the best available science combined with an iterative process of function refinement.

Although there are numerous areas in which advances in wildfire behavior modeling, fire effects modeling, non-market valuation techniques, and management science will improve the quality and relevance of wildfire risk assessment, we focus on pressing science needs that will facilitate realistic tradeoff analyses within the wildfire policy simulation effort. Two immediate research needs that limit our ability to simulate alternative wildfire management scenarios are: (1) modeling temporal dynamics and (2) understanding the effectiveness and efficiency of investments in suppression activities (in terms of changing risk to HVRs, including public and 
(A)

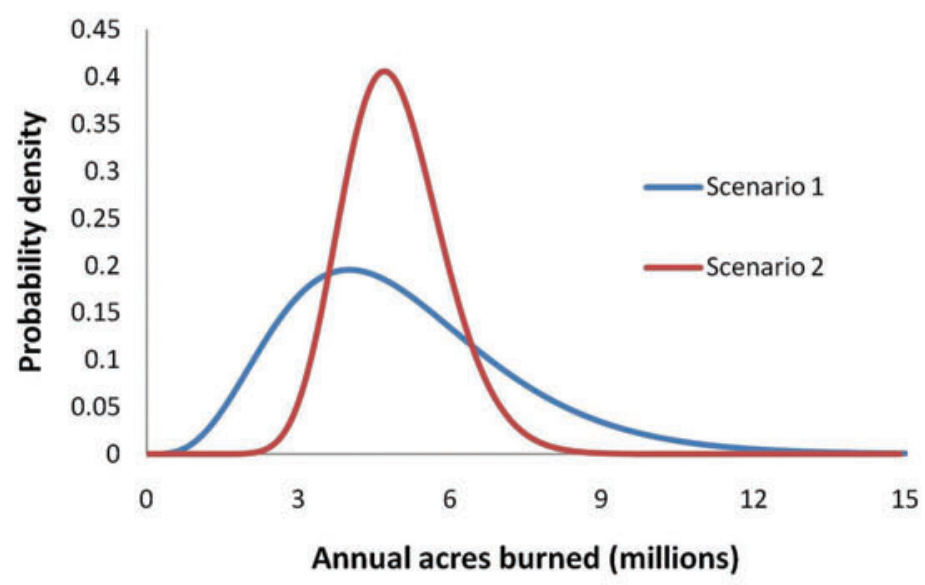

(B)

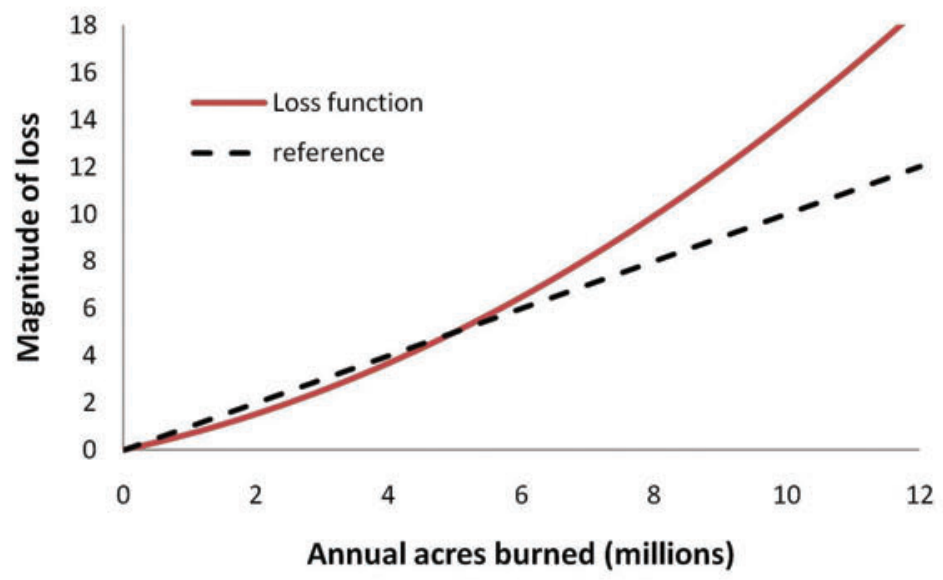

(C)

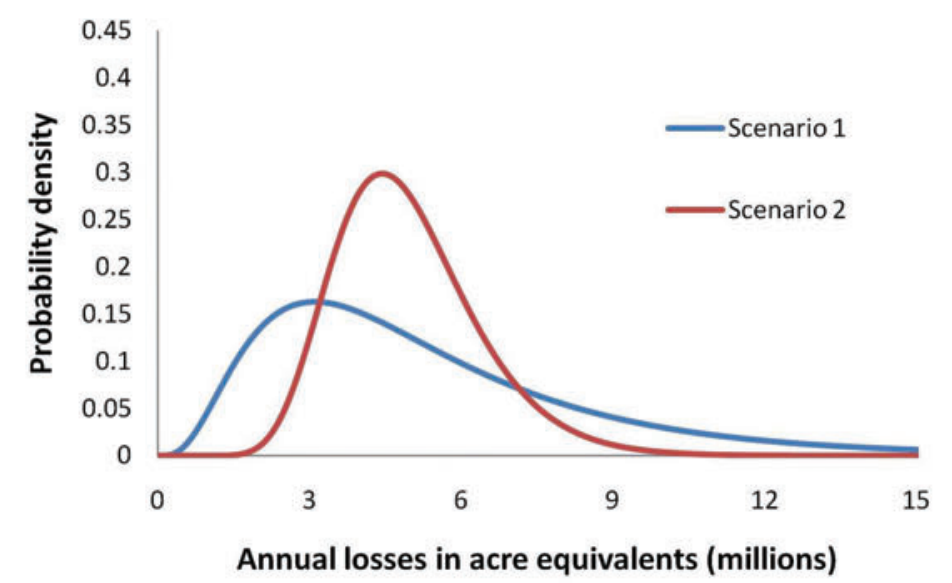

Figure 38-Quantifying risk begins with a probability distribution (A), which is mathematically combined with a loss function $(B)$ to produce the risk profile $(C)$ that indicates both the magnitude and probability of potential losses. 
firefighter safety) in both the short and long term. Additional considerations include the assignment of social weights to reflect societal values and preferences, the incorporation of socioeconomic variables that better characterize community vulnerability to fire, and issues related to the production and management of smoke.

\section{The Tipping Point Problem: Temporal Dynamics}

A major gap in the science to address the Flame Act and GAO concerns is the lack of an operational modeling framework to examine spatiotemporal effects of policy scenarios. Specifically, a national-scale planning model is needed that incorporates the spatial and temporal dynamics of management, succession, and disturbance. This modeling is required to determine the mix of wildfire and fuels management that will result in sustainable and stable or decreasing level of risk, and to determine whether constraints related to management objectives, land allocations, and policies create barriers that preclude moving landscapes toward this goal.

A large number of succession and dynamics models have been developed and published (Keane and others 2004). The Landsum model (Keane and others 2002) was used by LANDFIRE to develop the LANDFIRE FRCC departure index, and VDDT was used by Hann and Bunnel (2001) to model scenarios for the previous Cohesive Strategy. However, it could be argued that neither of these models carries the spatial detail required to accurately model the potential effects of fuel treatments on wildfire and risk to HVRs. A spatial implementation of VDDT (Tool for Exploratory Landscape Scenario Analyses [TELSA]) has been demonstrated to examine the landscape effects of increased fire frequency and size (Miller 2007), but TELSA is not a topological model of fire spread and rather relies on fire size distributions to simulate fires on the landscape. Moreover, the outputs from these models are difficult to downscale to address Forest and project-scale issues. The ideal model to continue progress on the Cohesive Strategy would be similar to that of Finney and others (2007). However, substantial re-engineering of the FVS would be required. With the development of national tree-list datasets (Drury and Herynk 2011) and programs like FSim (Finney and others 2011) it is possible to perform national-scale temporal analyses of different fuel treatment policies. A logical approach for prototyping a new generation of models would be to build detailed policy planning models for 1 million-ha landscapes (for example, National Forests or National Parks) that would carry sufficient detail for local planning while sufficiently broad scale to inform national policies regarding alternative fuel treatment policies. A further layer of complexity is added to dynamic modeling when the role of other disturbances beyond wildfire and a changing climate are brought into the picture.

\section{Accounting for a Changing Climate}

Projecting into the future requires the simultaneous consideration of human development (including land use and land cover change), vegetative succession, species migration, disturbance dynamics, climate change, and feedbacks therein. Key areas of investigation are: the impacts of climate change on wildfire (and other disturbance) regimes, the effectiveness of management opportunities to mitigate climate change, and the development of adaptation strategies to reduce future social and ecological losses to wildfire. Climate change is predicted to affect the frequency, intensity, duration and timing of fires, thereby magnifying threats to human and ecological values and possibly inducing climate feedbacks through increased wildfire-related emissions (Running 2006; Westerling and others 2006; Flannigan and others 2009). Mitigation strategies associated with wildfire management have largely focused on (1) reducing emissions via fuel reduction treatments and improving prevention and suppression efforts and (2) using removed biomass to replace fossil fuels for energy production (Canadell and Raupach 2008; Malmsheimer and others 2008; Wiedinmyer and Hurteau 2010). Identifying future management and adaptation strategies requires combining environmental projections with projections of management effectiveness, both of which are subject to significant uncertaintyespecially large fire management (Finney and others 2009). In summary, modeling 
limitations, knowledge gaps, and other uncertainties pose a significant challenge for addressing spatiotemporal dynamics of climate change within the comparative risk assessment framework described within this report. Future advancements in modeling efforts (for example, Crookston and others 2010) may help us better understand future climate effects on ecosystems.

\section{Quantifying Treatment Effectiveness}

The effect of management actions, both pre-fire and suppression, on fire occurrence and behavior remains a significant source of scientific uncertainty. Risk analysis appears the most advanced in regard to evaluating the effects of fuel treatments (see Chapter 4). Estimating changes in fire occurrence and behavior in response to investments in prevention or fire response capacity is more challenging. Suppression of large fires in particular is poorly understood (Finney and others 2009). Within FSim, suppression is not modeled directly; rather, the predicted number of consecutive burning periods is a driver of final fire size.

Existing containment algorithms useful for modeling initial attack (for example, Fried and Fried 1996) consider the role of all firefighting resources to be building fireline; this is often not the case for large fires. More refined models can consider alternative strategies and tactics such as structure protection, but increasing analytical scope and flexibility comes at a considerable cost in terms of data collection and management (Fried and others 2006). In the future, econometric studies can be employed in addition to simulation efforts to better understand firefighting resource productivity and effectiveness. For instance, research being conducted since the 2010 fire season within the National Fire Decision Support Center Fire Economics Group is using production theory to explore the effectiveness and efficiency of fire suppression efforts using field-based data. Analysts are capturing actual line production from individual resources during wildfire events and mapping fire activities relative to the active and final fire perimeters to determine how suppression resources influence final fire outcomes. Results from this research should inform measures to determine fire suppression effectiveness on large events.

\section{Resource Value Measures}

If resource value change could be measured in monetary terms for all of the important natural and developed resources impacted by fire, determining appropriate management strategies would be a relatively straightforward exercise in selecting the strategy that has the highest net present value. However, as Venn and Calkin (2009) noted, a number of significant challenges restrict the ability to use price-based decision support tools to understand the monetary value change of natural resources due to wildfire. The lack of resource value measures to guide prioritization challenges the ability to roll up regional analyses into a cohesive national strategy that best meets societal objectives. Preferences are heterogeneous across the nation, across decision makers, and even across time for individuals. The fields of non-market valuation and decision sciences will need to be employed to better understand societal preferences, managerial preferences, and the degree of convergence/divergence between the two. In the absence of definitive prices or value weights, much of the responsibility for determining appropriate tradeoffs lies with policy makers. While decision science can facilitate these often contentious processes, policy discussions and decisions will be required (see Chapter 8).

\section{Socioeconomic Vulnerability}

The intersection of human population and valued resources with expected wildfire probabilities creates opportunities to strategically allocate wildfire response or prevention actions to minimize risk to human life and property. In the field of hazards, risk, and resiliency, a clear distinction is made between risk assessments that describe the expected loss of assets and vulnerability assessments that characterize the exposure, sensitivity, and resilience of communities to a hazard (Turner and others 
2003). Both types of analyses apply to the goals and objectives of the Cohesive Strategy and are included in the USGS Science Strategy under the Hazards element (http://www.usgs.gov/hazards/).

In the risk assessment realm, additional research would address the expected impact of wildfires on economic activity and housing/infrastructure value. By looking at regional economic output in addition to the potential damage to structures, a more complete view of the economic costs of wildfires can be compared across regions and among communities. Such analyses could, for example, highlight areas where natural resource or recreational-dependent communities might be affected more severely by wildfire compared to communities with a diversified economic base.

Social vulnerability to natural hazards is a growing area of interdisciplinary research included in risk reduction strategies. Studies have analyzed how vulnerability varies among different segments of the population and how they will respond to a hazard (Wood 2009; Wood and Soulard 2009), how hazards affect business and regional economic output (Jones and others 2008), and how social vulnerability to hazards has changed over time across the United States (Cutter and Finch 2008). This research attempts to characterize hazards and vulnerability from a more holistic perspective, particularly in the wake of natural disasters such as Hurricane Katrina or the Gulf Oil Spill where economic damages do not fully represent the long-term changes made to the physical, ecological, social, and economic structure of the communities in the Gulf of Mexico.

\section{Smoke Management}

There are considerable smoke-related issues associated with fuel treatments as well as wildfire. Management options regarding the use of fire in a beneficial way are limited due to existing and potential regulations on smoke. Existing national assessments (Chapters 4 and 5) use designated non-attainment areas, which tend to be spatially identified as portions of or as entire counties; this mapping process could be refined to better identify where air quality issues are likely to affect communities. These and other areas, including exploring tradeoffs between smoke associated with prescribed fire and large fire and modeling the spatial spread of smoke, will be explored in subsequent phases of this project. We may look to the AirFire project (www.airfire.org) and related sources for data and modeling improvements relative to interactions of atmosphere and wildland fire.

An additional complexity with smoke management is the uncertainty associated with the impacts of wildfire smoke on human health. This uncertainty is related to our prior discussion regarding the lack of relevant resource value measures to inform fire management tradeoffs. Kochi and others (2010) found that much of the limited studies that attempted to quantify economic loss due to wildfire smoke relied on conventional dose response estimates from industrial sources that differed significantly from wildfire smoke events in duration, intensity, and chemical composition. The authors concluded that, "The health-related cost of wildfire-smoke exposure should undoubtedly be an important consideration for wildfire management policy," but knowledge about the nature of this cost is still limited (Kochi and others 2010). 


\section{Policy Issues for Tradeoff Analysis}

Advances in wildfire simulation interacting with spatial resource data have improved our ability to articulate how programmatic investments can influence management objectives and highlight tradeoffs among competing objectives. Although analytical tools (such as MCDA) can be used to facilitate preference articulation and prioritization, the identification of management priorities is a task for policy makers, not wildfire scientists. An extra layer of complexity is added to the picture when one considers heterogeneous regional priorities. Therefore, developing a robust set of performance measures and constraining budgets based upon rolled up regional assessments will require national decision makers to determine the relative importance of protecting non-commensurate resources in geographically disparate regions. The national performance measures would also need to share, in some sense, a common currency, which, in turn, places constraints on the scope and nature of regional analyses. There is a fine line to walk between encouraging analytical flexibility at regional and local scales and retaining the ability to informatively aggregate results at the national level.

A design question arises as to whether regions will be allowed to define their own priorities or whether national priorities will drive the roll up process. Allowing performance measures to be weighted by regional priorities would complicate tradeoff analysis - instead of risk to resources, decision makers would be balancing value-weighted risk to resources, which creates incommensurability. A possible compromise approach is to allow regions to define and provide their priorities (either quantitatively as weights or qualitatively in ordinal scale) to national decision makers for the purposes of informing national tradeoff analysis.

A further component to consider in the design of performance measures is the distinction between performance measures to guide investment strategies in the context of the analytical protocol and performance measures as congressionally mandated agency reporting quantities. In the case of the latter, performance measures will need to be updated and reported on an annual basis. There are logistical and technical hurdles to address before a suite of risk-based performance measures could be reported every year. Ideally, planning and reporting across scales would take into account the current state of vegetation in response to harvests, fuel treatments, fires, and other disturbances. Thus, spatial reporting (including fuel model changes) requirements would increase as a necessary input to fire simulation modeling in order to estimate fire behavior and risk measures for the coming year. This additional spatial reporting burden might not be feasible. Therefore, it would be fruitful to start considering alternatives to annual reporting measures. Perhaps a reporting outcome could be "area treated qualified by the relative risk." So, for instance, area could be characterized in terms of burn probability, conditional flame length, proximity to valued resources, etc. This would allow more periodic updating of fire simulations and risk models, while annual reporting and project implementation could be based on the most recent simulation outputs.

It may be possible to obtain specific risk measures that could be used as performance measures (for example, reduce the current likelihood of wildfire in populated areas by $x$ percent per period). The issues that surround frequency of performance measure generation are related to data availability, resources required to generate the measures, and the utility of such measures on an annual basis. As previously stated, obtaining geospatial data that identify changes in fuels structure on an annual basis at the national level might be too costly and resource consuming. The degree to which risk might change on an annual basis might be high in local areas but gradual change is more likely at regional and national scales. The congressionally identified update cycle for the Cohesive Strategy — at least once every five years - may be more realistic in terms of witnessing wildfire risk changes at the regional and national scale. 


\section{Discussion and Concluding Remarks}

Comparative risk assessment is a powerful tool that could facilitate open discussion of fire management priorities among Federal, State, and local management partners through the development of a Cohesive Strategy. Advances in fire modeling, geospatial data, and computing allow for a more thorough analysis of the tradeoffs among alternative courses of action and their impacts to resources that society most values. Open discussion using consistent, science-based analyses will promote dialogue regarding the overarching objectives of fire management organizations and will help to highlight similarities and differences in our preferences for alternative strategic outcomes among the range of fire management partners.

This document provided a broad overview of a suite of modeling tools and approaches that can inform future development of the Wildland Fire Cohesive Strategy. Similarities and differences with past and ongoing efforts (for example, FRCC, HFPAS, and state and regional assessments) were highlighted, and notable improvements associated with this product were discussed, including: an increased reliance on topological models of fire spread, an increased focus on both human and ecological values, and, in particular, a transition to a risk-based framework. A review of several wildfire risk analysis case studies, conducted at various planning scales, demonstrated the utility and applicability of the risk assessment framework promoted here.

However, strategy development will require a thorough understanding of modeling and data limitations as well as an open discussion of tradeoffs among competing policy interests of the participating parties. Given our limited understanding of the effects of fire on valued resources, the effects of management actions on changing fire outcomes, social values/preferences across resources at risk, and, in particular, spatiotemporal dynamics (human development, vegetative succession, disturbance regimes, climate change, etc.), care must be taken to align the most appropriate decision support tools with the nature of the uncertainty being addressed. In many cases, there may be sufficient confidence in computer models, whereas in other cases, a reliance on expert judgment or collaborative exercises may be warranted. In particular, the process of rolling up regional analyses with disparate priorities, management objectives, and values-at-risk will require careful attention.

Though this document does not provide step-by-step instructions for answering all questions, it does provide a rigorous, science-based platform from which to view and address questions of interest to the wildfire management community. A comparative risk assessment framework enables analysis of strategic alternatives across planning scales and facilitates exploration of tradeoffs across multiple objectives. With this analytical framework established, scientists and practitioners will be better able to address elements identified in the FLAME Act and will be better able to achieve the goals of the Wildland Fire Cohesive Strategy. 
Agee, J.; Bahro, B.; Finney, M.; Omi, P.; Sapsis, D.; Skinner, C.; van Wagtendonk, J.; Weatherspoon, C. 2000. The use of shaded fuelbreaks in landscape fire management. Forest Ecology and Management. 127(1-3): 55-66.

Agee, J.K. 1994. Fire and weather disturbances in terrestrial ecosystems of the eastern Cascades. Gen. Tech. Rep. PNW-GTR-320. Portland, OR: U.S. Department of Agriculture, Forest Service, Pacific Northwest Research Station. 52 p.

Agee, J.K. 2002. The fallacy of passive management managing for firesafe forest reserves. Conservation in Practice. 3(1): 18-26.

Ager, A.; Finney, M.; McMahan, A.; Cathcart, J. 2010a. Measuring the effect of fuel treatments on forest carbon using landscape risk analysis. Natural Hazards Earth System Sciences. 10: 2515-2526.

Ager, A.A.; Finney, M.A.; Kerns, B.K.; Maffei, H. 2007a. Modeling wildfire risk to northern spotted owl (Strix occidentalis caurina) habitat in Central Oregon, USA. Forest Ecology and Management. 246(1): 45-56.

Ager, A.A.; McMahan, A.J.; Barrett, J.J.; McHugh, C.W. 2007b. A simulation study of thinning and fuel treatments on a wildland-urban interface in eastern Oregon, USA. Landscape and Urban Planning. 80: 292-300.

Ager, A.A.; Vaillant, N.M.; Finney, M.A. 2010b. A comparison of landscape fuel treatment strategies to mitigate wildland fire risk in the urban interface and preserve old forest structure. Forest Ecology and Management. 259(8): 1556-1570.

Ager, A.A; Vaillant, N.; Finney, M.A. [Submitted April 2011]. Spatial patterns of wildfire risk factors and transmission among human and ecological values on a national forest in the Pacific Northwest, USA. Ecological Applications.

Andrews, P.L.; Loftsgaarden, D.O.; Bradshaw, L.S. 2003. Evaluation of fire danger rating indexes using logistic regression and percentile analysis. International Journal of Wildland Fire. 12: 213-226.

Bachman, A.; Allgöwer, B. 2000. The need for a consistent wildfire risk terminology. In: Neuenschwander, L.; Ryan, K.; Golberg, G., eds., Crossing the millennium: integrating spatial technologies and ecological principles for a new age in fire management. The University of Idaho and the International Association of Wildland Fire, Moscow, ID: 67-77.

Bachmann, A.; Allgöwer, B. 2001. A consistent wildland fire risk terminology is needed! Fire Management Today. Fall 2001, 61(4): 28-33.

Bar Massada, A.; Radeloff, V.; Stewart, S.; Hawbaker, T. 2009. Wildfire risk in the wildland-urban interface: a simulation study in northwestern Wisconsin. Forest Ecology and Management. 258(9): 1990-1999.

Barret, S.; Havlina, D.; Jones, J., eds. 2010. Interagency fire regime condition class guidebook. Version 3.0 [Homepage of the Interagency Fire Regime Condition Class website, USDA Forest Service, U.S. Department of the Interior, and The Nature Conservancy]. [Online]. Available: www.frcc.gov.

Bhaduri, B. 2010. Oak Ridge National Laboratory (ORNL) improvements to LandScan USA 2008. Personal communication with David Calkin, March 2010: Rocky Mountain Research Station, Missoula, MT.

Bonnicksen, T. 2009. Impacts of California wildfires on climate and forests: a study of seven years of wildfires (2001-2007). Forest Carbon and Emissions Model Report 3. Auburn, CA: The Forest Foundation. 22 p.

Brillinger, D.R.; Preisler, H.K.; Benoit, J.W. 2006. Probabilistic risk assessment for wildfires. Environmetrics. 17: 623-633.

Calkin, D.C.; Finney, M.A.; Ager, A.A.; Thompson, M.P.; Gebert, K.M. 2011. Progress towards and barriers to implementation of a risk framework for US Federal wildland fire policy and decision making. Forest Policy and Economics. doi: 10.1016/j.forpol.2011.02.007. $12 \mathrm{p}$.

Calkin, D.E.; Ager, A.A.; Gilbertson-Day, J., eds. 2010. Wildfire risk and hazard: procedures for the first approximation. Gen. Tech. Rep. RMRS-GTR-235. Fort Collins, CO: U.S. Department of Agriculture, Forest Service, Rocky Mountain Research Station. 62 p. Available: http://www.fs.fed.us/rm/pubs/rmrs_gtr235.pdf.

Canadell, J.G.; Raupach, M.R. 2008. Managing forests for climate change mitigation. Science. 320(5882): 1456. 
Chuvieco, E.; Aguado, I.; Yebra, M.; and others. 2010. Development of a framework for fire risk assessment using remote sensing and geographic information system technologies. Ecological Modelling. 221(1): 46-58.

Cohen, J.D. 2008. The wildland-urban interface fire problem: a consequence of the fire exclusion paradigm. Forest History Today. 20-26.

Collins, B.M.; Stephens, S.L.; Moghaddas, J.J.; Battles, J. 2010. Challenges and approaches in planning fuel treatments across fire-excluded forested landscapes. Journal of Forestry. 108(1): 24-31.

Crookston, N.L.; Rehfeldt, G.E.; Dixon, G.E.; Weiskittel, A.R. 2010. Addressing climate change in the forest vegetation simulator to assess impacts on landscape forest dynamics. Forest Ecology and Management. 260: 1198-1211.

Cutter, S.L.; Finch, S. 2008. Temporal and spatial changes in social vulnerability to natural hazards. Proceedings of the National Academy of Sciences. 105(7): 2301-2306.

Diaz-Balteiro, L.; Romero, C. 2008. Making forestry decisions with multiple criteria: a review and an assessment. Forest Ecology and Management. 255(8-9): 3222-3241.

Dicus, C.; Scott, M. 2006. Reduction of potential fire behavior in wildland-urban interface communities in southern California: a collaborative approach. In: Andrews, Patricia L.; Butler, Bret W., comps. 2006. Fuels management-how to measure success: conference proceedings. 28-30 March 2006; Portland, OR. Proc. RMRS-P-41. Fort Collins, CO: U.S Department of Agriculture, Forest Service, Rocky Mountain Research Station: 729-738.

Drury, S.A.; Herynk, J.M. 2011. The national tree-list layer. Gen. Tech. Rep. RMRS-GTR-254. Fort Collins, CO: U.S. Department of Agriculture, Forest Service, Rocky Mountain Research Station. 26 p. Available: http://www.fs.fed.us/rm/pubs/rmrs_gtr254.pdf.

Environmental Protection Agency (EPA). 1998. Guidelines for ecological risk assessment. EPA/630/R-95/002F. Washington, DC: U.S. Environmental Protection Agency. 78 p. Available: http://oaspub.epa.gov/eims/eimscomm.getfile?p_download_id=36512.

Fairbrother, A.; Turnley, J.G. 2005. Predicting risks of uncharacteristic wildfires: application of the risk assessment process. Forest Ecology and Management. 211: 28-35.

Finkral, A.; Evans, A. 2008. The effects of a thinning treatment on carbon stocks in a northern Arizona ponderosa pine forest. Forest Ecology and Management. 255(7): 2743-2750.

Finney, M.; Cohen, J. 2003. Expectation and evaluation of fuel management objectives in fire, fuel treatments, and ecological restoration. In: U.S. Department of Agriculture, Forest Service, Rocky Mountain Research Station. Proc. RMRS-P-29. Fort Collins, CO: U.S. Department of Agriculture, Forest Service, Rocky Mountain Research Station: 353-366.

Finney, M.A. 2001. Design of regular landscape fuel treatment patterns for modifying fire growth and behavior. Forest Science. 47(2): 219-228.

Finney, M.A. 2002. Fire growth using minimum travel time methods. Canadian Journal of Forest Research. 32(8): 1420-1424.

Finney, M.A. 2005. The challenge of quantitative risk assessment for wildland fire. Forest Ecology and Management. 211(1-2): 97-108.

Finney, M.A.; Grenfell, I.C.; McHugh, C.W. 2009. Modeling containment of large wildfires using generalized linear mixed model analysis. Forest Science. 55(3): 249-255.

Finney, M.A.; McHugh, C.W.; Grenfell, I.C.; Riley, K.L.; Short, K.C. 2011. A simulation of probabilistic wildfire risk components for the continental United States. Stochastic Environmental Research and Risk Assessment. doi: 10.1007/s00477-011-0462-Z. [Published online 27 March 2011]. 28 p.

Finney, M.A.; Seli, R.C.; McHugh, C.W.; Ager, A.A.; Bahro, B.; Agee, J.K. 2007. Simulation of long-term landscape-level fuel treatment effects on large wildfires. International Journal of Wildland Fire. 16(6): 712-727.

Fire Effects Information System (FEIS). 2011. Fire Effects Information System database. Last updated: 28 February 2011. U.S. Department of Agriculture, Forest Service, Rocky Mountain Research Station, Fire Sciences Laboratory (Producer). Accessed: 10 March 2011. Available: http://www.fs.fed.us/database/feis/.

Fire Executive Council (FEC). 2009. Guidance for implementation of Federal wildland fire management policy. Washington, DC: U.S. Department of Agriculture and U.S. Department of Interior. 20 p. Available: http://www.nifc.gov/policies/policies_documents/GIFWFMP. pdf.

Fire Program Analysis (FPA). 2009. Understanding how fuels treatments are used in FPA. FL026-WP. Boise, ID. 4 p. Available: http://www.fpa.nifc.gov/Library/Papers/Docs/FPA_2/ WP_Understanding_How_Fuel_Treatments_Used\%20in\%20FPA_01_30_09_final.pdf. 
Flannigan, M.D.; Krawchuk, M.A.; de Groot, W.J.; Wotton, B.M.; Gowman, L.M. 2009. Implications of changing climate for global wildland fire. International Journal of Wildland Fire. 18(5): 483-507.

Fried, J.S.; Fried, B.D. 1996. Simulating wildfire containment with realistic tactics. Forest Science. 42(3): 267-281.

Fried, J.S.; Gilles, J.K.; Spero, J. 2006. Analysing initial attack on wildland fires using stochastic simulation. International Journal of Wildland Fire. 15: 137-146.

Gadow, K. 2000. Evaluating risk in forest planning models. Silva Fennica. 34(2): 181-191.

Gebert, K.; Calkin, D.; Yoder, J. 2007. Estimating suppression expenditures for individual large wildland fires. Western Journal of Applied Forestry. 22(3): 188-196.

Graham, R.; McCaffrey, S.; Jain, T. 2004. Science basis for changing forest structure to modify wildfire behavior and severity. Gen. Tech. Rep. RMRS-GTR-120. Fort Collins, CO: U.S. Department of Agriculture, Forest Service, Rocky Mountain Research Station. 43 p.

Graham, R.T.; Jain, T.B.; Matthews, S. 2010. Fuel management in forests of the Inland West. In: Elliot, William J.; Miller, Ina Sue; Audin, Lisa, eds. Cumulative watershed effects of fuel management in the western United States. Gen. Tech. Rep. RMRS-GTR-231. Fort Collins, CO: U.S. Department of Agriculture, Forest Service, Rocky Mountain Research Station: 19-68. Available: http://www.fs.fed.us/rm/pubs/rmrs_gtr231.pdf.

Hann, W.J.; Bunnell, D.L. 2001. Fire and land management planning and implementation across multiple scales. International Journal of Wildland Fire. 10(4): 389-403.

Hardy, C.; Schmidt, K.; Menakis, J.; Sampson, R. 2001. Spatial data for national fire planning and fuel management. International Journal of Wildland Fire. 10(4): 353-372.

Hardy, C.H. 2005. Wildland fire hazard and risk: problems, definition, and context. Forest Ecology and Management. 211: 73-82.

Haynes, R.; Cleaves, D. 1999. Uncertainty, risk, and ecosystem management. In: Johnson, N.C.; Malk, A.J.; Szaro, R.C.; Sexton, W.T., eds. Ecological stewardship: a common reference for ecosystem management. Elsevier Science: 413-429.

Holsinger, L.; Keane, R.E.; Steele, B.; Reeves, M.C.; Pratt, S. 2006. Chapter 11-Using historical simulations of vegetation to assess departure of current vegetation conditions across large landscapes. In: Rollins, Matthew G.; Frame, Christine K., tech. eds. 2006. The LANDFIRE prototype project: nationally consistent and locally relevant geospatial data for wildland fire management. Gen. Tech. Rep. RMRS-GTR-175. Fort Collins, CO: U.S. Department of Agriculture, Forest Service, Rocky Mountain Research Station: 315-366. Available: http://www.treesearch.fs.fed.us/pubs/24703.

Hubbard, D.W. 2009. The failure of risk management: why it's broken and how to fix it. Hoboken, NJ: John Wiley and Sons. 304 p.

Hurteau, M.D.; Koch, G.W.; Hungate, B.A. 2008. Carbon protection and fire risk reduction: toward a full accounting of forest carbon offsets. Frontiers in Ecology and the Environment. 6(9): 493-498.

Johnson, J.F.; Bengston, D.N.; Fan, D.P.; Nelson, K.C. 2006. US policy response to the fuels management problem: an analysis of the public debate about the Healthy Forests Initiative and the Healthy Forests Restoration Act. In: Andrews, Patricia L.; Butler, Bret W., comps. 2006. Fuels management — how to measure success: conference proceedings. 28-30 March 2006; Portland, OR. Proc. RMRS-P-41. Fort Collins, CO: U.S. Department of Agriculture, Forest Service, Rocky Mountain Research Station: 59-66.

Jones, L.M.; Bernknopf, R.; Cox, D.; Goltz, J.; Hudnut, K.; Mileti, D.; Perry, S.; Ponti, D.; Porter, K.; Reichle, M. 2008. The ShakeOut Scenario. U.S. Geological Survey, Open File Report. Available: http://pubs.usgs.gov/of/2008/1150/.

Keane, R.; Cary, G.; Davies, I.; Flannigan, M.; Gardner, R.; Lavorel, S.; Lenihan, J.; Li, C.; Rupp, T. 2004. A classification of landscape fire succession models: spatial simulations of fire and vegetation dynamics. Ecological Modelling. 179(1): 3-27.

Keane, R.E.; Parsons, R.; Hessburg, P. 2002. Estimating historical range and variation of landscape patch dynamics: limitations of the simulation approach. Ecological Modelling. 151(1): 29-49.

Kochi, I.; Donovan, G.H.; Champ, P.A.; Loomis, J.B. 2010. The economic cost of adverse health effects from wildfire-smoke exposure: a review. International Journal of Wildland Fire. 19(7): 803-817.

Krankina, O.N.; Sierra, C.A.; Harmon, M.E. 2008. Modeling study of carbon dynamics for selected treatments of forest fuels in southern OR. [Unpublished Report]. Corvallis, OR: Oregon State University Department of Forest Science. 19 p. 
Krist, F.J.; Sapio, F.J.; Tkacz, B.M. 2007. Mapping risk from forest insects and diseases, FHTET 2007-06. Fort Collins, CO: U.S. Department of Agriculture, Forest Service, Forest Health Production, Forest Health Technology Enterprise Team. 115 p. Available: http:// www.fs.fed.us/foresthealth/technology/pdfs/FHTET2007-06_RiskMap.pdf.

Lutes, D.C.; Keane, R.E.; Caratti, J.F. 2009. A surface fuel classification for estimating fire effects. International Journal of Wildland Fire. 18(7): 802-814.

Malmsheimer, R.W.; Heffernan, P.; Brink, S.; Crandall, D.; Deneke, F.; Galik, C.; Gee, E.; Helms, J.A.; McClure, N.; Mortimer, M. 2008. Forest management solutions for mitigating climate change in the United States. Journal of Forestry. 106(3): 115-118.

Martell, D.L.; Bevilacqua, E.; Stocks, B.J. 1989. Modelling seasonal variation in daily peoplecaused forest fire occurrence. Canadian Journal of Forest Research. 19: 1555-1563.

Mendoza, G.; Martins, H. 2006. Multi-criteria decision analysis in natural resource management: a critical review of methods and new modelling paradigms. Forest Ecology and Management. 230(1-3): 1-22.

Mercer, D.E.; Prestemon, J.P. 2005. Comparing production function models for wildfire risk analysis in the wildland-urban interface. Forest Policy and Economics. 7(5): 782-795.

Miller, C. 2007. Simulation of the consequences of different fire regimes to support wildland fire use decisions. Fire Ecology. 3(2): 83-102.

Mitchell, S.R.; Harmon, M.E.; O'Connell, K.E.B. 2009. Forest fuel reduction alters fire severity and long-term carbon storage in three Pacific Northwest ecosystems. Ecological Applications. 19(3): 643-655.

Morgan, M.G.; Henrion, M. 1990. Uncertainty: a guide to dealing with uncertainty in quantitative risk and policy analysis. New York: Cambridge University Press. 332 p.

North, M.; Hurteau, M.; Innes, J. 2009. Fire suppression and fuels treatment effects on mixedconifer carbon stocks and emissions. Ecological Applications. 19: 1385-1396.

Oak Ridge National Laboratory (ORNL). 2008. LandScan USA population database 2008, version 1.3. UT-Battelle, LLC, operator of Oak Ridge National Laboratory under Contract No. DE-AC05-00OR22725 with the U.S. Department of Energy. Homeland Security Infrastructure Program (HSIP) Gold 2008 Database [Accessed 15 March 2010]. Washington, DC: U.S. Department of Homeland Security. [Data use agreement required for access].

Ohlson, D.W.; Berry, T.M.; Gray, R.W.; Blackwell, B.A.; Hawkes, B.C. 2006. Multi-attribute evaluation of landscape-level fuel management to reduce wildfire risk. Forest Policy and Economics. 8(8): 824-837.

O'Laughlin, J. 2005. Conceptual model for comparative ecological risk assessment of wildfire effects on fish, with and without hazardous fuel treatment. Forest Ecology and Management. 211(1-2): 59-72.

Parisien, M.; Moritz, M. 2009. Environmental controls on the distribution of wildfire at multiple spatial scales. Ecological Monographs. 79(1): 127-154.

Peterson, D.L.; Johnson, M.C.; Agee, J.K.; Jain, T.B.; McKenzie, D.; Reinhardt, E.D. 2003. Fuels planning: managing forest structure to reduce fire hazard. In: Proceedings of the second international Wildland Fire Ecology and Fire Management Congress and fifth symposium on fire and forest meteorology. November 2003; Orlando, FL. American Meteorological Society: Boston. $10 \mathrm{p}$

Preisler, H.; Westerling, A. 2007. Statistical model for forecasting monthly large wildfire events in Western United States. doi: 10.1175/JAM2513.1. Journal of Applied Meterology and Climatology. 46: 1020-1030.

Preisler, H.K.; Brillinger, D.R.; Burgan, R.E.; Benoit, J.W. 2004. Probability based models for estimation of wildfire risk. International Journal of Wildland Fire. 13: 133-142.

Prestemon, J.P.; Butry, D.T.; Abt, K.L.; Sutphen, R. 2010. Net benefits of wildfire prevention education efforts. Forest Science. 56(2): 181-192.

Public Law 108-148. 2003. Healthy Forests Restoration Act of 2003. Washington, DC Available: http://www.gpo.gov/fdsys/pkg/PLAW-108publ148/pdf/PLAW-108publ148.pdf.

Radeloff, V.C.; Hammer, R.B.; Stewart, S.I.; Fried, J.S.; Holcomb, S.S.; McKeefry, J.F. 2005. The wildland-urban interface in the United States. Ecological Applications 15(3):799-805.

Reinhardt, E.D.; Keane, R.E.; Calkin, D.E.; Cohen, J.D. 2008. Objectives and considerations for wildland fuel treatment in forested ecosystems of the interior western United States. Forest Ecology and Management. 256(12): 1997-2006. 
Rideout, D.B.; Ziesler, P.S.; Kling, R.; Loomis, J.B.; Botti, S.J. 2008. Estimating rates of substitution for protecting values at risk for initial attack planning and budgeting. Forest Policy and Economics. 10(4): 205-219.

Roloff, G.J.; Mealey, S.P.; Clay, C.; Barry, J.; Yanish, C.; Neuenschwander, L. 2005. A process for modeling short- and long-term risk in the southern Oregon Cascades. Forest Ecology and Management. 211(1-2): 166-190.

Running, S.W. 2006. Is global warming causing more, larger wildfires? Science. 313(5789): 927-928.

Schmidt, D.A.; Taylor, A.H.; Skinner, C.N. 2008. The influence of fuels treatment and landscape arrangement on simulated fire behavior, Southern Cascade Range, California. Forest Ecology and Management. 255: 3170-3184.

Schmoldt, D.L. 2001. Application of artificial intelligence to risk analysis for forested ecosystems. Notes. In: Von Gadwo, K., ed. Risk analysis in forest management. Dordrecht, Netherlands: Kluwer Academic Publishers: 49-74.

Scott, J.; Helmbrecht, D. 2010. Wildfire threat to key resources on the Beaverhead-Deerlodge National Forest. Unpublished report to U.S. Department of Agriculture, Forest Service, Beaverhead-Deerlodge National Forest. 46 p.

Seli, R.C.; Ager, A.A.; Crookston, N.L.; Finney, M.A.; Bahro, B.; Agee, J.K.; McHugh, C.W. 2008. Incorporating landscape fuel treatment modeling into the Forest Vegetation Simulator. In: Havis, Robert N.; Crookston, Nicholas L., comps. 2008. Third Forest Vegetation Simulator conference. 13-15 February 2007. Proc. RMRS-P-54. Fort Collins, CO: U.S. Department of Agriculture, Forest Service, Rocky Mountain Research Station: 27-39.

Sexton, T. 2006. U.S. Federal fuel management programs: reducing risk to communities and increasing ecosystem resilience and sustainability. In: Andrews, Patricia L.; Butler, Bret W., comps. 2006. Fuels management—how to measure success: conference proceedings. 28-30 March 2006; Portland, OR. Proc. RMRS-P-41. Fort Collins, CO: U.S. Department of Agriculture, Forest Service, Rocky Mountain Research Station: 9-12.

Sikder, I.U.; Mal-Sarkar, S.; Mal, T.K. 2006. Knowledge-based risk assessment under uncertainty for species invasion. Risk Analysis. 26(1): 239-252.

Stephens, S.L.; Moghaddas, J.J.; Edminster, C.; Fiedler, C.E.; Haase, S.; Harrington, M.; Keeley, J.E.; Knapp, E.E.; McIver, J.D.; Metlen, K. 2009. Fire treatment effects on vegetation structure, fuels, and potential fire severity in western US forests. Ecological Applications. 19(2): 305-320.

Sturtevant, B.R.; Miranda, B.R.; Yang, J.; He, H.S.; Gustafson, E.J.; Scheller, R.M. 2009a. Studying fire mitigation strategies in multi-ownership landscapes: balancing the management of fire-dependent ecosystems and fire risk. Ecosystems. 12(3): 445-461.

Sturtevant, B.R.; Scheller, R.M.; Miranda, B.R.; Shinneman, D.; Syphard, A. 2009b. Simulating dynamic and mixed-severity fire regimes: a process-based fire extension for LANDIS-II. Ecological Modelling. 220(23): 3380-3393.

Syphard, A.D.; Franklin, J.; Keeley, J.E. 2006. Simulating the effects of frequent fire on southern California coastal shrublands. Ecological Applications. 16(5): 1744-1756.

Syphard, A.D.; Radeloff, V.C.; Keeley, J.E.; Hawbaker, T.J.; Clayton, M.K.; Stewart, S.I.; Hammer, R.B. 2007. Human influence on California fire regimes. Ecological Applications. 17(5): 1388-1402.

Syphard, A.D.; Radeloff, V.C.; Keuler, N.S.; Taylor, R.S.; Hawbaker, T.J.; Stewart, S.I.; Clayton, M.K. 2008. Predicting spatial patterns of fire on a southern California landscape. International Journal of Wildland Fire. 17(5): 602-613.

Thompson, M.; Calkin, D.; Gilbertson-Day, J.; Ager, A. 2010. Advancing effects analysis for integrated, large-scale wildfire risk assessment. Environmental Monitoring and Assessment. doi: 10.1007/s10661-10010-11731-x: 1-23.

Thompson, M.P.; Calkin, D.E.; Finney, M.A.; Ager, A.A.; Gilbertson-Day, J.W. 2011. Integrated national-scale assessment of wildfire risk to human and ecological values. Stochastic Environmental Research and Risk Assessment. doi: 10.1007/s00477-011-0461-0. 20 p.

Turner, B.; Kasperson, R.; Matson, P.; and others. 2003. A framework for vulnerability analysis in sustainability science. Proceedings of the National Academy of Sciences. 100(14): 8074-8079. 
U.S. Department of Agriculture (USDA) and U.S. Department of the Interior (USDI). 2001. National Fire Plan. A collaborative approach for reducing wildland fire risks to communities and the environment: 10-year comprehensive strategy. Washington, DC: U.S. Department of Agriculture, Forest Service, and U.S. Department of the Interior. 24 p. Available: http:// www.westgov.org/component/joomdoc/doc_download/252-final-fire-report.

U.S. Department of Agriculture (USDA) and U.S. Department of the Interior (USDI). 2002. Cohesive Strategy: a collaborative approach for reducing wildland fire risks to communities and the environment: 10-Year Comprehensive Strategy Implementation Plan. Washington, DC: U.S. Department of Agriculture, Forest Service, and Department of the Interior. 27 p. Available: http://www.wy.blm.gov/fireuse/docs/collaborative_strategy_implementation0502.pdf.

U.S. Department of Agriculture (USDA) and U.S. Department of the Interior (USDI). 2011. In: Interagency standards for fire and fire aviation operations 2011. (Chapter 1). National Fire Educational Series 2724. Washington, DC: U.S. Department of the Interior and U.S. Department of Agriculture. 10 p. Available: http://www.nifc.gov/PUBLICATIONS/redbook/2011/Ch01.pdf.

Vaillant, N.M. 2008. Sagehen Experimental Forest past present and future: an evaluation of the fireshed process. Berkley, CA: University of California, Berkeley. 172 p. Dissertation.

Venn, T.J.; Calkin, D.E. 2009. Challenges of socio-economically evaluating wildfire management on non-industrial private and public forestland in the western United States. Smallscale Forestry. 8: 43-61.

Westerling, A.L.; Hidalgo, H.G.; Cayan, D.R.; Swetnam, T.W. 2006. Warming and earlier spring increase western U.S. forest wildfire activity. Science. 313(5789): 940-943.

Wiedinmyer, C.; Hurteau, M.D. 2010. Prescribed fire as a means of reducing forest carbon emissions in the Western United States. Environmental Science and Technology. 44(6): 1926-1932.

Winter, P.; Bigler-Cole, H. 2006. Improving a national fire information program: a needs assessment approach. In: Decker, D; Miller, M., comps. 2006. Proceedings of the third international fire ecology and management congress. 12-17 November 2006; San Diego, CA. Pullman, WA: Washington State University.

Wolf, J.; Buckley, D. 2010. West wide wildfire risk assessment—-state forest resource assessment data survey summary. Unpublished draft report. $18 \mathrm{p}$.

Wood, N. 2009. Tsunami exposure estimation with land-cover data: Oregon and the Cascadia subduction zone. Applied Geography. 29: 158-170.

Wood, N.; Soulard, C. 2009. Variations in population exposure and sensitivity to lahar hazards from Mount Rainier, Washington. Journal of Volcanology and Geothermal Research. 188: 367-378. 


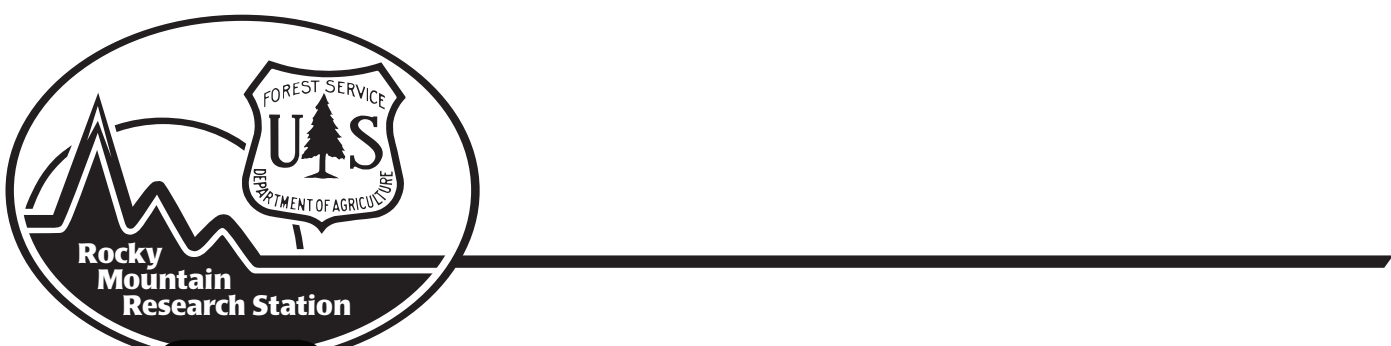

The Rocky Mountain Research Station develops scientific information

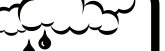
and technology to improve management, protection, and use of the forests and rangelands. Research is designed to meet the needs of the National Forest managers, Federal and State agencies, public and private organizations, academic institutions, industry, and individuals. Studies accelerate solutions to problems involving ecosystems, range, forests, water, recreation, fire, resource inventory, land reclamation, community sustainability, forest engineering technology, multiple use economics, wildlife and fish habitat, and forest insects and diseases. Studies are conducted cooperatively, and applications may be found worldwide.

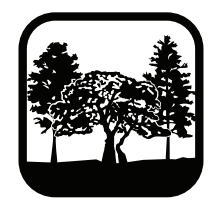

\author{
Station Headquarters \\ Rocky Mountain Research Station \\ 240 W Prospect Road \\ Fort Collins, CO 80526
}

(970) 498-1100

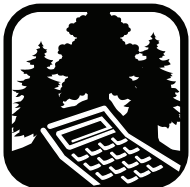

Research Locations

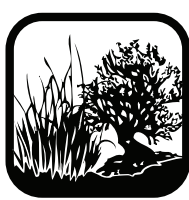

Flagstaff, Arizona

Fort Collins, Colorado

Boise, Idaho

Moscow, Idaho

Bozeman, Montana

Missoula, Montana

Reno, Nevada

Albuquerque, New Mexico

Rapid City, South Dakota

Logan, Utah

Ogden, Utah

Provo, Utah

The U.S. Department of Agriculture (USDA) prohibits discrimination in all its programs and activities on the basis of race, color, national origin, age, disability, and where applicable, sex, marital status, familial status, parental status, religion, sexual orientation, genetic information, political beliefs, reprisal, or because all or part of an individual's income is derived from any public assistance program. (Not all prohibited bases apply to all programs.) Persons with disabilities who require alternative means for communication of program information (Braille, large print, audiotape, etc.) should contact USDA's TARGET Center at (202) 720-2600 (voice and TDD). To file a complaint of discrimination, write to USDA, Director, Office of Civil Rights, 1400 Independence Avenue, S.W., Washington, DC 20250-9410, or call (800) 795-3272 (voice) or (202) 720-6382 (TDD). USDA is an equal opportunity provider and employer. 